\title{
Stand-Up Comedy and Social Justice: A Discussion of Freedom of Speech and Inclusive Democracy
}

By

\section{Samuel Labun}

A thesis submitted to the Faculty of Graduate and Postdoctoral Affairs in partial fulfillment of the requirements for the degree of

Master of Arts

in

Philosophy

Carleton University

Ottawa, Ontario 


\section{Samuel Labun}

Abstract

This thesis explores freedom of speech and its capacity to promote individual agency and well-being, relieve the oppression of excluded social groups, and increase understanding and communication across differences in democratic society. The thesis applies the insights of John Stuart Mill, Amartya Sen, and Iris Marion Young to stand-up comedy. The thesis argues that comedians and audiences have a responsibility not to exclude oppressed social groups from comedy and democratic society in general. Open mics fulfill all Young's conditions for inclusive communication, and professional comedians like Robin Tyler, Hannah Gadsby, Dave Chappelle, and Ms. Pat use their comedy to increase communication and understanding across group differences. The thesis concludes that comedy can provide an effective, inclusive, and public opportunity for social groups to voice their needs, concerns, and demands for equal concern and respect, and that comedy can edify the public about their democratic society. 


\section{Acknowledgements}

First of all, I would like to thank my supervisor, Professor Christine Koggel, for her help and guidance in teaching the Research Seminar and in the writing of this thesis. Professor Koggel's experience and insights were very helpful in the development of my thesis, and her wisdom and patience taught me a great deal about the process of writing and refining a long thesis, especially on such a challenging topic.

I would like to thank Professor David Matheson for participating in my thesis defence as the internal, and also for teaching my first graduate philosophy seminar at Carleton. Professor Matheson's approachable demeanour and deep knowledge of philosophy helped ease me into my first seminar, and his comments during the defense contributed to some minor revisions on the thesis, and I am very grateful for his help. I would also like to thank Professor Brian Johnson from the English Department at Carleton for participating in my thesis defence. His comments during the defense led to very interesting discussions, and also contributed to a minor revision, and I am very grateful for his help.

I am extremely grateful for all my colleagues in the world of stand-up comedy who have helped me on my journey. Jordan Strauss, for nudging me onto the stage and participating in many interesting discussions of stand-up comedy, and David Kopp, for founding and running one of the best comedy environments in the country at Dakoda's Comedy Lounge in Kelowna B.C., for providing me with my first open-mic spot, my first spot on a booked show, and my first co-headlining show.

Finally, I would like to thank my parents, Andrew and Carolyn Labun, for their love, patience, encouragement, and unconditional support throughout my life. 


\section{Table of Contents}

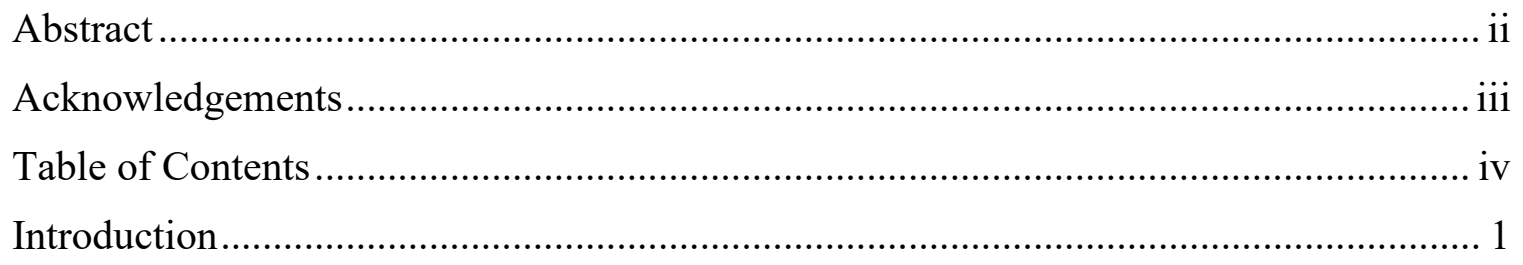

Chapter 1: How Democracy Promotes Agency and Well-Being................................... 7

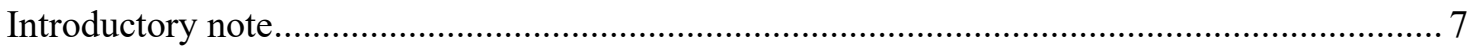

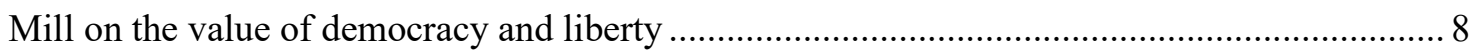

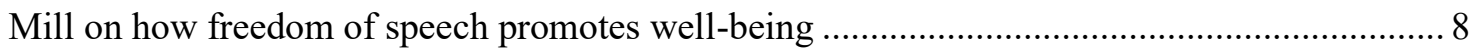

Mill's account of free speech can allow restrictions on speech ............................................. 11

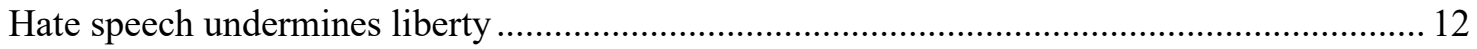

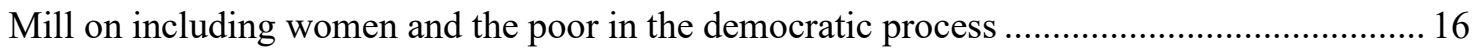

Mill would exclude the uneducated from the democratic process ............................................ 17

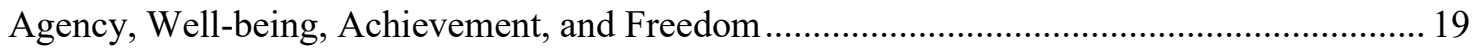

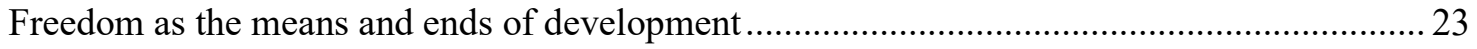

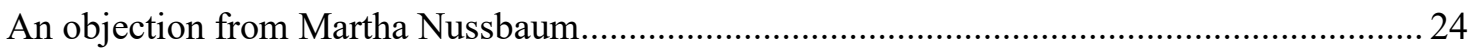

Freedom of Speech is Non-Derivatively Good (But not intrinsically morally good) ................26

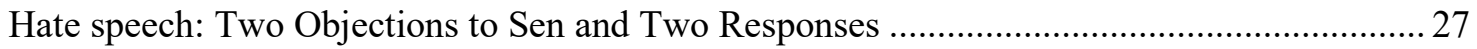

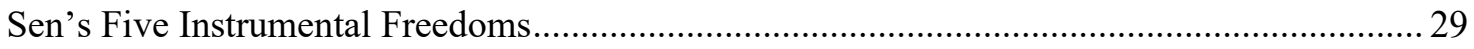

Linkages between economic facilities and other freedoms................................................... 30

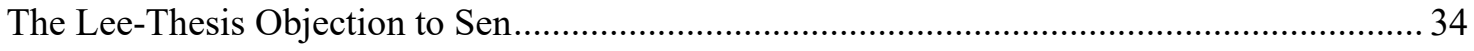

Freedom of speech is essential for achieving political freedoms ............................................. 37

Criticisms of Sen's focus on individual freedom and well-being ............................................ 41

Chapter 2: From Sen to Young: Oppression, Social Groups, and Inclusive Democracy . 43

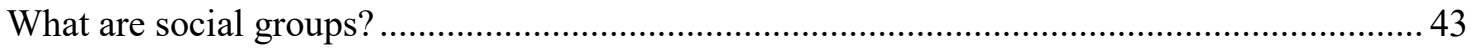

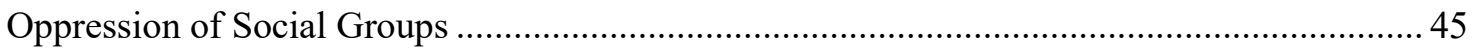

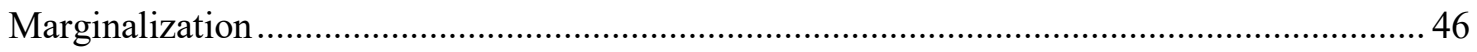

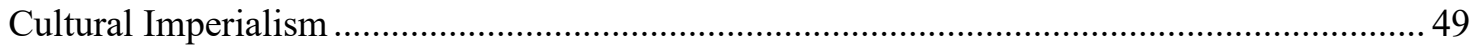

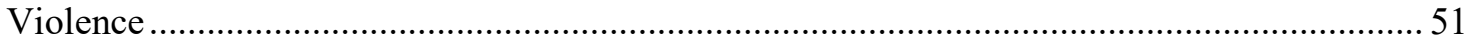

Inclusion and Democracy: Social differences are a resource for democracy ........................... 53

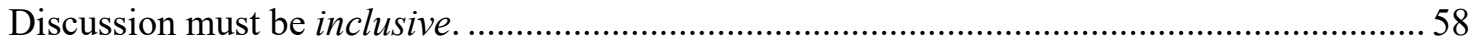

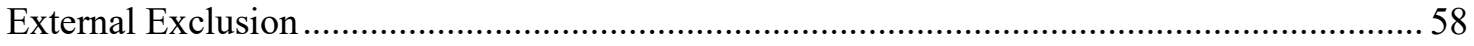




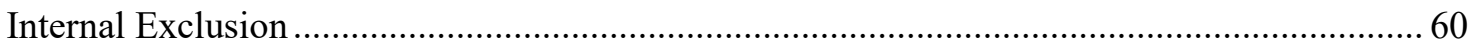

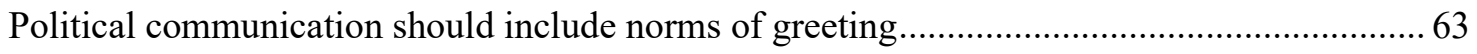

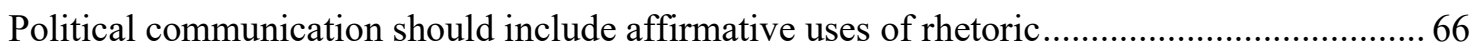

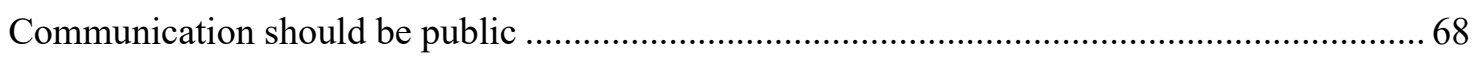

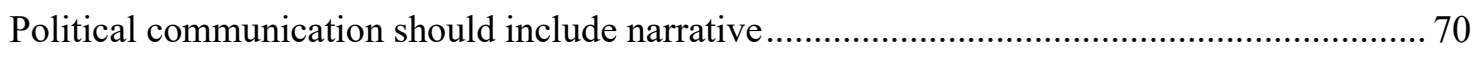

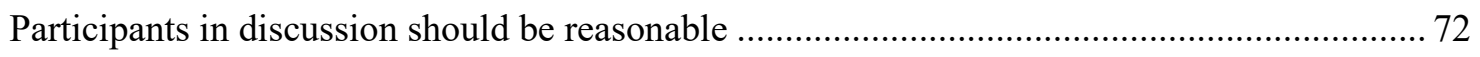

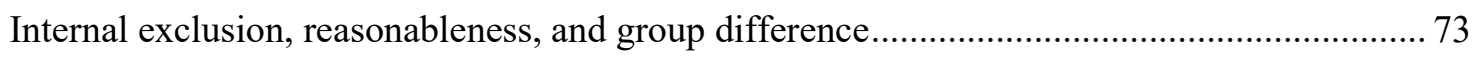

Chapter 3: Comedy that Fails to Respect Norms of Inclusion....................................... 77

Young's account of how greeting, rhetoric, and narrative can be abused and manipulated ...... 77

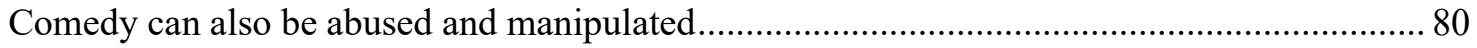

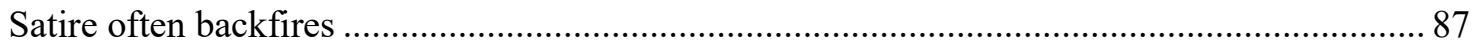

Superiority Humour can entrench Marginalization, Cultural Imperialism, and Violence ......... 91

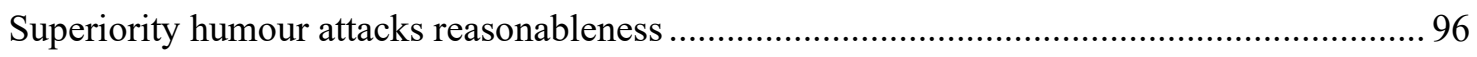

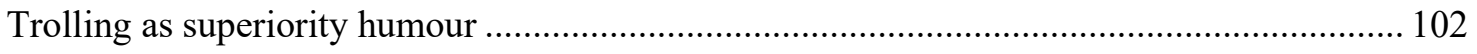

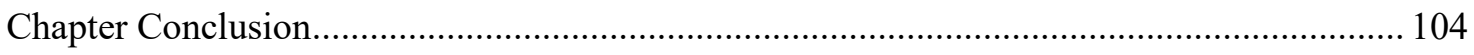

Chapter 4: Comedy that Respects Norms of Inclusion ............................................. 106

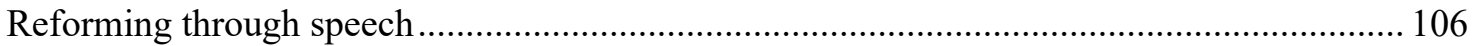

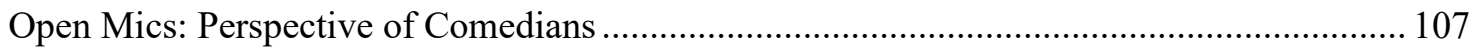

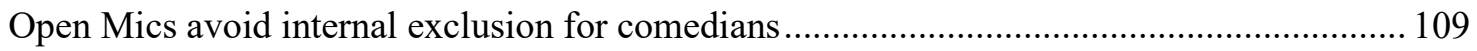

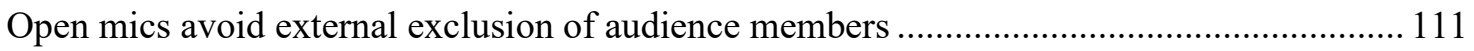

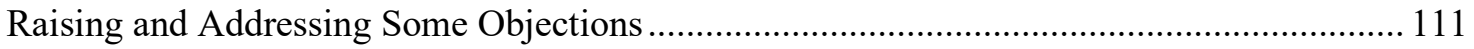

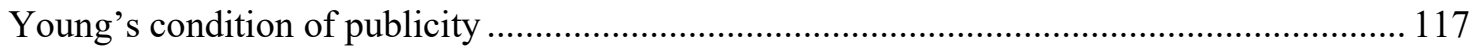

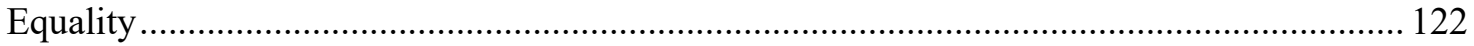

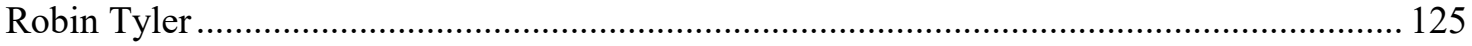

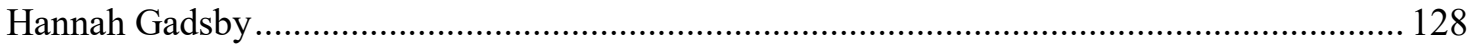

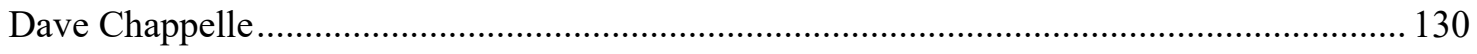

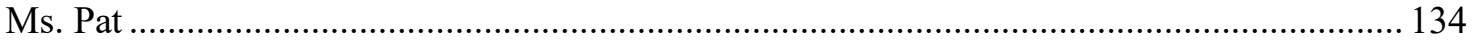

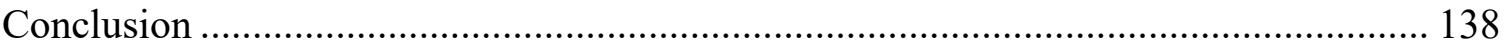

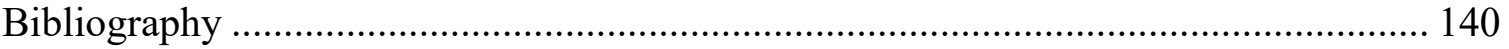


Introduction

In this thesis, I argue that freedom of speech is essential not just for individual agency and well-being, but for oppressed social groups and democratic society in general. Freedom of speech can increase the agency and well-being of individuals, give an effective opportunity for oppressed social groups to participate in democratic discussions, and increase communication and understanding across group differences in society. However, to accomplish these lofty goals, freedom of speech must occur under conditions of equal concern and respect. In Chapter 1, I show that John Stuart Mill demonstrates freedom of speech is essential for mental well-being, and that Mill is not fundamentally opposed to restrictions on speech to prevent violence and the destruction of property. However, I find that Mill excludes some oppressed social groups from the democratic process, he fails to account for freedom of speech's capacity to promote individual agency, and his proposed framework for speech-restrictions would fail to prevent many forms of hate speech.

So, in the second part of Chapter 1, I show that Amartya Sen's capability approach, which he refers to as "development as freedom," fills in many of the gaps in Mill's account. Sen shows that freedom of speech is not just important for well-being, but also indispensable for promoting individual agency and allowing people to lead lives they have reason to value. Sen's account offers a richer understanding of how freedom of speech is essential for obtaining political freedom, and how political freedom is essential for obtaining economic freedoms and other agency and well-being freedoms, such as education and healthcare. Furthermore, Sen's account of freedom of speech is compatible 
with restrictions on hate speech; hate speech harms individual agency and well-being, and as such Sen would classify hate speech as an unfreedom. However, Sen's account also has shortcomings, in that he does not recognize that oppressed social groups often lack an effective opportunity to participate in political discussions, and hence do not have equal access to the other substantive freedoms linked to effective freedom of speech.

In Chapter 2, I show that Iris Marion Young's account of freedom of speech and democracy provides a better account of how to include oppressed social groups in the democratic process. Young agrees with Mill and Sen that freedom of speech is indispensable to democracy, because democracy is a discussion-based process. However, she argues that certain social groups, especially those who suffer oppression in the forms of cultural imperialism, marginalization, and violence, are often unjustly excluded from discussion. Thus, the most vulnerable and oppressed groups in society are prevented from making their voices heard and effectively expressing their needs and interests. Young argues that when entire social groups are excluded from discussion, or treated like obstacles to the democratic process, then the democratic process will fail to produce wise and just outcomes for everyone in society. In particular, discussions will not produce good outcomes for those whose voices are ignored. However, Young shows that when oppressed social groups are treated as a resource to democracy, the benefits to democratic society in general can be substantial. Young argues that treating social group differences as a resource demonstrates equal concern and respect for the needs of oppressed groups, it causes groups in society to frame their expressions of need and interest as appeals to justice, and finally it increases the knowledge and understanding of the democratic public about their own society. Therefore, I conclude that Young's approach provides the richest 
account of freedom of speech's importance for individuals, social groups, and democratic society in general.

In the final two chapters, I apply these insights to an important domain of free speech: stand-up comedy. My inspiration to write a thesis about comedy comes from my experiences attending and performing at open mic comedy nights. I performed at my first open mic in 2017 , and it was a transformative experience.

On the advice of a friend who was already several years into stand-up, I wrote a few jokes down and went to an open mic. After attending a few open mics, I decided to sign up. The experience was nothing short of electric. I spoke the words I had written, and the audience laughed. I have never felt more empowered than when doing stand-up comedy. And the price of this power? It is free. Anyone can sign up for an open mic. There are no restrictions based on age, race, gender, sexuality, and so on. All you must do is sign up. Since then I have performed at hundreds of open mics and booked shows.

As an audience member, my favourite aspect of the open mic experience is its unpredictability. With most other art forms, the consumer gets to choose what they experience - they find a book they like, they pick a movie they want to see, they go to a gallery because it has a collection that interests or intrigues them. While making choices about what to consume is perfectly acceptable, our choices are often in accord with our existing beliefs and attitudes. Thus, choice can lead us down a path that reinforces our biases and prejudices.

Open mics, on the other hand, do not let the audience choose. The audience does not know who will perform. At open mics, I find myself excited about what strange, eccentric, and unique voices I will hear. In addition to the open mic experience, I found 
my favorite professional comedians were those who offered social commentary that let me see society from a new angle or perspective. I began watching comedians like Dave Chappelle, Ms. Pat, Colin Quinn, and others. As a young white man living in predominantly white Kelowna, British Columbia, I had not heard these perspectives before. The comedy of Dave Chappelle and Ms. Pat, for example, introduced me to the realities of systemic racism and violence in the United States.

My experience with comedy has led me to believe that hearing comedy and attending live comedy shows, especially open mics, can be a powerful way for people to empower themselves and make their voices heard. Comedy rewards those who have unique or unfamiliar perspectives and experiences, and it gives them an opportunity to express themselves. However, comedy is most empowering when adhering to conditions of equal concern and respect. Comedy does not always respect these standards, and sometimes undermines them. In Chapters 3 and 4, I focus on multiple genres of comedy, such as superiority humour, satire, political talk shows, trolling, open-mics, and autobiographical humour. Rather than conduct a narrow examination of one or two comedians, I show that comedy is a diverse and reflexive form of communication.

In Chapter 3, I examine forms of stand-up comedy that fail to treat group differences as a resource. Superiority humour, for example, exploits inequitable distributions of agency and well-being freedoms, and gloats over the oppression of social groups. Superiority humour can be bad for individuals, social groups, and democratic society in general because it can normalize oppressive practices such as cultural imperialism, marginalization, and violence identified by Young. Furthermore, I show that political stand-up comedy often fails to offer persuasive critiques and instead merely 
reinforces existing political attitudes, making people less open minded and reasonable. Finally, I argue that the practice of trolling, particularly about political topics, can cause hostility between groups and makes reasonable discussion extremely difficult. Therefore, I conclude that these forms of comedy exemplify how freedom of speech can harm the well-being and agency of individuals, entrench the oppression of vulnerable social groups, and cause closed-mindedness in democratic society.

In Chapter 4, I examine forms of comedy that treat group difference as a resource and demonstrate equality of concern and respect, improve the agency and well-being freedoms of individuals, increase understanding and communication across group differences, and educate the democratic public about their own society. I argue that open mic comedy is inclusive, equal, reasonable, and public. I examine four stand-up comedians whose comedy offers benefits to individuals, social groups, and democratic society in general: Robin Tyler, Hannah Gadsby, Dave Chappelle, and Ms. Pat. Tyler's comedy is an historical example of how stand-up can give a powerful voice to the oppressed and marginalized; Gadsby demonstrates that mainstream comedy can effectively, explicitly, and sometimes painfully, address issues of trauma and sexual violence; Chappelle demonstrates that comedy can offer effective and edifying critiques of racial oppression; and finally, Ms. Pat demonstrates that comedy can overcome racial biases and stereotypes, and it can enhance individual agency and well-being.

In conclusion, I stress that comedy will not end the oppression of social groups, nor will it persuade everyone who views social differences as obstacles that social differences ought to be treated as resources. Rather, comedy at its best reminds audiences that they have a responsibility to listen to the claims of equality and respect expressed by 
the most marginalized members of democratic societies. Comedians who wish to positively impact social justice have a responsibility to continue to raise issues of agency and well-being, criticize structural differences, and demonstrate equal concern and respect for social group differences. 


\section{Chapter 1: How Democracy Promotes Agency and Well-Being}

Introductory note

In a democratic society, freedom of speech must be in accord with fundamental democratic values. Raphael Cohen-Almagor argues that "freedom of speech should not contradict fundamental rights of...equality of concern and respect, which underlie a free democratic society."1 Freedom of speech is a necessary component of democracy, but it must be tempered by equality of concern and respect.

When freedom of speech is balanced with equal concern, consideration, and respect, then this account of freedom of speech is compatible with restrictions on some speech. While it is outside the scope of this thesis to defend or critique any particular restrictions, I argue that a failure to restrict hate speech, for example, could result in a failure to treat all members of society with equal concern and respect.

Amartya Sen argues that democracy is not merely majority rule, and that there is more to democracy than elections. Sen argues democracy must also protect liberties and freedoms, ensure all sides have an adequate chance to state their views, ensure a free press, and allow open discussions and debates of political issues. ${ }^{2}$ Iris Marion Young argues that "democratic politics entails a rule of law, promotion of civil and political liberties, [and] free and fair election of lawmakers." 3 Both agree that freedom of speech is indispensable for the democratic process, which is primarily discussion-based. As I will

\footnotetext{
${ }^{1}$ Cohen-Almagor, Raphael. "Harm Principle, Offence Principle, and the Skokie Affair," Political Studies 41, no. 3 (09/01/1993) p. 470.

${ }^{2}$ Amartya Sen, “Democracy as a Universal Value," Journal of Democracy 10, no. 3, July 1999, pp. 9-10. 3Iris Marion Young, Inclusion and Democracy (Oxford: Oxford University Press, 2000), p. 4.
} 
argue in this chapter and the next, both Sen and Young develop accounts of democracy that are meant to include more than the importance of free and fair elections and the protection of civil and political liberties.

Mill on the value of democracy and liberty

John Stuart Mill argues that democracy is good because it can promote liberty. ${ }^{4}$ When Mill speaks of liberty, he is speaking of liberty in what Isaiah Berlin called the negative sense. Liberty in this sense is freedom from interference by other human beings in the pursuit of one's interests. ${ }^{5}$ For Mill, freedom of speech is connected with the liberty to lead a life of one's choosing and that this is necessary for the development of mental well-being, "upon which all well-being depends." " So, Mill values liberty not for its own sake, but because it is necessary for achieving mental well-being, and for allowing human beings to develop their cognitive capacities to their full potential, and reach the "mental stature" they are capable of. 7

Mill on how freedom of speech promotes well-being

Therefore, freedom of speech is an important liberty for Mill, who places a high value on human individuality and spontaneity. According to Mill, human individuality is best developed when people are unrestricted in what they can say, write, read, watch, listen to, absorb, and so on. Mill believes that "the free development of individuality is

4John Stuart Mill, On Liberty, Electric Book Company, 200o. ProQuest Ebook Central, https://ebookcentral-proquest-com.proxy.library.carleton.ca/lib/oculcarletonebooks/detail.action?docID $=3008614$.

5Isaiah Berlin, Two Concepts of Liberty (Oxford: Clarendon Press, 1958), p. 11

${ }^{6}$ Mill., p. 69.

7Ibid., p. 50. 
one of the leading essentials of well-being,"» and that through freedom of speech, individuals can develop strong faculties of "perception, judgment, discriminate feeling, mental activity, and even moral preference." Liberty, especially freedom of speech, is necessary to develop these faculties. Mill argues that without liberty of thought and discussion, humans cannot achieve their highest degree of well being or what he most often refers to as "happiness".

For Mill, achieving human well-being requires respecting human nature, which he likens to the growth of a tree:

Human nature is not a machine to be built after a model, and set to do exactly the work prescribed for it, but a tree, which requires to grow and develop itself on all sides, according to the tendency of the inward forces which make it a living thing. ${ }^{10}$

If a tree is grown in cramped conditions or a frame, it will not grow to its natural extent and form. Likewise, Mill thinks humans have innate characters, and that if humans are granted sufficient liberty, their characters can develop and express themselves to their fullest extent. In the metaphor, "inward force" implies that humans are self-directed according to their opinions, beliefs, and desires; "grow and develop on all sides" implies that humans must not be impeded from following their interests, and making choiceswe must be allowed to branch out and make choices to achieve our fullest well-being.

8Ibid., p. 74. 9Ibid., p. 76. 10Ibid., p. 77. 
Mill reasoned that our mental faculties could only be developed through making choices about how to live one's life-whether to adopt a custom or not, whether to accept an argument or not, whether to live by a certain code of ethics or not, and so on. A society that encourages freedom of speech would expose people to more choices in customs, arguments, codes of ethics, and so on, increasing their possibilities and allowing them to make genuine choices across a variety of options.

Mill would say that a society that harshly restricted freedom of speech would consequently restrict the potential well-being the individual could achieve. Mill thinks that limiting a person's range of choices also limits the development of their mental faculties. If individuals cannot develop their mental faculties to their full potential, then they cannot achieve their highest degree of well-being. In other words, restricting an individual's range of choices in the customs or traditions they could adopt or reject, or the code of ethics they could choose to live by, also restricts them from attaining their greatest possible well-being. A person who does not make choices about how to live their life, but instead merely copies what others do, does not develop or strengthen the faculties of perception, judgment, and so on, but instead needs and makes use of only the "faculty of imitation." ${ }^{11}$ So, Mill thinks the liberty to choose one's path in life is essential for achieving mental well-being.

According to Mill, leading a self-directed, robustly intellectual life is essential to human happiness. He explicitly states that happiness cannot be complete if one's behaviour is chiefly governed by traditions and customs, rather than one's own internal spontaneity: "Where, not the person's own character, but the traditions or customs of

${ }^{11}$ Ibid., p. 76. 
other people are the rule of conduct, there is wanting one of the principal ingredients of human happiness, and quite the chief ingredient of individual and social progress." ${ }^{12}$ Therefore, Mill opposes social institutions and relations that threaten the expression and flourishing of individual characters and capacities.

However, Mill was also aware of harms to individuals caused by speech itself.

After all, speech can cause significant harm as his example of speech that can incite riots shows. This will also apply, I will argue, in the case of hate speech (something that Mill did not discuss directly) that can cause significant psychological and social harms.

Mill's account of free speech can allow restrictions on speech

Mill's arguments do not support the claim that speech can never be restricted. He does not argue that all speech must be permitted regardless of its tendency to cause harm or incite violence: "The liberty of the individual must be thus far limited; he must not make himself a nuisance to other people."13 Mill's example of the corn-dealer shows that he thinks even written opinions can be stifled if they are used to cause harm to people or their property. Even if the information on the placard was true, and the corn-dealer really was a starver of the poor, Mill thinks circulating the placard among the angry mob to incite them to violence would still merit a response from authorities to prevent violence. However, Mill argues the same information can circulate in the press, where it is less likely to give rise to harm (presumably because Mill thinks readers are less likely to be whipped into a frenzy), although still widespread enough to raise awareness about that corn-dealer's misdeeds.

${ }^{12}$ Ibid., p. 74 .

13Mill, p. 74. 
Mill argues that expressions can only be legitimately restricted by the state when those expressions threaten to cause imminent harm. Mill's example of the corn-dealer suggests that imminent harm means physical damage to individuals or their property; he does not seem to consider that hate speech undermines liberty and can cause psychological, social, and economic harms.

It seems, then, that Mill's justification for liberty of thought and discussion would preclude restrictions on hate speech. Hate speech can be hate speech without threatening to incite imminent violence to people and property. Indeed, as Mari Matsuda argues, violence is the endgame of racism, but hate speech, such as racist propaganda, is used to slowly build towards that violent, "final solution." 14 Thus, hate speech circumvents Mill's restriction on speech that threatens imminent violence. However, as I will go on to argue in the sections that follow, hate speech causes other kinds of harm that restrict liberties for some in significant ways. Mill's account of free speech needs greater specification of who is harmed. As I will to on to argue in Chapter 2, Young's account of oppression gives us a base from which to understand hate speech as hatred directed to people who are members of oppressed groups perceived to be undeserving of equal concern and respect.

Hate speech undermines liberty

Susan Brison defines hate speech as "speech that vilifies individuals or groups on the basis of such characteristics as race, sex, ethnicity, religion, and sexual orientation,

\footnotetext{
${ }^{14}$ Mari Matsuda, "Public Response to Hate Speech," in Words that Wound (Boulder: Westview
} Press, 1993) p. 72 
which (1) constitutes face-to-face vilification, (2) creates a hostile or intimidating environment, or (3) is a kind of group libel."15

Hate speech undermines liberty for members of some groups. As Mari Matsuda explains, "Victims are restricted in their personal freedom... To avoid the hate messages, they must quit jobs, forgo education, move from their homes, avoid certain public areas, limit the exercise of their own rights to speak, and change their behaviour and demeanour."16 Furthermore, hate speech causes significant harm: "victims of vicious hate propaganda experience physiological symptoms and emotional distress ranging from fear in the gut to rapid pulse rate and difficulty in breathing, nightmares, post-traumatic stress disorder, hypertension, psychosis, and suicide." ${ }^{17}$

Charles R. Lawrence argues that hate speech, in this case, racist hate speech, "inflicts real harm, and this harm is far from trivial."18 Lawrence notes that calls for "offensive speech" to be protected downplay the real injuries caused by hate speech. Lawrence identifies three injuries caused by hate speech, particularly in the context of a university campus and the racial segregation of schools in the U.S.: "psychic, reputational, and the denial of equal educational opportunity." 19

First, racist hate speech can cause psychological injury to its victims. In the sense of face-to-face vilification or environmental harassment, Lawrence points out that hate speech causes "deep emotional scarring and feelings of anxiety and fear that pervade

\footnotetext{
15Susan Brison, "The Autonomy Defense of Free Speech," Ethics 108, no. 2 (1998), p. 314. Accessed April 2, 2020. doi:10.1086/233807.

16 Matsuda, p. 24.

17 Ibid., p. 24.

18 Charles R. Lawrence III, "If He Hollers Let Him Go," in Words That Wound, Matsuda et al. (Boulder: Westview Press, 1993), p. 72

19 Lawrence, p. 76.
} 
every aspect of a victim's life." ${ }^{20}$ As a result of pervasive fear and anxiety, victims suffer from physiological symptoms including rapid pulse rate and difficulty breathing. ${ }^{21}$

Finally, victims of hate speech suffer feelings of vulnerability and shame because the message of hate speech is that they are inferior and immoral, and should be subservient to the dominant group. The message of hate speech is that the targets should not be afforded the same rights as other members of the community. These messages can warp the psyches of victims, causing self-hatred and a sense of inferiority, and preventing victims from seeing themselves as rational, self-legislating beings. The fear and anxiety caused by hate speech can intimidate individuals from engaging in political discussion. It can make them fearful to raise their voice in town hall meetings, thereby restricting their opportunities to advocate for their own interests.

Second, Lawrence argues that racist hate speech is a form of group defamation, causing reputational injury to victims. For example, Lawrence considers the case of Brown vs. Board of Education, a case about segregation of schools. The psychological and reputational injuries inflicted by segregation were not inflicted by the act of segregation itself, but by the message, or meaning, of segregation. The message of segregation was that black children were unfit to attend school with white children. The effect of segregation was not just significant psychological harm to the "hearts and minds of black children...unlikely ever to be undone, ${ }^{, 22}$ but loss of employment opportunities and loss of the "right to be regarded as respected members of the body politic." ${ }^{23}$

20Ibid., p. 72.

${ }^{21}$ Ibid., p. 74.

${ }^{22}$ Ibid., p. 74.

23 Ibid., p. 75 . 
The third kind of injury Lawrence identifies is the denial of equal educational opportunity. This injury is an effect of the first and second injuries. In the case of segregation, despite the material equality of education in terms of curriculum, text books, quality of teachers, and so on, Lawrence argues black children were prevented from receiving the same educational benefits as white children, because the black children could not learn and participate in an equal way. Their learning and participation were impeded by the psychological injuries and group defamation that accompanied the message of segregation.

This third injury, Lawrence notes, occurs to college students who are subjected to hate speech on campus. Students who are the victims of hate speech do not have an equal educational opportunity, because they are "forced to live and work in an environment where at any moment they may be subjected to denigrating verbal harassment and assault." ${ }^{24}$ This kind of injury makes it significantly more difficult for students to achieve their highest level of academic performance and also raises barriers against social integration.

Students cannot be expected to perform well academically if they are weighed down by the burdens of face-to-face vilification, hostile environmental harassment, and group libel. Deprived of the opportunity to study in peace as fully respected and integrated members of the student body, students suffer a significant impact to their learning, holding them back from their full potential.

The three kinds of injury Lawrence identifies are not necessarily restricted to campuses or segregated schools. On the contrary, in each case the form of injury inflicted

24 Ibid., p. 76. 
is caused by the kinds of hate speech that Brison identifies: face-to-face vilification, hostile environmental harassment, and group libel. All these injuries can have a powerful, negative impact on people's liberty, and all of them can occur at any time or place.

Mill on including women and the poor in the democratic process

To be fair to Mill, it should be mentioned that his account of democracy recognizes and condemns the exclusion of women and the poor from the democratic process because of gender and wealth, respectively. Mill argues that women should be included in the democratic process because effective participation in politics would help inculcate democratic values and improve their well-being: "- an equal right to be heard - to have a share in influencing the affairs of the country - to be consulted, to be spoken to, and to have agreements and considerations turning upon politics addressed to one - tended to elevate and educate the self-respect of the man, and to strengthen his feelings of regard for his fellow-men." ${ }^{25}$ Mill thinks that this argument also applies to women. According to Mill, if men and women were provided equal education and treated equally by society, there would probably be no difference at all in "the character and capacities which would unfold themselves. ${ }^{{ }^{26}}$ So, Mill seems to be aware that there are significant, unjustified inequalities in society with respect to men and women.

Furthermore, Mill is aware that the inequitable distribution of wealth tends to exclude poor people from the political process, and Mill argues strongly against a

\footnotetext{
25John Stuart Mill, Public and Parliamentary Speeches : Volumes XXVIII-XXIX (Toronto: University of Toronto Press, 1988), Accessed March 29, 2020. ProQuest Ebook Central, p. 39. ${ }^{26}$ John Stuart Mill, Subjection of Women, Project Gutenburg 2008, http://www.gutenberg.org/files/27083/27083-h/27083-h.htm, p. 105.
} 
government of the rich. Mill is described as raising this issue in a meeting of electors and non-electors before the Westminster Elections of 1865: "Did they think it was the right and best thing that the House of Commons should be composed exclusively of rich men, or men with rich connections? (No.) There were a good many reasons why this was not desirable, and one was that the rich naturally sympathised with the rich. (Hear, hear.)"27 Mill praises the "cheap press" because it has allowed even the poorest of people to gain access to political knowledge: the cheap press gives "any man, however humble his circumstances, the means of acquiring the best information respecting political knowledge, written by some of the most able men of the country. (Cheers.)"28

Mill would exclude the uneducated from the democratic process

However, Mill continues that the existence of the free press is not enough to grant universal suffrage. For example, Mill argues that if someone cannot read, then they cannot benefit from the knowledge provided in and through the free press, and therefore they should not be allowed to vote. ${ }^{29}$ Mill is opposed to extending political representation to anyone who cannot pass a basic test in reading, writing, and simple arithmetic: "Mr. Mill said that he did not want uneducated men voters, and was in favour of an educational test—reading, writing, and simple arithmetic...to men, therefore, who had the qualification of reading, writing, and arithmetic, he would entrust a share in the management of the destinies of this country..." ${ }^{\prime 30}$ But if they could not pass such a test, they would not have a share in the management of the destinies of the country, and

27Mill, Public and Parliamentary Speeches, p. 32.

${ }^{28}$ Ibid., p. 31.

29Ibid., p. 31.

30Ibid., p. 31. 
therefore, to the extent that the state of the country impacted their lives, no share in the management of their own destinies.

Thus, Mill favours excluding the most disadvantaged and deprived from effective political participation. This is a problematic position, because the uneducated, disadvantaged, and deprived are the most vulnerable members of society, the least able to make their needs and interests known, and also the least likely to be responded to by politicians (if they cannot vote, politicians are unlikely to pay attention).

Indeed, as Amartya Sen has argued, in his discussion of famines, these tend to affect the poorest and most destitute because governments have the least incentive to respond to their needs and interests. Sen points out that there has never been a famine in a functioning multi-party democracy with freedom of the press and universal suffrage. ${ }^{31} \mathrm{I}$ will discuss Sen's views on freedom of speech and democracy in more detail later; suffice it to say that freedom of speech and the press have an even greater capacity to promote people's well-being than Mill recognized, but only if democracies extend political freedoms to everyone, equally.

Mill's account of democracy and freedom of speech, therefore, does not demonstrate equal respect and consideration for the interests of everyone in society. Mill's account recognizes the importance of being able to pursue life plans and goals without interference from the state or others. He also recognizes how women and the poor fail in their ability to speak and be heard. He takes education to be vital but thinks that one must be educated first in order to engage in democratic processes of speaking and being heard. It will, I argue, take more than freedom of speech to achieve what Mill

${ }^{31}$ Amartya Sen, Development as Freedom (New York: Random House, 2000), p. 178. 
calls for in his account of happiness as the flourishing of all. Therefore, Mill's account of freedom of speech as a component of democracy falls short, and a better account is needed. I argue that Amartya Sen's approach to development (conceived broadly as human development or the capabilities approach) offers a significant improvement on Mill's account of liberty and democracy, especially with respect to the vital importance of human agency, well-being, and the equitable distribution of political freedom.

Agency, Well-being, Achievement, and Freedom

To understand Sen's capabilities approach, we must understand four concepts: agency, well-being, achievement, and freedom. David Crocker offers a useful table for comparing these linked concepts: ${ }^{32}$

\begin{tabular}{|l|l|l|}
\hline & Agency & Well-being \\
\hline Achievement & Agency Achievement & $\begin{array}{l}\text { Well-being } \\
\text { Achievements } \\
\text { (functioning's) }\end{array}$ \\
\hline Freedom & Agency Freedom & $\begin{array}{l}\text { Well-being } \\
\text { Freedoms } \\
\text { (capabilities) }\end{array}$ \\
\hline
\end{tabular}

An achievement is a particular goal or objective that a person actually manages to accomplish, whereas freedom is the "real opportunity to accomplish what we have reason to value. ${ }^{{ }^{33}}$ Sen thinks a society should not be evaluated merely by what people have achieved, but by their freedom to achieve goals they have reason to value. This distinction

32David Crocker, Ethics of Global Development (Cambridge: Cambridge University Press, 2008), p. 151.

33Amartya Sen, Inequality Reexamined, (Oxford Scholarship Online, November 2003 DOI: 10.1093/0198289286.001.0001), p. 30. 
is centrally important, because the achievements a person manages to accomplish might not coincide with the goals or objectives that they have reason to value. For example, a woman in an oppressive society might achieve certain goals and objectives, like raising her children. However, she lacks the freedom to achieve the goals she values or would have reason to value, such as learning to read and write. For Sen, societies should implement policies that maximize freedom, allowing agents to make achievements.

Agency is the active aspect of a person. Agents "shape their own destiny" 34 and strive to accomplish goals they have reason to value. Agents can act or refuse to act; they can act one way and refuse to act in another way. ${ }^{35}$ Improving a person's agency means giving them more opportunities and ways to act. An agent reviews the opportunities and resources available to them and decides which opportunity to take, or not take. Agents are responsible for what they do or do not do. When a government treats people as agents, it respects them as autonomous, responsible persons who wish to lead lives they have reason to value.

Well-being, on the other hand, can be improved without agency. For example, a government welfare program can improve the well-being of individuals living in deprived conditions, just as a doctor can alleviate the sickness of a patient. Indeed, when government policy seeks only to improve the well-being of persons, they are treating people like patients. When a government only treats people as patients, it fails to treat them with the respect they deserve as responsible agents who ought to shape their own destiny.

\footnotetext{
34Sen, p. 11
}

35Ibid., p. 190. 
Sen argues that agency and well-being are fundamentally distinct, but not independent. ${ }^{36} \mathrm{~A}$ person cannot be an agent if they do not reach a certain threshold of well-being. A society or country might offer many opportunities for agents to choose from; however, if a person is limited by their ill-health, many of these opportunities might not be realizable. A person who suffers from malnutrition, for example, might simply lack the energy to pursue many opportunities that might otherwise be available to them.

Now that these four concepts of freedom, achievements, agency, and well-being have been explained, we can return to Crocker's table and examine the intersections. A person's agency achievements are actual, accomplished achievements that the agent (subjectively) has reason to value, but are not necessarily connected to the agent's (objective) well-being. A person could make an agency achievement while compromising their well-being. For example, a person might have the agency achievement of winning a college basketball championship. They have reason to value this achievement because they earned it through hard work and dedication, even though it may have come at the cost of well-being (e.g. injuries, fatigue, etc.). On the other hand, a person might accomplish an agency achievement (completing a 12-week work-out program) that simultaneously improves their well-being (exercise is good for health). However, if the person accomplished a goal they had reason to value, they have made an agency achievement.

A person's "agency freedom" refers to the actual opportunities a person has to achieve goals they have reason to value; again, this not necessarily connected to the

36Ibid, p. 190. 
person's well being, and the agent can choose to take a particular opportunity or not. Agency freedom is extremely important for Sen. These opportunities must be actually achievable, not pipe dreams. For example, a society might be divided into a city and a countryside. Residents of the city have high agency freedom, because the city is a hub of business and culture, and urban residents have many actual opportunities to pursue goals they have reason to value. However, residents who are stuck in the countryside are very limited in their actual opportunities to pursue goals they would have reason to value. If the society implements a public transit system to help rural residents commute to urban centres, the society can greatly improve the agency freedom of rural residents.

"Well-being achievements" are actual, accomplished achievements that improve an agent's well-being, but do not necessarily increase their agency achievements or freedoms, nor do they have to be accomplished by the agent. The recipient of a government welfare subsidy, for example, has attained a well-being achievement just by receiving the aid. However, if the financial assistance increases their agency freedom, this well-being achievement might incidentally lead to agency achievements.

Finally, "well-being freedoms" refer to actual opportunities a person has to improve their well-being, whether they choose to take the opportunities or not. For example, a company might offer a benefits package that gives employees many opportunities to increase well-being through health benefits, exercise classes, massage therapy, and so on. Employees are not obligated to take these opportunities, but they have the freedom to choose. 
For Sen, the focus of development should not stop at providing welfare to peopleas-patients; rather, the focus of development should be on maximizing freedoms: real opportunities that agents have reason to value. ${ }^{37}$

Freedom as the means and ends of development

Sen considers freedom to be both the means and the end of development. Sen's concept of development is expansive and applies to all countries. Even a country with a relatively high GDP might require development with respect to freedom. Freedom is an end in the sense that public policy should aim at increasing people's capabilities to lead lives they value, and freedom is a means to that end in the sense that people can use their freedom/capabilities to influence public policy. ${ }^{38}$ Sen argues that the success of a society should be measured not only by its GDP, but rather by the "substantive freedoms that members of the society enjoy." ${ }^{39}$ The more freedom people have to pursue the things they value, the better their lives will be. When certain freedoms are improved or certain unfreedoms are removed, Sen writes, our personal lives can become richer and our social presence can become more influential. ${ }^{40}$ Sen's approach seeks to improve people's capability to live a life they have reason to value.

37Ibid, p. 11. ${ }^{38}$ Ibid., p. 18. 39Ibid., p. 18. 4oIbid., p. 15. 
An objection from Martha Nussbaum

Sen thinks freedom is intrinsically good as an end, i.e. freedom is worth striving towards for its own sake. Martha Nussbaum has been critical of Amartya Sen's claim that freedom is intrinsically good, because some freedoms violate agency. ${ }^{41}$ The hypothetical freedom for husbands to beat their wives is a freedom for one kind of citizen (wifebeating husbands), that comes at the expense of another kind of citizen (wives). If a law were passed to criminalize wife-beating, the freedom of husbands would be reduced, but the agency, health and safety of wives would be increased. Restricting the freedom to commit domestic violence is a good thing, but only if freedom is not intrinsically good. If freedom were intrinsically good, then any restriction of freedom would be intrinsically bad. But it is clearly not bad to restrict the freedom to commit domestic violence. So, Nussbaum concludes, contrary to Sen, that freedom is not intrinsically good.

Nussbaum's objection would be correct if Sen were arguing that freedom is intrinsically morally good. However, while Sen claims that freedom is intrinsically good, he does not seem to mean that freedom is intrinsically morally good. Rather, by intrinsically Sen seems to mean non-derivatively: the goodness of freedom does not derive from the consequences of freedom. Further, Sen uses good not in the sense of morally good but in the sense of something being good for one's interests. So, when Sen says freedom is intrinsically good, he means freedom is in everyone's interests nonderivatively. In other words, freedom is something that agents want to have, regardless of the consequences that follow.

\footnotetext{
${ }^{41}$ Martha Nussbaum, Creating Capabilities: The Human Development Approach, (Cambridge:
} Harvard University Press, 2011), p. 71. 
Sen thinks freedom is non-derivatively good - the goodness of freedom does not derive from the consequences of freedom. ${ }^{42}$ Sen seems to be speaking in the Aristotelian sense that something is intrinsically good if it is desirable for its own sake, and not for the sake of some further end. For example, Sen references Aristotle on the value of wealth. Aristotle denies that wealth is intrinsically good because we do not desire wealth for its own sake, but rather for other goods that wealth can procure for us. If a person were not wealthy, but somehow still had reliable access to everything that could be procured through wealth, then they would have no reason to desire wealth. In contrast, Sen thinks freedom is desirable for its own sake, and not for some further end.

The freedom to choose between options — in beliefs, values, religion, and so onis desirable for agents, because agents desire to live a life of their choosing. Whatever the choice may be, it is important that they are free to make the choice, and not have it made for them. ${ }^{43}$ It is important to note that, for Sen, freedom does not exist in the absence of actual opportunities and choices. It is intrinsically good, Sen thinks, for agents to have a multiplicity of actual opportunities and choices they have reason to value.

Secondly, by "good," Sen does not mean that freedom is morally good. Sen means it is in everyone's interest to be free, as it is in everyone's interests to be healthy. For example, a mass murderer might be imprisoned and lose his freedom--but it is still in the murderer's interest to be free, even though it would be morally bad if the murderer was free.

\footnotetext{
${ }^{42}$ Aristotle and George Henry-Lewes, "Book I," In The Ethics of Aristotle: With Introductory Essay by George Henry-Lewes (Walter Scott Publishing Co, London, 1890), p. 8. doi:http://dx.doi.org.proxy.library.carleton.ca/10.1037/12981-001. https://proxy.library.carleton.ca/login?url=https://search-proquestcom.proxy.library.carleton.ca/docview/867640887? accountid=9894. 43Sen, p. 37.
} 
Freedom of Speech is Non-Derivatively Good (But not intrinsically morally good)

Under Sen's theory, freedom of speech is non-derivatively in everyone's interests, because it is in everyone's interest to have the opportunity to say what they need to say, to make their needs known, to participate in political discussions and debate, and so on. Even if a person has no immediate interest in speaking their mind-perhaps all is right with the world, or they have voluntarily taken a vow of silence- the inability to choose to speak freely is a deprivation. Presumably a vow of silence is a voluntary act, and a voluntarily silent person can still choose to speak. But if someone is forced into silence by an authoritarian regime, they suffer a deprivation. Again, Sen thinks having the opportunity to exercise freedom of speech is intrinsically in everyone's interests, but he does not demand that everyone make the choice to exercise this freedom. Nor does he claim that all possible exercises of freedom of speech are morally good.

Though Sen takes freedom as such to be non-derivatively in everyone's interests, it does not follow that particular freedoms are intrinsically morally good. And while for Sen freedoms in general can be instrumentally morally good, they are not all intrinsically morally good. In the case of freedom of speech, then, if it were intrinsically morally good, then it would be intrinsically morally bad to place any restriction on speech. However, Sen does not think it is morally bad to restrict someone from publishing libel and slander. So, Sen's approach has no problem with restricting harmful freedoms, or condemning them as morally bad. 
Hate speech: Two Objections to Sen and Two Responses

Recall Susan Brison's analysis of Sen's concept of agency (Brison speaks of “autonomy," but Sen's concept is more aptly called agency because of its emphasis on substantive freedoms and capabilities, rather than merely self-government). Brison argued that the only way Sen's account would not be compatible with restrictions on hate speech would be if Sen supported the (implausible) claim that the restrictions undermined the agency of speakers more than the agency of target groups.

This does not seem to be a position that Sen would support, as hate speech seems to cause far more serious harms to its targets (as recounted in Matsuda et al.) than restrictions on hate speech. Hate speech causes major unfreedoms and serious harms. Unfreedoms prevent people from leading lives they have reason to value, and Sen's account is about the removal of unfreedoms that hinder what people can be and do. Thus, my defence of Sen on the topic of hate speech mirrors my response to Nussbaum's objection. Just as Sen would not be against restrictions on domestic violence, he would not be against restrictions on hate speech. Hate speech undermines people's ability to lead lives they have reason to value, and therefore hate speech is an obstacle to Sen's account of what he refers to as "development as freedom".

However, critics of Sen might take another angle, and argue that Sen's account is incompatible with restrictions on hate speech because Sen is so concerned with promoting the freedom of individuals and groups to lead lives they have reason to value. The critics could say that when a speaker expresses hate speech towards a target individual or group (under Brison's classification of hate speech as face-to-face vilification, hostile environmental harassment, or group libel), the speaker is striving to 
lead a life they have reason to value. According to the objection, the speaker thinks the best way for them to lead the life they value is by expressing political opinions that are hateful towards a target group. The speaker might believe that the target group is responsible for political arrangements and policies designed to promote the interests of the target group at the expense of everyone else. By uttering hate speech against these groups, the speaker is merely calling attention to what they believe is a major injustice. So, if hate-speech is restricted, then the state is impeding individuals from leading a life they have reason to value. Therefore, the objection goes, Sen's account is incompatible with restrictions on hate speech.

However, this objection fails to establish that the speaker actually has reason to value a life that includes expressing hate speech towards a target group. The reason hate speech is not taken seriously as a reasoned expression of views is because the claims made by those issuing hate speech are false. For example, the fundamental claim of antiSemitic hate speech is that Jewish people are conspiring with other Jewish people to control the world and shape arrangements for their benefit at the expense of everyone else. But this claim is simply not true. Moreover, hate speech targets all members of an oppressed group merely because of their membership in that group. I discuss this in more detail in Chapter 2, where I examine Young's account of oppression.

Thus, expressing hate speech will not actually assist the speaker in living a life they have reason to value, because the purported obstacle to that life (e.g. a conspiracy involving a target group or some other imagined reason) does not exist. So, hate speech cannot be justified on the grounds that speakers have reason to value a life that lets them express hate speech toward specific target groups. Moreover, hate speech violates 
equality at the base of democracy in that it relies on the fundamental beliefs by those uttering hate speech that some people are not deserving of equal concern and respect.

Sen's Five Instrumental Freedoms

Sen argues for five categories of freedoms, which he calls the instrumental freedoms. These freedoms play instrumental and constructive roles in contributing to a person's agency and well-being. They are: (1) political freedoms, (2) economic facilities, (3) social opportunities, (4) transparency guarantees, and (5) protective security ${ }^{44}$ These freedoms are not to be taken in isolation, but are best understood as empirically linked, such that strengthening some strengthens others, and weakening some weakens others. I will first define the freedoms, and then explain important linkages between them.

First, Sen describes political freedoms as freedoms concerned with people's relationship to the state; he also refers to them as civil rights. These freedoms include the freedom to vote in fair elections involving multiple political parties, the freedom to express political opinions, freedom to report and/or consume news, the freedom to hold government accountable, and so on.

Economic facilities refer to freedoms concerned with an individual's opportunities for consumption, production, and exchange of economic resources and private goods in markets. ${ }^{45}$ Economic facilities are instrumentally good because they increase agency. Agents with capital can make investments, start businesses, begin projects, travel, pay for post-secondary education, and make other achievements they have reason to value.

44Ibid., p. 38.

45Ibid., p. 39. 
As I will explain in more detail in the next section, Sen thinks that the freedom to "buy and sell, to exchange, and to seek lives that can flourish on the basis of transactions," is also an intrinsically good freedom, and any society that denies this freedom has failed its people. ${ }^{46}$

Social opportunities are the opportunities society offers individuals to improve their well-being through education, healthcare, and other programs. For Sen, it is very important for societies to develop policies that increase social opportunities without treating people as merely patients to receive welfare. Social opportunities, for Sen, should facilitate an agent's capacity to determine their own destiny.

Transparency guarantees refers to "a basic presumption of trust" that underwrites dealings between individuals in a society. ${ }^{47}$ Such guarantees are essential to protect against fraud, corruption, fiscal recklessness, and other unscrupulous dealings.

Finally, protective security is necessary to protect vulnerable populations in a society from unfreedoms such as illness, poverty, starvation, and death. Protective security is usually provided in the form of welfare policies and programs.

Linkages between economic facilities and other freedoms

Sen thinks the best way to assess a market is to look at the substantive freedoms that markets generate, and at how equitably these freedoms are distributed. Ideally, a balance will be struck between the efficiency of markets in generating agency freedom and enhancing well-being freedoms. However, Sen is aware of the limitations of the

46Ibid., p. 112.

47Ibid., p. 40. 
market mechanism for increasing well-being freedom in a society and for equitably distributing it..$^{48}$

The market mechanism alone cannot guarantee that the substantive freedoms and capabilities it generates will be equitably distributed across society. For instance, the conditions and circumstances that impede individuals from earning income also impede them from using the income they earn. If someone struggles to work because of illness, injury, illiteracy, and so on, then these same problems will also impede their ability to use their income. Illness, injury, illiteracy and other circumstances of deprivation limit the attractive options the individual can choose from. Thus, societies must offer security guarantees such as welfare, and social opportunities, such as education and health care, to balance out the unequal distribution of substantive freedoms and capabilities.

Sen illustrates this need with the historical example of rich countries. In these countries, Sen writes, there is "a remarkable history of public action to provide education, health care, land reform, and so on." ${ }_{49}$ Education, for example, increases people's competency in different fields, thereby increasing the range of employment opportunities they have to choose from, and also increasing their leverage in salary negotiations. Improving health care resources can also contribute to increased economic freedom. It is difficult for an ill person to earn the income they need to pay for healthcare, compounding their illness and poverty. However, if society offers the social opportunity of healthcare, then their illness can be alleviated. Free from the encumbering illness, the individual can access the labour market to earn more income. With increased income and

\footnotetext{
48Ibid., p. 143.
}

49Ibid., p. 143. 
health, the individual's freedom is greatly increased: they have more attractive options and opportunities to lead a life they have reason to value.

So, Sen concludes that the market mechanism, "has achieved great success under those conditions in which the opportunities offered by them could be reasonably shared." ${ }^{50}$ Economic facilities and social opportunities are linked, and societies must use them in concert to ensure that people can enjoy substantive freedoms and capabilities.

Social opportunities are also important for increasing political freedoms. Political freedoms are more easily accessible for individuals who are literate and informed. Political discussion often occurs in writing, in newspapers, editorials, blogs, internet forums, and so on. Politicians release their detailed platforms in writing, and lawyers and judges communicate their reasoning in writing. If an individual is illiterate, they will not have access to these ubiquitous modes of discussion.

Markets alone are not an ideal mechanism for increasing literacy in a society. This is because basic education is what Sen calls a semi-public good. A public good, Sen writes, is a good that cannot be sold exclusively to one person at a particular time. ${ }^{51}$ For example, an environment of unpolluted air is a public good: if the air in a major city is unpolluted, everyone in the city can enjoy the air. While it's true that someone might be gullible enough to pay for the right to breathe clean air in a city, if the air is clean, then everyone enjoys it, even people who were not gullible enough to pay.

Likewise, Sen points out that the benefits of a basic education extend beyond the person who receives it. "The general expansion of education and literacy in a region can facilitate social change," and this social change is enjoyed by everyone in the region,

50Ibid., p. 143 .

51Ibid., p. 128. 
even those who did not receive an education. ${ }^{52}$ However, it is still possible to "sell" an education to one person at a time. Education is not entirely public, and not entirely private, and so Sen classifies basic education as a semi-public good. So, Sen thinks education is an important social opportunity for societies to provide - and because it enhances other important freedoms and opportunities.

Providing individuals with education is a way of treating people as agents, rather than as patients. Education can improve political competence by facilitating participation in political discussions and decision making, and this in turn can help individuals shape society according to values they have chosen, or even values they have discovered through education. Education can thereby increase the range of actual choices an individual has for leading a life they have reason to value.

Political freedom is important to protect the interests of the public against the interests of vested, powerful interests. Another reason markets alone should not be relied on to supply education is that the interests of dealers do not necessarily coincide with the interests of the public. ${ }^{53}$ Dealers are interested in maximizing their profits, and this can lead employers to favour conditions and circumstances that are directly opposed to the interests of the public. A multi-national employer with production facilities in a poor country might favour policies that limit access to education in this country: increased education could lead people to negotiate for better working conditions and higher pay, or seek different employment, which would reduce profits. The remedy for this problem, Sen argues, is more political freedom.

52Ibid., p. 129.

53Ibid., p. 123 . 
Sen writes that "there is no reason why vested interests must win if open arguments are permitted and promoted." ${ }^{54}$ There is need for public discussion where both sides, the dealers and the public, can make their voices heard. In a functioning democracy, public interests are not doomed to failure against the interests of the dealers, because the public can vote for economic policies that prevent vested interests from selfishly manipulating markets at the expense of the public. Thus, political freedoms are essential for achieving further freedoms - in this case, economic openness (which is part of transparency guarantees, illustrating another linkage between the five freedoms). ${ }^{55}$

The five instrumental freedoms are inextricably linked. A society with strong economic freedoms but without political freedoms will struggle to protect the interests of the public against powerful vested interests. Likewise, a society with strong political freedoms that lacks economic freedoms will fail to offer attractive opportunities for employment and generation of income, limiting the substantive freedoms people can enjoy. In both cases, it seems important for the people to make their needs known through discussion and participation in the political decision-making process. However, before I explain why freedom of speech is so important under Sen's approach, I will consider two objections to Sen on the importance of political freedom.

The Lee-Thesis Objection to Sen

I will address a few objections to Sen's argument for the intrinsic importance of political freedom. The upshot is that there is no democracy without this freedom and all

54Ibid., p. 123.

55Ibid., p. 123 . 
that it brings to a society. The first objection comes from Lee Kuan Yew, former prime minister of Singapore.

According to the Lee thesis, civil and political liberties are taken to be detrimental to the economic development of poor countries. Lee points to the economic success of authoritarian East Asian countries like South Korea (formerly authoritarian), Singapore, and China, and the economic struggles of Asian democracies like India.

Sen's rebuttal to Lee is that the thesis is inadequately supported by the evidence: the thesis is not based on statistical analyses over large sets of data, but rather on selective information about certain East Asian countries. Sen points to counterexamples such as Botswana, which is the fastest-growing African nation and a democracy. Furthermore, Sen notes that the economic success of East Asian countries was helped by policies that are compatible with democracy: education to achieve high literacy rates, incentives for entrepreneurs, and openness to competition and international markets. ${ }^{56}$

Additionally, Sen argues that political and civil liberties are also an important factor in economic development. He points specifically to the importance of voting and protesting as a way for citizens to make their needs known, hold government accountable, and prevent disasters like famines. So, Sen concludes that the Lee thesis is not a very successful objection to the importance of political and civil liberties for nations. There is insufficient empirical evidence to prove the thesis or save it from counterexamples such as Botswana. Finally, the thesis fails to account for the effectiveness of civil and political liberties, especially voting and freedom of speech, for making government responsive and responsible to the suffering of citizens and for

${ }^{56}$ Sen, p. 150. 
preventing famines. As discussed earlier in Sen's work on famines and in the section that follows, a free press can make such suffering known and force a government to respond in democracies that hold frequent multi-party elections.

The second objection Sen addresses is the claim that until people's economic needs are met, they are indifferent to political liberty and civil rights. In such countries, poverty frequently forces people to risk life and limb simply to survive. According to the objection, people living under severe economic pressure are too concerned with staying alive to care about luxuries like voting and freedom of speech.

This objection begs the question by assuming that people's economic needs will not be well met by opting for political liberty and civil rights. Political freedoms are linked to economic freedoms. As Sen's arguments about famine demonstrate, autocratic rulers are not always incentivized to pay attention to the economic needs of their subjects. However, if the subjects gain democratic political freedom, then their leaders have incentives to respond to their economic needs. Thus, enhancing people's political freedom can be a necessary first step to meeting economic needs. When people have increased political freedom, they can vote for representatives who will legislate policies that will help people achieve economic freedom. Therefore, the objection fails.

Sen argues that the objection fails in another important respect as well. The objection is a claim about what people actually prefer. However, to determine what people actually prefer, you would have to offer them a choice between alternatives, in this case, authoritarianism or democracy. To test the objection's claim about what people actually prefer, investigators would have to use democratic methods, e.g. free elections with multi-party opposition and expression, allowing people to choose between political 
liberties/civil rights or authoritarian policies. ${ }^{57}$ Sen offers the counter-example of $1970 \mathrm{~s}$ India, where an election was held that was essentially a referendum on whether basic political and civil rights should be suspended to improve national security and the economy. The impoverished Indian electorate refused to relinquish their liberties despite their abject poverty. They desired to be treated as agents, rather than as patients. Now that the importance of political freedoms has been defended, I will explain why freedom of speech is so important for Sen's approach to development.

Freedom of speech is essential for achieving political freedoms

Under Sen's approach, freedom of speech is essential for achieving political freedom. Sen holds that political freedom includes the freedom to vote in fair elections between multiple political parties, freedom to report and/or consume news, the freedom to hold government accountable, the freedom to express political opinions, and so on. Freedom of speech is necessary for all these political freedoms.

My focus will be on the importance of freedom of speech for expressing political opinions, because, on Sen's account, free and open discussion of political opinions is necessary for democracy to achieve wise and just outcomes that provide substantive freedoms and capabilities for members of the polity.

First, free and open political discussion is necessary for people to criticize the policies of the existing government or leaders. If the existing government restricts speech critical of the leaders or their policies, then it is impossible to have an open discussion.

57Ibid., p. 151. 
An excellent example of the positive benefits a society can experience when restrictions against political speech are lifted comes from the post-Stalinist USSR.

During his reign of terror, Joseph Stalin was responsible for millions of murders and other atrocities, but these deaths and his disastrous policies (e.g. the collectivization of farms, the Holodomor, the purge of the Red Army) went unchallenged until his death, because to speak against the cult of personality, or even to be suspected of harbouring disloyalty, was grounds for execution.

Not until Nikita Kruschev’s “Secret Speech” (a fierce criticism of Stalin’s excesses and a call for a return to Leninism) was the ruling apparatus of the USSR finally able to discuss and challenge policies in a relatively free manner, resulting in what was called the Kruschev thaw, a relaxation of censorship and renewed literary expression. However, the "Secret Speech" was deemed so dangerous to the political fabric of the USSR that it was kept secret from ordinary citizens until 1989.58 The leaders of the Soviet Union understood the power of speech to change society, even in a non-democratic society without elections or a multi party system.

In democracy, freedom of political expression is even more important. In a democracy, citizens have the power to vote in elections between multiple political parties. But this power is only effective if citizens are well informed. James Madison, one of the architects of the U.S. constitution, argued that freedom of political speech is necessary to have an informed populace, and an informed populace is necessary to prevent a democracy from becoming a farce, a tragedy, or both. ${ }^{59}$ The press must be allowed to

\footnotetext{
58“Kruschev's Secret Speech," ed. by Amy Tikkanen, The Encyclopedia Brittanica, https://www.britannica.com/event/Khrushchevs-secret-speech, February 18, 2019. 59James Madison, The Writings of James Madison, ed. Gaillard Hunt (New York: G.P. Putnam's Sons, 1901), volume 9, p. 103.
} 
freely report on candidates in elections, and on the behaviour of politicians already in power. If the press is barred from reporting on malfeasance by politicians and powerful, vested political interests, then the populace will not know how they ought to hold the corrupt government accountable.

Holding government accountable is another important political freedom, and this freedom can only be safely exercised when individuals are free to express political opinions. After receiving information about political matters from the press, citizens can hold government accountable by expressing their political opinions in protests, editorials, petitions, open letters, at the ballot box, and so on. ${ }^{60}$

The freedom to be critical of the government and hold it accountable has a direct linkage to economic facilities and security guarantees. Sen argues that the reason no major famine has ever occurred in a functioning democracy is because democracies allow citizens to hold their leaders accountable. ${ }^{61}$

Journalists and opposition parties have, respectively, economic and political incentives to report information that is embarrassing to the government: "a free press and an active political opposition constitute the best early-warning system a country threatened by famines can have." ${ }^{22}$ If a dictator suppresses news reporting that would embarrass the government, or if opposition parties cannot conduct investigations, then people living in famine-threatened areas will not have sufficient information to prepare.

\footnotetext{
${ }^{60}$ Holding government accountable reveals another linkage between social opportunities (in this case, education) and political freedom: effectively expressing critical political opinions requires literacy and competence. ${ }^{61}$ Amartya Sen, Development as Freedom, p. 178. ${ }^{62}$ Sen, p. 181.
} 
An important second advantage is that democracies with universal suffrage can hold leaders accountable - if a famine occurs in a democracy, voters can point the "accusing finger" 63 at the government and vote them out of office. Thus, there is a political incentive for leaders to respond to citizens' interests. In non-democracies, or democracies where uneducated or marginalized people cannot vote, there is no such incentive: leaders can simply ignore the famine (famines usually affect only small proportions of the population who are too poor to buy food) or blame it on some politically convenient scapegoat.

So, democracy's two advantages for preventing famine both stem from its responsiveness to the interests of all citizens, especially to citizens who live in conditions of deprivation and inequality. Leaders from ruling and opposition parties have political incentives to prevent famines because they can be voted out of or into office, respectively. Journalists and the media have economic incentives to report on famines because citizens want to know if policies are working to protect their interests.

So, the freedom to express political opinions is incredibly important, especially because the five instrumental freedoms are so closely linked. The famine case demonstrates that political freedoms are essential for holding governments accountable, and that holding governments accountable is essential for ensuring that governments respond to the interests of the people with respect to social opportunities and economic facilities.

63 Sen, p. 171. 
Criticisms of Sen's focus on individual freedom and well-being

But there is another sense in which freedom of speech is necessary for democracy, one that Sen does not address. Discussion is also valuable for helping people in a democratic society understand each other across their differences, so that they can work together to arrive at mutually beneficial, wise, and just decisions (the constructive role of public and political debate). However, for discussion to help disparate groups in society understand each other, and for discussion to achieve political freedoms for these disparate groups, all groups must be able to participate in free and open discussions.

Unfortunately, it is not the case that all groups have equal, effective opportunity to participate in discussions, the democratic process, and social life in general. For example, in the United States, some groups of people (Blacks, Latinos, women, and so on) are systematically oppressed and therefore have very different life experiences and form different perspectives than groups that are not as systematically oppressed (wealthy white men, for example). As I argued in my discussions of hate speech, there are psychological, social, and economic harms for members of oppressed groups targeted by this speech. These are the kinds of harms that often prevent those targeted from engaging in free and open debate about their experiences or their interests in having policies restricting such speech.

Christine Koggel argues that Sen misses the forest for the trees-he pays too much attention to individuals and insufficient attention to groups. Koggel argues that Sen's approach fails to consider "how political, economic, and social institutions embed norms, structures, and practices that stand in the way of removing some inequalities and 
of having some people participate in debates about those inequalities." ${ }^{94}$ In other words, oppressed groups face serious inequalities, including unequal access to effective opportunities to participate in the democratic process to discuss the very inequalities they face. While Sen rightly points out that substantive freedoms should be equitably distributed for all individuals, he does not say enough about how to achieve equitable, effective opportunity to participate in democratic discussions for oppressed groups. In the chapter that follows, I will show that Iris Marion Young's work on oppression and group difference can fill in the gaps in Sen's account, providing an account of democracy that considers oppressed social groups and how to better include them in the democratic process.

${ }^{64}$ Christine Koggel, “A Critical Analysis of Recent Work on Empowerment,” Journal of Global Ethics 9, no. 3, DOI: 10.1080/17449626.2013.818383, September $1^{\text {st }} 2014$, p. 266. 
Chapter 2: From Sen to Young: Oppression, Social Groups, and Inclusive Democracy

What are social groups?

"While I agree that individuals should be free to pursue life in their own way, it is foolish to deny the reality of groups." 65

Before we can understand how certain social groups are oppressed, I must explain how Young conceives of social groups. Social groups, for Young, are not like species or substances. Differences between human social groups are not like the differences between iron and copper. Young argues that a social group "should not be understood as an essence or nature with a specific set of common attributes." ${ }^{66}$ A social group for Young is not like an aggregate of individuals who all possess a shared characteristic, e.g. redheads, or people with dimples, and so on. Redheaded individuals are in the group "redheads" even if they have never met another redhead, and even if no one acknowledges them as a redhead. This kind of group membership is not important for the democratic process.

Young holds that for all groups as such "there is no common nature that members of a group have." ${ }^{67}$ Members of groups certainly share some common characteristics or properties, e.g. they share the property of belonging to a particular group. However, Young does not claim that this amounts to sharing a common nature, i.e., people within the same group are irreducibly different from one another. Just because two people belong to the same social group does not mean they share a common nature: Two people

\footnotetext{
65Iris Marion Young, Justice and the Politics of Difference (Princeton: Princeton University Press, 2011), p. 47. 66Ibid., p. 187.

67Ibid., p. 187.
} 
who are both "fans of the Toronto Raptors," or "Roman Catholics," or "African American," are still irreducibly particular and different from one another.

Furthermore, Young points out that groups are fluid, not permanent. Gay men have existed throughout history, but "gay male group identification exists only in the West in the twentieth century." ${ }^{68}$ Some groups have persisted for hundreds, even thousands of years. But even these groups are fluid and change with time: "Roman catholic" has been a social group for over a thousand years, but the characteristics and nature of the group and its members are not what they once were.

Young also distinguishes social groups from associations, which are collectives assembled to achieve a specific goal (e.g. a professional basketball team is an association - a group assembled for a specific objective) ${ }^{69}$

Rather, Young defines a social group as "a collective of persons differentiated from others by cultural forms, practices, special needs or capacities, structures of power or privilege. ${ }^{70}$ These differentiated forms and practices are not created on purpose to achieve a specific goal, as in the case of associations. Instead, they "emerge from the way people interact." ${ }^{71}$ Young illustrates this point with the Maori of New Zealand. Before the arrival of the British, "Maori" was not a social group. There were hundreds of groups living on the islands, with different languages and practices. When the British arrived, they saw the natives as more like each other than they were to the British, and classed them as a single group, Maori. Likewise, the people living on the islands saw the British

\footnotetext{
68Ibid., p. 187.

${ }^{69}$ Young, Inclusion and Democracy, p. 90.

70Ibid., p. 90.

${ }^{71}$ Ibid., p. 90.
} 
as more different to them than they were to themselves, causing them to draw closer together. ${ }^{72}$

The most interesting aspect of social groups, for Young, is how they are "positioned in interactive and institutional relations that condition their opportunities and life prospects." ${ }^{73}$ In other words, Young seems interested in the capabilities and substantive freedoms that members of a particular social group possess, or do not possess because of oppression. They constitute a social group because of their "thrownness" in the group as determined by those in power. In Sen's terminology, these are features of social groups that shape the kinds of unfreedoms they experience and that limit what people in these groups can be and do.

\section{Oppression of Social Groups}

Referred to as "five faces of oppression", Young describes five different ways social groups are often oppressed: exploitation, marginalization, powerlessness, cultural imperialism, and violence. All these forms of oppression can exclude members of a particular social group from effectively participating in the democratic process. Thus, oppression of social groups prevents those groups from using the democratic process to achieve greater substantive freedoms like political freedom, social opportunities, and economic facilities. Furthermore, as I will argue in the section that follows, the distribution of some important freedoms, like security guarantees (e.g. welfare), can actually contribute to oppression that can reduce individual freedom. Sen's account is

\footnotetext{
72Ibid., p. 90.
} 73Ibid., p. 97. 
thus inadequate because he does not consider that security guarantees like welfare can generate additional inequalities and unfreedoms. To show this, I will consider three of the faces in more detail: marginalization, cultural imperialism, and violence.

\section{Marginalization}

"It was the summer of 1988. I'm 16 years old, I got two kids, two and one years old, and I'm living in the hood in Atlanta. In this hood I'm trying to survive, so I go out and start me a small business. Well, I was selling crack but we gonna call it a small business tonight, okay white people? When you're 16 years old in the hood and you got two kids there's only two things you can do for a job: sell drugs or sell your body. So I sold the one that paid the most." ${ }^{\prime 74}$

Young argues that, in the modern United States, racial oppression (i.e. oppression of a social group on the basis of race) mostly takes the form of marginalization. ${ }^{75}$ In this case, an individual is marginalized if they are excluded from opportunities in the labour force. The marginalized include young people (especially Blacks and Latinos) who cannot find a first or second job, people who are laid off and cannot find another job, single mothers, Native Americans on reservations, people with mental disabilities, the elderly, and so on. ${ }^{76}$ Marginalization is very harmful to people's freedom and real opportunity to pursue a life they have reason value.

According to Young, marginalization is very dangerous because "a whole category of people is expelled from useful participation in social life, and thus potentially subjected to severe material deprivation and even extermination." "77 For example, Young

\footnotetext{
74Ms. Pat, This Is Not Happening, Comedy Central, February 25, 2015, https://www.youtube.com/watch?v=pFVNt1jbnqE 75Young, Justice and the Politics of Difference, p. 53. ${ }^{76}$ Ibid., p. 53. 77Ibid., p. 53.
} 
notes that people of colour in urban neighbourhoods constitute a social group, and that this social group is systematically oppressed (in the form of marginalization) by racially discriminatory actions and policies. Racist housing policies limit options for people of colour, forcing them into segregated neighbourhoods with dilapidated infrastructure and poorly maintained housing. Politicians typically respond to more affluent neighbourhoods, leading to weak social opportunities (like education) in the impoverished neighbourhoods that are most desperate for resources in schools and public services. Thus, pervasive poor education creates an environment where few young people qualify for employment. Thus, discriminatory actions and policies marginalize people of colour in these urban neighbourhoods. Some turn to selling illegal drugs and prostitution. Governments often try to offset marginalization by providing welfare.

Recall that Sen classified welfare as a security guarantee, or one of the five instrumental freedoms. Welfare, according to Sen, increases the freedom and real opportunities of those who receive it. Indeed, this is true to an extent. For example, a welfare program that includes job opportunities that could lead to advancement could improve people's agency and well-being freedoms. However, Young points out that receiving welfare also generates unfreedoms that entrench marginalization, in two ways.

First, liberal democracies tend to treat "dependents" with less respect than people who are "independent." Young notes that liberal democracies have "traditionally asserted the right of all rational, autonomous agents to equal citizenship. Early bourgeois liberalism explicitly excluded from citizenship all those whose reason was questionable, or not fully developed, and all those not independent." ${ }^{\prime 78}$ Recall that even Mill, a very

78Ibid., p. 54. 
progressive thinker in his time, did not want "uneducated men voters." Sen's goal seems to be to make as many people as possible independent, and because welfare gives people additional resources, it would seem to make them more independent than they were. But the paradox of welfare is that those who receive it become dependent on the state and often they need to prove they cannot work and actually need these resources.

Democracies tend to view people who receive welfare as dependent, like children, and therefore the state does not extend full rights of privacy and choice. For example, welfare recipients are under the authority of social workers and bureaucratic administrators who manage their aid. These authorities determine what the welfare recipients need, and welfare recipients must comply. Young notes that dependents, such as the elderly and the mentally disabled, are often subjected to "patronizing, punitive, demeaning, and arbitrary treatment" ${ }^{19}$ by authorities.

Secondly, Young argues that marginalization persists even if dependents have all their basic material needs met and are treated with respect and dignity by social institutions. Marginalization continues because dependents are excluded from meaningful, useful participation in social life. In societies like ours, "productive and recognized activities take place in contexts of organized social cooperation." ${ }^{" 0}$ Young argues it is unjust for social structures, like the labour market, to exclude people from social participation and cooperation. "Marginals" who cannot participate in social cooperation will experience injustice in the form of "uselessness, boredom, and lack of self-respect." ${ }^{\prime 81}$ Thus, security guarantees like welfare can succeed in correcting serious

79Ibid., p. 54.

8oIbid., p. 55 .

${ }^{81}$ Ibid., p. 55. 
distributive injustices; however, marginalization continues because societies like ours do not give "dependents" sufficient opportunity to exercise their capacities and capabilities in socially cooperative efforts to include them in public debates about policies that affect their lives.

\section{Cultural Imperialism}

Cultural imperialism is a form of oppression tied to freedom of speech. Sen argued that an equitable distribution of freedom of speech is very important for attaining political freedom. However, it is difficult to understand what is meant by an equitable distribution of freedom of speech. For example, the first amendment to the U.S. constitution seems to ensure that everyone has an equal right to free speech. In other words, everyone has an equal right to express themselves, to demand equal concern and respect, and to voice their needs and interests. However, as Young's analysis of cultural imperialism shows, some social groups benefit far more from this right than others, and in fact dominant social groups can use freedom of speech to oppress other groups.

Cultural imperialism occurs when a dominant group ignores the actual lived experiences and perspectives of a dominated group, and instead stereotypes the oppressed group and casts them as Other. ${ }^{82}$ Furthermore, the dominant group casts its own perspectives and experiences as the norm. This includes the dominant group's perspectives towards minorities or the marginalized. Cultural imperialism thus often takes the form of racist stereotypes.

82Ibid., p. 58. 
For example, a particularly infamous form of cultural imperialism is the practice of blackface, where white performers use make-up to create an unrealistic and insulting portrayal of black people. Cultural imperialism has often occurred against women; for example, female comedians are often expected to be self-deprecating and not make jokes at the expense of men, thus reinforcing the male-dominant perspective as the norm. These stereotypes are reinforced ad nauseum such that the dominant group fully accepts their accuracy. When this occurs, the dominant group ignores the experiences and perspectives of the dominated, instead seeing only the stereotypes they themselves have created: "American Indians are lazy alcoholics, that's why they are marginalized;" "Mexicans are lazy, that's why they have bad jobs;" "Black people are violent and dangerous, that's why they are all in gangs."

Young notes that those on the receiving end of cultural imperialism paradoxically experience themselves as invisible and as Other. ${ }^{83}$ And this, for Young, is the primary injustice of cultural imperialism. The dominant culture ignores the oppressed group's efforts to express their life experiences, perspectives, and interpretations of social life. Instead, the dominant culture imposes its own interpretation of social life on the oppressed group. ${ }^{84}$ The oppressed group not only suffers the injustice of having their speech ignored, they also suffer the injustices of being treated according to the dominant culture's stereotypical, often demeaning, perspective.

Thus, even though every individual in a democratic society has a right to freedom of speech, it does not follow that their speech will be heard or that they will gain political freedoms. While Sen is correct to claim that access to news and the ability to vote can

83Ibid., p. 60.

84Ibid., p. 60. 
protect the oppressed from disasters like famines, and that protecting people from starvation and death is incredibly important, this will not be enough to have those affected by policies engage in a political process that can address their needs and interests. Without measures to address the lack of freedom that oppressed groups have, freedom of speech for those who dominate can be used as a weapon to further oppress people and cast them as Others on the margins of social life. While it is not part of Sen's project to address the ways in which the voices of the oppressed are absent or how they can be heard, Young gives us the tools for thinking in terms of freedom of speech as needing to amplify the voices of the oppressed.

\section{Violence}

Finally, the last form of social group oppression I will consider is violence. Young notes that violence against certain social groups is a social injustice when it occurs in a systemic way towards members of a particular social group. Young notes that, for example, all women and black people live day by day knowing they are vulnerable to violation, simply because they are a member of a particular social group. She points out that statistics show that one in three women will experience an attempted or successful sexual assault in their lifetime. Further, "regardless of what a Black man has done to escape marginalization and powerlessness, he lives knowing he is subject to attack or harassment." ${ }^{85}$ In addition to police brutality and profiling, harassment could also include

\footnotetext{
85Young, Justice and the Politics of Difference, p. 62.
} 
forms of hate speech addressed in the previous chapter, along with the harms hate speech generates.

Young notes that cultural imperialism often creates the social context in which social institutions tolerate, encourage, or enable violence against particular social groups ${ }^{86}$ The dominant group, for example, might stereotype an oppressed group as violent and dangerous, and the cultural products of the dominant group reinforce and ingrain these stereotypes, leading members of the dominant group to fear the oppressed group. Irrational fear often leads to irrational violence; for example, fear of a particular social group (caused by the dominant group's stereotypical perspective) can make them a scapegoat for crimes, and their status as Other has made and can make them targets of lynching and mob-violence.

Sen's approach does not seem to offer a way of dealing with this problem. I defended Sen from the objection that increasing freedom means increasing the freedom to commit violence. But that defence merely shows that Sen's approach is compatible with legal restrictions on violence. Young argues that distributive justice does not seem like a promising way to deal with the problems of oppression in terms of marginalization, cultural imperialism, violence, and so on. Rather, Young argues that reform can only come through "a change in cultural images, stereotypes, and the mundane gestures...of

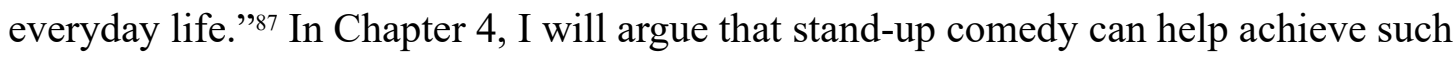
reform, but only when it satisfies communicative norms of inclusion and equality that treat social group difference as a resource.

\footnotetext{
86Ibid., p. 63.
}

87Ibid., p. 63. 
Inclusion and Democracy: Social differences are a resource for democracy

An account of oppression emerges from Young's account of social groups who are defined and treated differently because of their membership in a group. Those in positions of power do not have experiences and perspectives that reflect the burdens, anxieties, and suffering caused by oppression. Furthermore, the dominant group seldom see themselves as oppressors and may even see themselves as needing to protect themselves from dangerous Others marked as different from them. Young's account does not mean that all oppressed groups share experiences of marginalization and violence, for example. Her account means that all oppressed groups are vulnerable to experiencing one or more of the five faces of oppression.

Young argues that democracy is strengthened when different groups in a democracy come to a closer understanding of one another. In Inclusion and Democracy, she writes extensively on the relationship between democracy and group difference, arguing that social differences are not an obstacle to democracy, but are rather a resource. In this book, Young addresses group differences both in terms of social groups (as discussed in the previous sections on oppressed groups) and in terms of groups with political differences. According to Young, inclusion of different groups has three benefits to democracy: first, it demonstrates equal respect and ensures that legitimate interests in the polity receive expression. Second, it motivates members of different groups to frame their political claims as appeals to justice and rights. Third, it increases the understanding and knowledge of the democratic public about their society. ${ }^{88}$

88Young, Inclusion and Democracy, p. 115. 
The first point is a fundamental reason to favour democratic inclusion. A democracy that fails to prize equal respect and consideration towards all its members is not a healthy democracy, it is more like a tyranny of the majority. If a democracy is committed to the value of equal respect, it will not see group differences as an obstacle to democracy. Group differences are irreducible; rather than ignore them or fight them, a democracy committed to equal respect will listen and respond reasonably to claims made across differences. This will ensure that legitimate claims of justice are answered.

Second, Young argues that a disposition of reasonableness and inclusion of group difference causes people to frame their needs in terms of justice, rather than self-interest. If group difference is not respected, then members of a politically dominant group do not need to frame their claims in terms of justice. When group difference is not respected, the politically dominant group does not need to seek the support of weaker groups, and instead demands what it wants. But when group differences are respected, then dominant groups must listen to the claims of others in the discussion. When everyone in the discussion must listen to and respect the needs of others equally, claims of self-interest are less persuasive. No one's self-interest counts more than anyone else's. But if all groups must give and receive equal respect and consideration, then the claims that are the most deserving, the most just, will be more likely to gain acceptance. In other words, "I should have $x$ because I want $x$ " is unlikely to be accepted as a legitimate claim of need. However, "I deserve $x$ because of reasons of justice $a, b$, and $c$ " is much more likely to be taken seriously and garner acceptance. Thus, when groups in a discussion mutually respect one another, their deliberations are more likely to occur in terms of justice. But 
Young notes that simply framing needs in terms of justice is not sufficient to have discussion produce good outcomes.

Participants in discussion must be knowledgeable about their society as a whole and they must understand the social positions of other groups in their society. Only when participants are sufficiently knowledgeable about their society and the different groups that compose it can discussion lead to wise and just outcomes for society as a whole.

So, thirdly, Young argues that respecting group differences increases people's knowledge and understanding of their society, and therefore people will be more likely to make wise and just decisions. This is a powerful reason to respect group difference. Lack of knowledge of other groups is a driving cause of bias, stereotypes, discrimination, and hatred. When discussions and decision making are influenced by biases, stereotypes, and hatred, these discussions are likely to produce unequal and unjust outcomes. Rather, they are likely to lead unequal, unjust distributions of agency and well-being freedoms. The remedy for ignorance about group differences is not isolation, but respectful engagement. "Confrontation with different perspectives, interests, and cultural meanings" teaches us how others conceive themselves, and how they conceive us. Young calls this “contextualizing perspective." ${ }^{89}$

People have knowledge about their own social position, and it is important that people can share this knowledge with others. By "social position" Young refers to one's substantive freedoms and capabilities within a society, and how these freedoms and capabilities are undermined or enhanced by institutions and policies. An individual born into an impoverished family is in a different social position than an individual born into a

89Ibid., p. 116. 
wealthy family. If group differences in society are not respected, then people in these differentiated positions will have difficulty acquiring knowledge about each other.

Respect for group difference is a prerequisite for listening to others discuss their particular capabilities, needs, and interests, and for being able to share knowledge of one's own capabilities, needs, and interests. Young identifies five sorts of situated knowledge: (1) knowledge of one's needs and interests and their relation to others' needs and interests; (2) knowledge, like a map, of the overall positioning of groups in society; (3) knowledge of the society's history; (4) an understanding of the relations and processes that govern interactions between groups in the society; (5) a group-specific "experience and point of view on the natural and physical environment." ${ }^{90}$ When discussion participants are knowledgeable in these five categories, their discussions are more likely to produce wise and just results.

As with Sen, democracy for Young is primarily a discussion-based process. Discussion revolves around "problems, conflicts, and claims of need or interest. Through dialogue others test and challenge these proposals and arguments." ${ }^{91}$ Participants discuss problems that effect people's freedom to pursue lives they have reason to value: access to education (e.g., "Where should the school be built?"), land rights (e.g., "Should the pipeline be built across this land?"), and so on..$^{92}$ In a democratic society, members of the polity confront such problems, and craft solutions that everyone will cooperate to implement. ${ }^{93}$ On the other hand, in a monarchy, oligarchy, or other non-democratic form of government, the solution to a problem will be whatever the rulers decide. But in a

90Ibid., p. 119.

91'Ibid., p.22.

92Ibid., p. 28.

93Ibid., p. 28. 
democracy, the solution does not depend on the fiat of a single individual or a council, rather, the solution to a problem or claim will depend on whomever can persuade the most people to adopt their view.

The democratic norm of equal concern and respect entails that everyone's needs and interests count equally, and therefore everyone deserves an equal chance to persuade others to adopt their view. Furthermore, equality of concern and respect entails that people who will be affected by deliberative decisions are only morally bound to abide by those decisions if they had an equal opportunity to influence the outcome. ${ }^{94}$ Young departs from Sen in discussing the processes by which deliberation and debate should take place. She argues that the "democratic process entails several normative ideals," that must shape the deliberative process and guide participants in their discussions. ${ }^{95}$

Young argues that discussion must occur under certain ideal conditions if it is to produce the most wise and just outcomes for democratic society. These conditions underline the importance of two central democratic values: agency and equality. To respect these values, discussion must be inclusive, it must be free from domination, it must occur between reasonable participants, and finally it must be public. Young argues that when discussion occurs under these conditions, it is likely to produce the most wise and just outcomes for democratic society ${ }^{96}$ Young's conditions are fully compatible with Sen's approach to development as freedom, but it builds on his approach by offering a road-map for how to avoid inequalities and deprivations in the distribution of freedom of speech. When political discussion satisfies Young's conditions, it can equitably increase

94Ibid., p. 53 .

95Ibid., p. 23.

${ }^{96}$ Ibid., p. 30. 
people's substantive freedoms and capabilities to lead lives they have reason to value. Furthermore, discussion under these conditions will view social differences as a resource, which can further strengthen democratic society.

Discussion must be inclusive.

Democracy's presupposition that people are autonomous and equal entails the normative ideal of inclusion. The deliberative process is inclusive if it respects equality in two regards: equality of access to discussion, and equality of participation in discussion. In terms of equal access, everyone should be included in the discussion, and in terms of equal participation, everyone should have "an equal opportunity to influence the outcome." ${ }^{97}$ Thus, Young argues that democratic discussions can be afflicted by two kinds of exclusion: external exclusion, where people are barred from accessing discussion, and internal exclusion, where despite equal access to the fora of discussion, people are barred from effectively participating. ${ }^{98}$ In order to be inclusive, democratic discussion must be free of both kinds of exclusion.

\section{External Exclusion}

External exclusion refers to ways that individuals and groups who should be included in discussion are blocked from the fora of discussion. ${ }^{99}$ The people who should be included in discussions are the people who will be affected by the outcome of a

97Ibid., p. 52.

${ }^{98}$ Ibid., p. 53 .

99Ibid., p. 54. 
discussion. When these people are blocked or left out of discussion, then the discussion fails to be inclusive. Historically, many democracies allowed only white male landowners the right to vote. Such laws are an example of external exclusion. However, even when such laws are off the books, democracies still (wrongfully) permit external exclusion with respect to voting rights, by making voter registration unnecessarily cumbersome, by making polling stations difficult to access for certain neighbourhoods, and so on. This is an important form of external exclusion, but it is by no means the only way people are excluded. Even when citizens possess "formally equal rights to participate," inequality in resources can cause other forms of external exclusion. ${ }^{100}$

Young argues that in current democracies, the primary cause of external exclusion is inequality in power and resources. This reveals another important linkage between political freedom and economic facilities: unequal distribution of wealth and resources leads to unequal distribution of political freedom. For example, advertising space on mainstream media outlets is an important political resource for making one's voice heard. A political ad on a major network can significantly amplify an individual's voice, ensuring that millions hear their claim of need or interest. However, the vast majority of people are excluded from this powerful point of access to discussion. Access is exclusively available to the wealthiest individuals and groups. So, this is a clear demonstration of how inequality in one area (wealth) produces inequality in another area (political freedom), leading to a pervasive instance of external exclusion. The rich and powerful can dominate televised discussion by buying up all the air time, effectively

10oIbid., p. 54. 
excluding others from the discussion. Thus, in order to satisfy the condition of inclusion, communication must be free from domination.

Hate speech can be considered a form of domination in communication. Hate speech, as face-to-face vilification, hostile environmental harassment, or group libel, is a form of communication that implicitly or explicitly says that certain groups should not be given an equal opportunity to participate in discussion and make their needs known. Hate speech uses fear and intimidation to keep people away from political discussions, silence their voices, and even force them to move or flee.

External exclusion is relatively easy to notice. When people do not have equal opportunity to access the forum of discussion, it is easy to see who got in and who was kept out. It is usually obvious to people if they are externally excluded from discussion: most people know they are insufficiently wealthy to buy political ads, or lobby politicians. For this reason, Young argues that most theorists and reformers focus on external exclusion. It is simply easier to see. However, she points out that internal exclusion is much more difficult to see, but no less harmful to the quality and outcomes of the democratic process.

Internal Exclusion

Individuals and groups can still be excluded from discussion even if they are allowed equal access to the discussion. Internal exclusion occurs when, despite access to the discussion, individuals or groups lack a real opportunity to persuade others and 
influence the outcome of the discussion. ${ }^{101}$ People are internally excluded from discussion when other participants in the discussion discount their opinions. Discounting can occur for a variety of reasons, but the upshot is that certain powerful participants in the discussion demonstrate lack of respect for the opinions of other, less powerful participants. It does not matter what the less powerful participants say, it is as if their opinion does not matter at all. Young proposes that internal exclusion often occurs because political discussion is conceived as a form of argument.

Young argues that when political discussion is conceived as a form of argument, participants make "assertions and proposals, [and provide] reasons for them they claim ought to be acceptable to others." 102 Indeed, argument is a necessary component of political discussions. However, when two parties engage in an argument, they must share at least some premises. Young points out that in many situations of political conflict, there is virtually nothing the parties agree on, and discussion cannot progress. Thus, in order to increase possibilities for discussion and understanding, discussion should be conceived as more than just an argument. ${ }^{103}$

Another reason to expand our understanding of discussion and its role in democracy is that discussion-as-argument contributes to internal exclusion. The power to influence a discussion stems not just from wealth, but also from understanding the norms of discussion, and demonstrating competence and expertise in applying these norms. Young argues that internal exclusion sometimes occurs when an individual or group fails to engage in discussion according to the established norms of political discussion-it is

\footnotetext{
${ }^{101}$ Ibid., p. 55 .

${ }^{102}$ Ibid., p. 56.

103Ibid., p. 56.
} 
not what they say, rather it is how they say it. This is not to put the blame on the excluded person or group. Failure to engage in discussion according to the traditional norms often occurs because of historical external exclusion: individuals were barred from the process for so long they simply lacked opportunities to assimilate the traditional norms.

Norms of argument include articulateness, dispassion, orderliness, and so on. Participants are expected to emphasize logical connections, avoid gestures, metaphors, or stories, and refrain from displays of intense emotion. Thus, when participants fail to demonstrate these norms, others who are committed to these norms will discount their opinions. So, despite their formal inclusion in discussion, many participants find their claims, proposals, and justifying reasons are excluded from deliberation. The exclusion is harmful to the excluded individuals, but also to democratic society more generally.

When individuals are excluded from deliberations, despite expressing opinions and genuine claims of need, the outcome of the deliberation will be incomplete with respect to these individuals. However, these individuals and groups must still live within a society that does not hear or respond to their interests and needs. Internal exclusion not only impedes the political freedom of excluded groups and individuals, it also weakens social cohesion. When the discussion-based process excludes certain individuals and groups, those individuals and groups will be less motivated to engage in discussion or communication across their differences. Communication between differentiated individuals and groups is essential in democracy, where there are many competing claims of needs and interests. When a democracy is composed of a diverse population without uniform norms of political discussion, a theory of political communication should make room for these diverse norms of discussion. 
So, Young proposes that an expansive theory of political communication should welcome additional modes of discussion, to take deliberation beyond traditional norms of argument, and avoid internal exclusion. Young's expansive theory of political communication is fully compatible with Sen's expansive account of the capabilities approach, as both theorists are seeking to increase people's real opportunities to pursue lives they have reason to value. By expanding norms of political communication, fewer people will be internally excluded from discussion. With increased capability to participate and influence the results of discussion, many people will have their political freedoms increased. Political freedoms will be more equitably distributed. And, as Sen's arguments demonstrate, increases in political freedoms are linked with increases in economic facilities and social opportunities.

Young proposes that internal exclusion can be alleviated by expanding norms of political communication to include greeting, rhetoric, and narrative. As I will argue in chapters 3 and 4, stand-up comedy is an excellent mode of communication that incorporates and expands participants' understanding of greeting, rhetoric, and narrative. But before that discussion occurs, I will explain Young's position on these modes of communication. Young argues that expanding our understanding of communication to include these modes, we will increase our capacity to understand and interact with one another.

Political communication should include norms of greeting

Internal exclusion can occur when groups or individuals fail to greet or publicly acknowledge other groups and individuals who are attempting to participate in 
discussion. ${ }^{104}$ Greeting, or public acknowledgement, is a common norm of communication in most settings. Before engaging in discussion, participants greet one another. Modes of greeting differ from culture to culture: in European cultures, handshakes or hugs are common, whereas in some East Asian cultures, a bow is customary. The greeting is a gesture of respect in two ways: participants acknowledge each other as equals in the discussion, and gesture that they will abide by the norms of discussion.

Greeting is important for discussion to proceed in a productive and inclusive manner. When individuals attempt to participate in a discussion, but are not greeted or acknowledged by the other participants, the excluded individual may feel "as though they were not there, deprecated, stereotyped, or otherwise insulted." 105 Thus, Young identifies greetings as an important norm of communication for the democratic process. Young argues that political discussions in which participants greet and acknowledge other participants, "are more substantively inclusive than those that do not." 106

Greeting is an important communicative act because it signifies trust between participants. Young points out that in discussion, someone must make the first move. When someone offers a greeting, perhaps in the form of a handshake, they are putting themselves in a vulnerable position. Offering a greeting makes one vulnerable because there is no guarantee the greeting will be reciprocated. Everyone who has offered a handshake that was rejected can attest to the unpleasant and embarrassing situation that results. Greetings are a risk. However, they are a necessary risk because they reach out

\footnotetext{
104Ibid., p. 57.

105Ibid., p. 57.

106Ibid., p. 57.
} 
for trust, and trust is essential "to sustain a discussion about issues that face us together." ${ }^{107}$

Discussion participants must trust one another during the discussion, otherwise they will not believe others' claims, which would cause a breakdown in deliberations. But participants must also trust that others will honour the outcome of the discussion and cooperate to implement the decision. So, participants must establish trust with one another, and greetings have historically served to signify trust between participants.

In addition to signifying trust, greeting signifies that individuals have claims on each other, that they are in a sense "hostage" to one another. ${ }^{108}$ When individuals explicitly acknowledge each other in greeting, they acknowledge two things: that they are distinct, different individuals, and that they each have some responsibility for the other. Therefore, because participants who greet each other acknowledge their particularity and responsibility for one another, a greeting is a very important ethical moment for discussion.

Thus, Young argues that greeting helps us see discussion as not merely a mode of argument. If our discussions occurred entirely without greetings, Young argues, we would sound like robots, "for whom speech is only for getting things said, interrogating their truth or rightness, and getting things done." ${ }^{109}$ Greetings cast discussion in a different light, helping participants to see and recognize that everyone in the discussion is responsible and accountable to everyone else.

\footnotetext{
107Ibid., p. 58. ${ }^{108}$ Ibid., p. 58. 109Ibid., p. 59.
} 
Political communication should include affirmative uses of rhetoric

Young argues that political communication should include rhetoric for two reasons, one negative and one positive. The negative reason is that political communication necessarily involves rhetoric, even if the participants claim that their discourse is "purely rational." Young's argument for rhetoric is best explained by looking at a familiar argument against rhetoric.

Rhetoric has been criticized for relying more on stirring passions than on appealing to reason, and thus some consider rhetoric inappropriate as a mode of political discourse. Political communication, when conceived of as a mode of argument, is about making assertions and offering reasons to defend those assertions. Political communication, under this view, should be "universalistic, dispassionate, [and] culturally and stylistically neutral..." ${ }^{110}$ Political communication, the argument goes, should present evidence and reasons, to persuade others with logic. But rhetoric, the argument goes, is a strategic mode of communication that aims only at persuading others to adopt the view the speaker desires to have them adopt. Rhetoric uses non-rational devices like passion and humour to manipulate and persuade. Thus, rhetoric bypasses people's rationality, and uses people merely as a means to accomplish the speaker's ends.

Young defends rhetoric on the grounds that the counter-argument makes an arbitrary distinction between speech acts that seek to promote understanding and speech acts that seek to use others merely as a means to an end. ${ }^{111}$ While it is true that rhetoric includes many communicative devices that aim at persuasion, it does not follow that

\footnotetext{
${ }^{110}$ Ibid., p. 63 .
}

111Ibid., p. 66. 
persuasion itself treats people merely as a means to an end. Understanding someone often requires us to shift our perspective or consider a matter in a new light. Thus, a speaker can use rhetoric to persuade an audience to look at a matter from a new point of view, and this can further communication and understanding.

Furthermore, even when speakers attempt to communicate in a "purely rational manner," they cannot avoid using some rhetorical devices. Indeed, adopting a "purely rational" demeanour could even be considered an abuse of rhetoric, because no one is truly rational in the sense that they convey no emotion or style of communication. Rhetoric reveals the difference between what is said and how it is said. However, because rhetoric refers to the manner or style of a communication, even "purely rational" manners of communication bear a rhetorical component. When someone adopts a calm, measured stance, wearing dignified, professorial attire, and speaks dispassionately in neutral terms, they are (wittingly or unwittingly) using rhetorical devices to present themselves as impartial and knowledgeable. The cadence of their speech and the calmness of their emotions suggests to the audience that the speaker has assessed the issue in an unbiased, logical way.

However, cadence and calmness are rhetorical devices - they refer to how something is said, not what is said. So, rhetorical devices often communicate a suggestion of impartial and objective rationality. Young notes that many politicians and academics are good at adopting this manner of communication, a manner which suggests that they are "transcending the dirty world of interest and passion." 12 In short, rhetoric is often used to disguise the fact that everyone has biases, and no one is truly impartial. Human

112Ibid., p. 63. 
beings, even politicians and academics, do not transcend the world of interest and passion-we remain a part of it.

Therefore, rhetoric is an unavoidable part of political communication. This is the negative reason to accept rhetoric in political discourse - it is simply unavoidable. However, Young also proposes several positive reasons for accepting rhetoric in political discourse. I will focus on one, which is that rhetoric can satisfy the norm of publicity.

Communication should be public

Young's fourth condition for democratic communication is publicity. A deliberative process cannot produce a morally binding decision if affected parties are excluded from the discussion; i.e., binding decisions can only be produced by public processes. ${ }^{113}$ This condition is nominally satisfied by broadcasts of parliamentary debates and so on. But Young argues that the condition of publicity must also be satisfied by the content of political speech. Political speech that is phrased in esoteric language that virtually nobody can understand fails to satisfy the condition of publicity. Furthermore, political speech should not be uttered in an offensive manner, such that some cannot receive the speech without suffering setbacks to their "worth and dignity." 14

Norms of publicity require that speakers adapt to their audience, so that the speaker can communicate clearly. This is essential in modern mass democracies, which are composed of disparate groups and individuals. Achieving understanding across these differences requires taking one's audience into consideration. A good political

113Ibid., p. 68.

114Ibid., p. 68. 
communicator will try to phrase their claims in a manner that is most easily understood and therefore most persuasive to their audience.

Sometimes speakers must address people who do not speak the same language; in such cases a translator can be used. In other situations, both the speaker and audience might speak nominally the same language, but could still struggle to understand each other, due to differences in dialect, accent, regional idioms, and so forth. The speaker must take care not to slip into their own regional idioms, but instead should adapt their speech to match the language of their audience. In modern mass democracies, society is composed of disparate groups, differentiated by income, class, culture, education, and so on. Thus, a particular manner of speaking that succeeds in one context (a speech to financiers or physicists) would fail in another (a speech to workers at a meat packing facility). This is another illustration of how agency and well-being freedoms are linked: inequalities in political education and income lead to inequalities in the capacity to receive political communication.

Rhetoric focuses on persuasion and therefore rhetoric requires that language be couched in terms and manners best suited for persuading a audience. The speaker can use local jokes and idioms to construct a closer relation to the audience and frame the occasion of discussion. For example, different rhetorical flourishes must be used in celebrations than in the wake of tragedy - a speaker at a funeral cannot adopt the rhetorical posture of a stand-up comic without deeply offending the audience, and thus violating the condition of publicity. Persuasion requires speakers to consider the peculiarities of their audience - the particular occasion for discussion, their traditions, beliefs, manners, customs, assumptions, and idioms - in order to effectively 
communicate. ${ }^{115}$ Thus, rhetoric allows speakers to adapt to their audience, and this in turn facilitates discussion and understanding across differences.

Political communication should include narrative

Finally, Young argues that internal exclusion sometimes occurs from a profound lack of understanding between groups in a democratic society. Narrative, for Young, performs several important roles in bridging gaps in understanding between groups, but I will focus on the one most relevant to my purposes. Namely, the power of narrative to help people understand others' experiences and avoid biases and stereotypes. So, narrative can help with two problems. Both problems affect discussion at the outset: lack of understanding can leave participants in a discussion baffled about what the problem is, and biases can block participants from taking other participants seriously.

First, lack of understanding across group differences is a problem for modern mass democracies, which are composed of many disparate groups. Sometimes others' experiences are so different from our own that we cannot comprehend their claims of need or interest. For example, it is common for some white people to deny the existence of systemic racism, or for some men to deny the existence of sexism and misogyny in the workplace. In both cases, misunderstanding occurs because people do not have sufficiently shared experiences. White people rarely if ever experience negative systemic racism, and men almost never experience workplace sexism and misogyny. So, when members of a historically oppressed race or gender make claims of justice against their

115Ibid., p. 68. 
oppressors, those who lack an understanding of shared experience may deny that the problem even exists.

Narrative can play an important role, and fill in the experiential gap by simulating, or recapitulating the experience to others. The stories from victims of hate speech presented by Matsuda et. al. are powerful means of communicating an experience that many people can hardly imagine. When we understand how harmful these experiences are to those who suffer them, our views about proper responses can change. Prior to hearing stories of hate speech, we might think that hate speech consists of "offensive or intolerable ideas." If hate speech is conceived of as simply repulsive, immoral ideas, then counter-speech seems like an acceptable response: bad ideas and arguments should be met with good ideas and arguments. However, after hearing real stories of hate speech, it becomes clear that hate speech is more than just repulsive, immoral ideas. Hate speech causes major setbacks to people's physical and psychological well-being, which can in turn reduce their available agency and well-being freedoms. Narrative is instrumental in helping people who have not experienced hate speech to understand how harmful it really is. When the harms of hate speech are understood, our understanding of the ideal response shifts. Because hate speech involves more harm than just being exposed to repulsive ideas, the response could be restrictions on hate speech itself. Thus, narrative plays an important role in helping differentiated groups (those who have suffered the harms of hate speech and those who have not) come to an understanding across their differences.

Narratives communicate experience; they help us to see the world from a different perspective, and understand that the struggles, needs, and interests of others are often 
very different from our own. Lack of shared experience can prevent discussion participants from understanding the substance of each other's claims. Narratives help provide an understanding of experience to those who have not lived it themselves. As I will argue in Chapter 4, stand-up comedy is an excellent mode for communicating narratives that bridge gaps in understanding between differentiated groups.

Thus, we have seen that communication should be inclusive, and avoid both internal and external exclusion. This discussion has revealed that for communication to be inclusive, it must be free from domination, and it must be public. However, there is still a fourth condition that must be satisfied: participants in discussion must be reasonable. Being reasonable for Young means that participants "enter discussion to solve collective problems with the aim of reaching agreement." 116

Participants in discussion should be reasonable

When Young says participants must be reasonable, she does not mean they must be brilliant or ingenious. She simply means they must keep an open mind. ${ }^{117}$ The need for reasonable participants in discussion is clear when the other conditions for discussion are understood. Because communication must be inclusive, free from domination, and public, participants must be willing to listen to other peoples' ideas, claims, and criticisms. If participants enter discussion with their minds made up, rigidly adhering to their prediscussion views no matter what, then there is no point in engaging in discussion in the first place. However, discussion is a necessary part of the democratic process. If

\footnotetext{
116Ibid., p. 24.
}

117Ibid., p. 24. 
participants are not reasonable and open-minded, but merely state their claims and ignore everyone else, then a true discussion has not taken place.

In short, reasonable participants have open minds. When democracy is conceived as a deliberative process, the necessity of an open mind is clear. When participants are open-minded, they can be inclusive and refrain from dominating others. "Being open thus also refers to a disposition to listen to others, treat them with respect, make an effort to understand them by asking questions, and not judge them too quickly." 118 Thus, when participants are reasonable, they are capable of respecting Young's conditions for democratic communication. Indeed, reasonableness could be thought of as a disposition to communicate inclusively, in a public manner, and without attempting to dominate others.

Internal exclusion, reasonableness, and group difference

Recall that Sen's discussion of political freedom was mostly tied to political freedom's importance for living a life of one's choosing or increasing the possibilities for what one is able to do and to be. However, Young's analysis of discussion goes deeper, by noting that discussion can also strengthen, or weaken, the fabric of a democratic society itself. If a democratic society cannot engage in open-minded discussion across group differences, and discussion fails to hear the interests and needs of everyone, then the outcomes of the democratic process will not be just for all members of the society. Thus,

118Ibid., p. 25. 
it is important for discussion to be open-minded and inclusive for all the disparate groups in society.

Modern mass democracies are composed of many disparate groups. These groups are often differentiated by their vulnerabilities to unfreedoms and deprivations and they are also differentiated by their cultural traditions, ethnicity, customs, and so on. As discussed in the previous sections, these differences often contribute to difficulties in participating in democratic discussion (e.g. lack of capabilities related to literacy, access to fora, competence and confidence at engaging in public political discussion, and so on).

Young argues that some of these differences are irreducible, in the sense that "persons from one perspective or history can never completely understand and adopt the point of view of those with other group-based perspectives and histories." ${ }^{119}$ So, differences in access to the kinds of intrinsic and instrumental freedoms discussed by Sen are not fundamentally irreducible. Rather, differences in perspective that have been shaped by generations of culture, traditions, and history are irreducible. In other words, an individual steeped in a European background could never completely understand the point of view of someone steeped in an East Asian background, or vice versa. Achieving "complete understanding" seems to mean fully assimilating into that culture and seeing the world as individuals in that culture see it. This seems impossible: the cultural and historical differences are simply too vast for one party to come to a complete understanding of the other. But despite the impossibility of such complete understanding, Young argues that communication across such differences is possible if people are

\footnotetext{
119Iris Marion Young, "Polity and Group Difference," in Theorizing Citizenship, ed. by Ronald Beiner, (Albany: State University of New York Press, 1995), p. 184.
} 
committed to deliberating and deciding together. Thus, reasonableness is an important disposition to have with respect to group difference.

Internal exclusion sometimes occurs when other participants are not reasonable, and unwilling to listen to others' views. As discussed in the context of Young's account of social groups that opened this chapter, a hostile disposition to group difference is sometimes responsible for this closed-mindedness that makes discussion impossible. Hostile dispositions to group differences are therefore a major obstacle to inclusive democratic discussion. If some participants are unwilling to listen to the claims of other participants, then discussion cannot get off the ground. Without discussion, the democratic process can be said to grind to a halt or at least not respect what democracies are meant to be. Therefore, it is crucially important to consider the role of group difference in democratic discussion.

Both Young and Sen argue that discussion is necessary for the democratic process to produce wise and just results. Sen's arguments reveal that political freedom is inextricably linked to other substantive freedoms and capabilities, such as economic facilities and social opportunities. However, Sen acknowledges that if political freedom is not equitably distributed across all groups in a society, then discussion cannot play its role of producing wise and just outcomes, and as a result economic facilities and social opportunities will also be unequally distributed. Yet Sen says little about how to expand political freedoms for those who are excluded or marginalized. As a remedy, Young proposes an expansive theory of political communication, less in terms of distributive justice than in terms of inclusion and equality in order to treat group differences as a resource. 
Young argues that inclusion is not just formal or nominal recognition of citizenship. Instead, inclusion means respectfully listening to others, keeping an open mind about group differences, seeking to communicate in a public manner, acknowledging differences in experience and perspective, and "encouraging differently situated groups to give voice to their needs." ${ }^{120}$

To make political communication more inclusive, Young argues that discussion should not be limited to norms of argument. Instead, she argues that expansive, inclusive discussion will include other modes of communication, such as greetings, narratives, idioms, tones, and images. Thus, Young argues that rhetoric is an indispensable communicative tool for helping people in diverse social positions communicate with one another.

I will argue in Chapter 4 that stand-up comedy can be an excellent medium for achieving inclusive political communication that treats group difference as a resource. However, before assessing the positive ways comedy can contribute to democratic discussion, I must discuss the negative ways comedy influences democratic discussion. Just as comedy can facilitate discussion across group differences, it can also be used to stoke hatred and widen differences between groups.

120Ibid., p. 119. 
Chapter 3: Comedy that Fails to Respect Norms of Inclusion

In this chapter, I will examine ways comedy could be deficient as a form of political communication, how comedy can reinforce and normalize social injustices, and how it can entrench divisions between various social groups. Throughout this examination, I will show that comedy often functions as form of cultural imperialism, and humour is often used to oppress particular social groups. Recall that Young identified cultural imperialism as one of the five faces of oppression. Cultural imperialism occurs when a culturally dominant group ignores the perspectives and experiences of an oppressed group and treats them as Other, imposing their own perspectives and experiences, often reducing the oppressed to a few simplistic, inaccurate stereotypes. In this chapter, I will examine ways that comedy can entrench cultural imperialism, bypass critical thinking, and deepen divisions between those who dominate and those who are members of oppressed groups.

Young's account of how greeting, rhetoric, and narrative can be abused and manipulated

Iris Marion Young argues that an inclusive conception of democracy requires an expansive theory of political communication that incorporates other modes of communication, such as greeting, rhetoric, and narrative. ${ }^{121}$ However, she reports that these modes of communication are vulnerable to abuse and manipulation, and that there is general skepticism about the fruitfulness of expanding political communication to

121Young, Inclusion and Democracy, p. 77. 
include greeting, rhetoric, and narrative. Comedy, although distinct from greeting, rhetoric, and narrative, often makes use of these modes to achieve laughter. So, the criticisms of these forms of communication can be extended as criticisms of comedy.

The skeptics, according to Young, believe argument must be the primary mode of political discourse because argument is best suited for democratic discussion. According to the skeptics, argument "distinguishes truth from falsehood, honesty from deceit, and rational consent from manipulation." ${ }^{122}$ On the other hand, greeting, rhetoric, and narrative are often thought to be deceitful, outright false, and/or deliberately misleading and manipulative. Instead of using reason to persuade others of the justice of their claim, these modes use other means: they stroke egos, or sow fear and paranoia of the other, and so on. In short, these modes of communication are ripe for misuse. Democratic discussion is committed to truth, honesty, and reasoned persuasion. Rhetoric, greeting, and narrative use lies, deceit, and manipulation. Therefore, these modes of communication are incompatible with democratic deliberation.

Indeed, greeting, rhetoric, and narrative are easily and often abused. Young points to the common example where an elaborate greeting ceremony is used as an excuse to ignore the other party once the real deliberations are under way. For example, elaborate greetings are performed, with all the accompanying implications of respect, trust, vulnerability, and commitment to dialogue, only for one of the parties (often the more dominant) to completely ignore and discount the other party during the remainder of discussion. If the other party complains, the more dominant party can point to the

122Ibid., p. 77. 
elaborate ceremonies of greetings as evidence that they have already made great efforts to acknowledge the other and establish trust. ${ }^{23}$

Young shows that rhetoric too, is often abused. For example, she points out that political discourse is abused when style is used to mask a lack of substance. ${ }^{124}$ Politicians make many passionate promises during campaigns. They make commitments to many diverse groups of constituents to pay special attention to their needs, and they make these promises in a sincere manner. Politicians will sometimes fake a regional accent to win the trust of the locals; however, because the accent is faked, the trust is won under false pretenses. In other words, politicians misuse rhetoric to pretend to belong to a social group in order to win that group's trust, then once the votes are counted, the politician drops all pretense of belonging to the social group.

Finally, Young considers ways in which narrative is abused and manipulated. Narrative is particularly susceptible to abuse because audiences often generalize from narratives. ${ }^{125}$ Narratives can thus be a form of cultural imperialism, establishing the dominant group's perspectives and experiences as the norm. For example, a politician who wishes to normalize oppression and suspicion towards undocumented immigrants might tell a story about an immigrant who committed a violent crime, using rhetorical flourishes and literary devices to tell the story in a powerful way, allowing suspense to build towards the horrifying, emotional climax. Such stories often have a profound emotional impact on audiences, especially if the audience believes the story is true. But whether the story is true or false, when audiences are profoundly affected by a story, they

\footnotetext{
123Ibid., p. 78.

124Ibid., p. 78.

125 Ibid., p. 78.
} 
are more likely to over-generalize elements of the story. In the case of a story about an immigrant who committed a violent crime, the narrative could lead people in the audience to over-generalize their fear and hatred of the narrative's villain to fear and hatred of all immigrants. A story about one member of a social group becomes a story about all members of the social group. Thus, narrative is prone to causing and reinforcing biases and stereotypes.

Comedy incorporates greeting, rhetoric, and narrative. Thus, comedy also sometimes bypasses critical thinking, and persuades through humour rather than reason. Or, comedy does not seek to persuade at all, but only to reinforce what people already believe. Furthermore, comedy often deploys narratives that incorporate harmful stereotypes, normalizing the dominant group's perspective and experience at the expense of the oppressed. Finally, comedy, especially political comedy, often divides people against one another. All these criticisms suggest that comedy cannot play a role of serving as an alternative form of political communication.

However, for reasons that will be discussed in Chapter 4, Young still favours including greeting, rhetoric, and narrative in political discourse. In the final chapter, I will argue that comedy should also be included as a form of political discourse. For now, I will examine in more detail how comedy can be abused and manipulated. It is important to see the ways that comedy is flawed.

Comedy can also be abused and manipulated

Comedy, as a form of communication, can be used to oppress social groups through the use of cultural imperialism. Furthermore, because comedy makes use of 
greeting, rhetoric, and narrative, it can be abused in the ways Young identified. Like those alternative forms of communication, comedy can bypass people's critical thinking, appealing to emotions like anxiety, and cognitive biases like stereotypes and prejudices. Thus, comedy does not rely on valid arguments with true premises to produce true conclusions; rather, it can be said that comedy, by its very nature, relies on a set-up and surprising punchline to produce a laugh. In short, watching comedy is not an exercise in critical thinking or critical engagement with complex issues; rather, it is merely entertainment; at its worst comedy can reinforce our prejudices and stereotypes and cause us to dismiss important issues as merely "laughing matters."

Comedian Joe Rogan has described successful comedy as a form of "mass hypnosis" where those in the audience surrender control of their thinking to the comedian, who "thinks for them." 126 There are two sides to Rogan's simile, hypnosis and mass hypnosis.

Firstly, in Rogan's comparison to hypnosis, it is as if the comedian's voice takes over and inhabits the minds of the audience, replacing their own inner monologues with the comedian's. Another analogy might be made to reading a non-fiction book. When reading a novel, one must pay full attention to the author's words in order for their words to strike the chords of your imagination. It is hard to "sink into" a good book when there are many loud and noisy distractions. Likewise, when experiencing an act of comedy, there must be no distractions to take attention away from the comedian. Distractions include heckling from the audience, the audience talking among themselves during the set, music playing in the venue, phones ringing, and so on. However, the audience's own

\footnotetext{
${ }^{126}$ Joe Rogan, The Joe Rogan Experience \#1437: Stephen Dubner, March $5^{\text {th }}, 2020$,
} https://www.youtube.com/watch?v=DETj3ncN19g , (47:36). 
thoughts can be a distraction. When audience members are thinking about bills they must pay, or what they will eat for dinner tomorrow, then they will be less likely to get the jokes. They might still laugh out of a desire to imitate the laughter of others around them, but they will not be laughing because they got the joke (this relates to the second side of Rogan's simile, to be addressed in more detail below). To enjoy comedy, an audience member has to be silent and attentively regard the comedian, listen to their words, and follow their train of thought to the inevitable punchline.

It is a truism that if you do not "get" a joke, you will not laugh at it. I will not enter the debate about what it means to "get" a joke, but I will say that it is much easier to get a joke when one is paying undivided attention to the comedian. And it is easiest to get a joke when one is not thinking about what the comedian is saying but is just listening and going along with their words. Critically thinking about what the comedian is saying while the comedian is saying it is a distraction from the comedy, and it will inhibit most people from laughing at the punchline.

For example, in order to laugh at a comedian's joke, an audience member must not "beat them to punchline," i.e., to laugh, one must not guess the punchline before the comedian delivers it. This is like "getting a joke" too soon. The element of surprise is very important for getting a laugh. If an audience member is analyzing the joke as it is told, and critically questioning the propositions underlying the joke, then they will be less likely to laugh at the punchline.

So, comedians want their audience to suspend their critical thinking for the duration of the joke. Comedians do not want to pause after every punchline and wait while the audience thinks critically about arguments and propositions implied by the joke 
so that they can offer reasoned consent in the form of a laugh. Rather, the comedian is trying to bypass critical thinking and reasoned judgment to get an immediate "gut-laugh". To accomplish this, the comedian must deploy various comedic devices to take and hold the audience's attention. The comedian controls their tone, volume, cadence and timing, emphasizes key words and phrases, and supplements their speaking with act-outs, gestures, and facial expressions. The goal is to hold the audience's undivided attention, so that they are not thinking for themselves, they are raptly listening, reacting, and laughing.

The second side to Rogan's point is the "mass" in mass hypnosis. Laughter is often caused by the laughter of others. In such cases laughter is sometimes not even caused by the comedian's skilled use of set-ups and punchlines, but only by an audience members' desire to imitate others. It is a truism that laughter can be contagious, and laughter tends to be very contagious in comedy clubs. So, laughter in comedy clubs is sometimes caused by, or strengthened by, the laughter of others. Even if people do not get the joke, they might often still laugh just because everyone around them is laughing. So, it is not a reasoned argument, or an undeniable truth that has won the audience's endorsement.

Thus, critics could argue that comedy's reliance on mass hypnosis makes comedy unfit as a primary mode of political communication. Like greeting, rhetoric, and narrative, critics could argue that comedy fails to respect honesty, reasoning, and rational consent, and instead requires suspension of reasoning and judgment.

This is an important criticism, and it draws attention to the limits of what stand-up comedy is capable of achieving. Comedy, as a form of communication, is not ideal for treating complex issues with the vigorous analysis they deserve. Instead, comedy treats 
everything as a "laughing matter." When comedy does address complex social problems, it often relies on or exploits anxieties, biases, and prejudices to evoke laughter.

Otto Santa Ana argues that a comedy performance offers a kind of catharsis, purging audience members of anxieties they experienced before the performance. Ana analyzed one week of Jay Leno's Tonight Show monologues during the May Day immigration protest marches in the early 2000s. Ana points out that Leno's jokes were made during a particularly anxious time for many Americans: the terrorist attacks of 9/11 had occurred only a few years earlier, and George W. Bush had recently instituted a major immigration reform policy to authorize more immigration from Mexico. Millions of immigrants were marching in support of the policies, causing anxiety among many Americans, especially those who harboured attitudes that immigrants should be "silent workers" who do not speak out. ${ }^{127}$ In short, Leno recognized that laughing at something is a good way not to be scared of it, or anxious about it.

For example, during one his monologues, Jay Leno told the following joke: "It's terrible! Gas now costs $\$ 3.85$ a gallon. You know it's cheaper to have illegal immigrants push your car." ${ }^{\prime 28}$

Ana argues that this kind of joke purges the audience of their anxieties by causing them to laugh at something that was previously a source of worry, in this case, high gas prices and immigrants from Mexico. However, in order to purge the anxieties about immigrants, Leno resorts to biases and stereotypes.

\footnotetext{
127Ibid., p. 29.

${ }^{128}$ Otto Santa Ana, "Did you call in Mexican? The racial politics of Jay Leno's immigrant jokes," Language in Society, Vol. 38, No. 1 (Feb., 2009), p. 32.
} 
For example, the proposition contained in the punchline is that the labour performed by people who did not cross the border legally is extremely cheap. But there are other, more subtle propositions involved here. For example, the punchline includes the proposition that undocumented immigrants are so desperate to earn money that they are willing to work for absurdly low wages. Typically, this is not a cause for laughter and levity. On the contrary, as Ana points out, poverty and struggle usually evoke our sympathy. ${ }^{129}$ However, in this case, the poverty and struggle of the immigrants is used for a laugh. The punchline evokes an image of a relatively wealthy person in a car paying people absurdly low wages to perform a physically strenuous task. In other words, the joke causes an audience to laugh at a state of affairs with absurdly inequitable distribution of economic resources where a powerful, wealthy party exploits a weaker, impoverished party. Ordinarily, people would not react to this situation with levity. But when expressed in the form of a joke by a skilled comedian like Jay Leno, people can be persuaded to laugh at a situation they would otherwise find deplorable. Furthermore, it may even leave the audience feeling that such inequitable situations are not so bad, but rather something to laugh about.

Thus, Leno's style of humour in these monologues entrenches a status quo of cultural imperialism. An oppressed social group, in this case undocumented immigrants, is marching in protest, demanding equal concern and respect, and trying to make their needs and interests known. As an oppressed social group, the immigrants lack the same access to freedom of speech that Leno has-Leno has the platform of the Tonight Show, broadcasting to millions of households every night. On the other hand, the oppressed

129Ibid., p. 32. 
immigrants must resort to marches and mass protests to make their voices heard. The behaviour of the immigrants, loudly protesting and marching, does not fit with the dominant group's imposed perspective: as Ana pointed out, Mexican immigrants are expected to be silent workers. The protests, therefore, threaten to upend the dominant group's perspective and experience. The dominant group thus takes refuge in humour that eases their anxiety by reinforcing their (false) perspective and experience.

Of course, sometimes comedians really do want to offer a critique of what they perceive as an unjust state of affairs. Proponents of this view might argue that comedians often use satire to "speak truth to power" or to "point the accusing finger", to borrow Sen's expression. According to proponents of satire, political satire in comedy is thus a means of holding political leaders accountable. As was discussed in Chapter 2, holding political leaders accountable is essential for achieving political freedoms. According to the pro-satire argument, if a political leader is failing to respect the interests of the people and acting in a corrupt manner, a comedian could use satire to ridicule them before the eyes of the voters. Politicians and political leaders are very worried about being mocked and ridiculed because this could sway public opinion against them. An act of satire, aired on television or the internet, can reach millions of people with incredible speed. Many people might not read political op-eds in The Times, but they might enjoy watching satire. Thus, proponents argue that satire is another effective means of holding politicians accountable. 
Satire often backfires

However, research has shown that satire can paradoxically reinforce people's existing political attitudes, even when the comedian intended to satirize those attitudes. A comedian might intend to satirize and ridicule a certain target; however, if audiences are politically biased in favour of the comedian's target, then those audiences will think the satire is aimed in the opposite direction. In a study conducted at Ohio State University, Heather LaMarre et al (hereafter cited as LaMarre) found that satire reinforces existing political attitudes, because the message of political satire is often ambiguous. ${ }^{130}$

According to LaMarre when people are presented with an ambiguous message, they tend to interpret the message in a way that is favourable to their existing beliefs and attitudes. Rather than see the intended message, people see the message they want to see. ${ }^{131}$ Citing decades of research in the psychology of self-perception, LaMarre shows that people interpret ambiguous messages in ways favourable to themselves because they want to see themselves in a favourable light. So, when someone with existing political biases encounters an ambiguous political message, they are more likely to interpret that message in a way that validates or confirms their existing political beliefs. ${ }^{132}$ Satirical political messages are always somewhat ambiguous in the sense that the butt of the joke is not always clear.

An example of this phenomenon is the stand-up comedian Harry Enfield, who created a character named "Loadsamoney" to satirize Margaret Thatcher in the 1970s.

\footnotetext{
${ }^{130}$ Heather LaMarre et al, “The Irony of Satire," International Journal of Press/Politics 14, no. 2, April 2009, p. 213.

131Ibid., p. 213.

132Ibid., p. 214.
} 
Enfield, a self-professed Marxist, intended to use his "Loadsamoney" character to satirize those who supported Margaret Thatcher's policies. ${ }^{133}$ "Loadsamoney" was intended to satirize and mock people who supported Margaret Thatcher's policies, because those policies had created inequalities in economic facilities, making them suddenly very wealthy, while leaving many other people poorer. "Loadsamoney" was a construction worker who had suddenly become relatively wealthy and enjoyed flaunting his newfound wealth.

Enfield, as Loadsamoney, would walk out on stage dressed in flamboyant neon track suits, stumbling as if drunk. He would then begin yelling at the audience, "I've got piles!" while brandishing a huge wad of pound notes, and declaring that "the only thing you need to know about politics is that Mrs. Thatcher done a lot of good for the country but you wouldn't want to shag it [sic]." ${ }^{134}$ Enfield may have thought that no one could possibly witness such an over-the-top parody and judge that Enfield was endorsing Loadsamoney's behaviour. However, even the Loadsamoney character was too ambiguous.

When people saw the Loadsamoney character on television, their interpretation depended on their existing political attitudes toward Thatcher's policies and their attitudes towards the kind of person Loadsamoney was based on - a suddenly wealthy construction worker. Many people interpreted Loadsamoney as pro-Thatcher, or a symbol of "greed is good" culture. "Loadsamoney became either the signature tune or supreme

\footnotetext{
133Tom Foot, "Harry Infield: How Loadsamoney has changed Hampstead," Camden New Journal, January $17^{\text {th }}$, 2019, http://camdennewjournal.com/article/harry-enfield-how-loadsamoneyhas-changed-hampstead ${ }^{134}$ Harry Enfield, “Loadsamoney- I’ve got piles!” BBC's Friday Night Live, https://www.youtube.com/watch?v=gXuRvthgn4U.
} 
critique, of Thatcherism, depending on your perspective, ${ }^{135}$ writes Simon Hattenstone for The Guardian.

LaMarre's research focuses on another comedian who uses ambiguous political satire, Stephen Colbert of The Colbert Report. LaMarre describes Colbert's satirical style as "deadpan" or "a straight-faced approach to joke-telling." ${ }^{136}$ A deadpan comedian does not initially appear to be joking. Instead, they inhabit a character, and they do not break the character or acknowledge the laughter their words cause. The deadpan comedian maintains a serious expression. Whereas a traditional comedian like Jay Leno might begin a joke by saying, "But seriously folks," and proceed with a traditional joke, a deadpan comedian like Colbert does not say, "But seriously folks;" rather, they appear serious from the moment they speak, and provide no hints that they, the comedian, are sincere. LaMarre argues that Colbert is "an ambiguous source." 137 Audiences realize he is being humorous, but Colbert's style leaves audiences free to interpret who he is satirizing. One of LaMarre's most interesting findings was that both conservative and liberal audiences found Stephen Colbert hilarious, and both liberals and conservatives enjoyed watching his show. ${ }^{138}$

Stephen Colbert portrays a parody of a Republican talk-show host. For example, during the White House Press Correspondent's dinner in 2006, Colbert took to the podium and addressed President George W. Bush. He spoke seriously, in an authoritative, aggressive tone.

\footnotetext{
135Simon Hattenstone, “Harry Enfield: I Don't Like Doing Me,” The Guardian, September 25, 2010, https://www.theguardian.com/theguardian/2010/sep/25/harry-enfield-interview ${ }^{136}$ LaMarre et al, p. 217.

137Ibid., p. 217.

138Ibid., p. 226.
} 
Tonight, it is my privilege to celebrate this president. Because we're not so different, he and I. We both get it. Guys like us, we're not some brainiacs on the nerd patrol. We're not members of the factinista. We go straight from the gut. Right sir? That's where the truth lies. Right down here in the gut. Did you know you have more nerve endings in your gut than in your head? You can look it up. Now I know some of you will say 'I did look it up and that's not true.' That's cause you looked it up in a book. Next time, look it up in your gut. Every night on my show, The Colbert Report, I speak from the gut. I give people the truth, unfiltered by rational argument...I'm a simple man with a simple mind. I have a simple set of beliefs that I live by. Number one, I believe in America. I believe it exists. ${ }^{139}$

In an ironically self-aware turn, Colbert declares that on his show he tells the truth, "unfiltered by rational argument." Is his satire aimed at comedians like himself who try to get "gut laughs", or at Republican talk show hosts, or at the President? Or all three? It is also worth pointing out that Colbert deliberately pronounces "Colbert Report" with a silent ' $t$,' to match the silent ' $t$ ' in his name, Colbert. This makes him sound pretentious and uninformed at the same time-more ambiguity. If someone is inclined to think liberals are pretentious, they might take Colbert's mispronunciation as a satire of liberals. But if someone is inclined to think conservatives are less literate, then they might take it as satire of conservatives. LaMarre's research shows that audiences differed in their interpretations of Colbert's satire. In other words, if an audience member was politically conservative, they were more likely to perceive Colbert as politically conservative, affiliated with the Republican party, and that Colbert disliked liberalism. ${ }^{140}$

For example, in one segment, Colbert interviews CNN news anchor Anderson Cooper about global warming. Colbert adopts a line of argument that global warming is not so bad; for example, Greenland will actually be green. LaMarre points out that this

\footnotetext{
139Stephen Colbert, White House Press Correspondent's Dinner, April 29 ${ }^{\text {th }}, 2006$, https://www.youtube.com/watch?v=2X93u3anTco 140Ibid., p. 218.
} 
exact same argument was used by conservative talk show host Rush Limbaugh to downplay the importance of climate change. So, while liberal viewers might interpret Colbert's question as an over-the-top parody, conservative viewers would think Colbert is taking Cooper to task. ${ }^{141}$

Thus, LaMarre's research shows that Colbert's satire failed to change people's existing political beliefs or attitudes. On the contrary, people interpreted Colbert's message in a way that cast their own political beliefs in a positive light. LaMarre concludes that their findings reveal satire is not as effective a political tool as people once believed. ${ }^{142}$ Thus, sometimes satire reinforces existing biases and stereotypes. But this charge is not just limited to satire.

Superiority Humour can entrench Marginalization, Cultural Imperialism, and Violence

Political superiority humour creates internal and external exclusion, reinforces biases and stereotypes, preserves an unequal distribution of agency and well-being freedoms, and deepens divisions between social groups. Thomas Hobbes describes this sort of humour as, "sudden glory...caused either by some sudden act of their own that pleaseth them, or by the apprehension of some deformed thing in another by comparison whereof they suddenly applaud themselves." ${ }^{143}$ Hobbes notes that people who laugh at the misfortune of others do so because their own self-esteem is under threat. So, when they

141Ibid., p. 218.

142Ibid., p. 229,

143 Thomas Hobbes, Of Man, Being the First Part of Leviathan, 1651 (Hoboken, N.J.: Generic NL Freebook Publisher, Accessed March 2, 2020) http://search.ebscohost.com.proxy.library.carleton.ca/login.aspx?direct=true\&db=nlebk\&AN=2 008503\&site=ehost-live, p. 20. 
witness someone else make a faux pas, or trip over their shoelaces, or suffer some other embarrassing mishap, then their own self-esteem can increase. By comparing themselves to someone worse off, they increase their self-esteem: "conscious of the fewest abilities in themselves; [they] are forced to keep themselves in their own favour, by observing the imperfections of other men." ${ }^{144}$ Thus, people often engage in superiority humour to feel better about themselves at the expense of others. Superiority humour could be seen as schadenfreude, where people take pleasure at the downfall of another, and it can also be referred to as "punching down," a style of comedy that makes fun of people who are worse off.

Superiority humour, therefore, is related to each of the concepts central to Sen's capabilities approach: agency, freedom, achievements, and well-being. Superiority humour is about the differences in agency, freedom, achievements, and well-being between the target of the humour and the audience. Superiority humour, therefore, can call attention to and celebrate the superiority of one group over another.

Equality in the distribution of agency and well-being freedoms (political freedoms, economic facilities, social opportunities, etc.), as we have seen, is important for Sen and Young. If humour is used to attack the equitable distribution of important and interconnected freedoms, or to reinforce norms of exclusion towards certain individuals and groups, then that humour is harmful to those people it targets, and to democratic society. Superiority humour that is harmful in this sense often works at the level of social groups.

144 Ibid., p. 20. 
The most interesting aspect of social groups, according to Young, is how they are "positioned in interactive and institutional relations that condition their opportunities and life prospects." ${ }^{145}$ In other words, a social group's access to the range of important freedoms depends on its relations to institutions and society. When some social groups have less political freedom or less access to economic facilities than others, it is often because of structural arrangements in the social and political environment. For example, in many countries, women are oppressed through marginalization. They often lack effective opportunities for education, equal access to the labour market, political freedom, and so on.

As Young argues, cultural imperialism can reinforce, or normalize, other forms of oppression. Sometimes the dominant cultural group, in this case men, ignores the real perspectives and experiences of women, and instead imposes the male perspective and experience on women. When a dominant group uses comedy to normalize oppression of various social groups, it often deploys superiority humour.

This is one way that superiority humour is harmful to democratic society: when it is used to preserve an unjust distribution of agency and well-being freedoms across social groups, or to normalize the oppression of certain social groups. When superiority humour is used for these purposes, it blames those with less: superiority humour uses biases, stereotypes, and mockery to persuade people that those who are worse off deserve to be worse off, that they deserve to be excluded from political discussion, and that they do not deserve to have freedom to lead lives they have reason to value. Common targets of

145Ibid., p. 97. 
superiority humour in this respect include women, immigrants, members of the LGBTQ community, indigenous peoples, and so on.

Superiority humour can be harmful for democracy when it reinforces norms that exclude the target group from democratic discussion. Superiority humour necessarily casts another group as inferior. When the superiority humour suggests that the target should be excluded from democratic discussion and debate, then this humour is especially harmful to democracy and the equitable distribution of political freedoms.

One sub-set of superiority humour that can be extremely harmful to the equitable distribution of political freedoms is jokes about sexual violence towards women. Okey Bakassi is a Nigerian political talk-show host and comedian. In 2015 at the GLO Laffta fest in Nigeria, he told a joke about a woman who tries to report a rape to the police. In Bakassi's joke, the police quickly ask her if she knows who did it. When she replies it was her husband, Bakassi delivers his "punchline": "Your husband raped you? How? They say this expression is not possible." ${ }^{146}$ The mostly male audience laughs, while many of the women in the audience are visibly uncomfortable. This joke is an example of superiority humour. Those who laugh find humour in the woman's lack of agency (and lack of knowledge?) compared to themselves, in this case, husbands or men.

At this point it is worth recalling Nussbaum's objection to Sen's claim that freedom is intrinsically good from Chapter 1 . Nussbaum objected that if freedom were intrinsically good, then it would be intrinsically bad to restrict any freedom, even the freedom of husbands to abuse or assault their wives. The reply to this objection was that

\footnotetext{
${ }^{146}$ Okey Bakassi, “Okey Bakassi Thrills Crowd at GLO Laffta Fest,” October $18^{\text {th }}, 2015$, https://www.youtube.com/watch?v=DhQGudsL4w\&list=PLlhgitmxGouaj44yByKZywVqCbcoVPBhg.
} 
spousal abuse and assault is an unfreedom and cannot be good because it only exists when someone else's freedom (in terms of agency and well-being) is significantly harmed. Bakassi's joke is problematic because it finds humour in something that significantly harms women's agency and well-being freedoms.

In a piece for The Guardian on rape humour in Nigerian stand-up comedy, Rachel Hamada argues that rape humour, especially in a country like Nigeria that suffers from high levels of abuse towards women, reinforces rape culture by teaching young men and women that rape is a laughing matter. Rape humour declares that a woman is something "passive, a thing, without agency." 147 Jokes about rape in this sense reinforce a harmful norm that women should enjoy less freedom, in terms of agency and well-being, than men.

Therefore, rape humour acts as a form of external exclusion. It reinforces norms that women do not deserve a voice in democratic discussions. This is very harmful to women's ability to participate in the democratic process in Nigeria. For example, in 2016 the president of Nigeria, Muhammadu Buhari, visited Germany with the first lady, Aisha Buhari. Aisha Buhari had previously spoken critically of the German government's performance. During a press conference, a journalist asked Buhari about these criticisms. While standing beside German Chancellor Angela Merkel, Buhari responded, “I don’t know which [political] party my wife belongs to, but she belongs to my kitchen and my living room and the other room." ${ }^{148}$ Even though the president's joke was about one

\footnotetext{
147Rachel Hamada, “Nigerians Turn On Comic For Rape 'Joke'," The Guardian, January $8^{\text {th }}$ 2014, https://www.theguardian.com/world/2014/jan/o8/nigeria-basketmouth-rape-joke ${ }^{148}$ Sede Alonge, “'My Wife Belongs In The Kitchen'? President Buhari isn't helping Nigeria,” The Guardian, October $17^{\text {th }}, 2016$. https://www.theguardian.com/commentisfree/2016/oct/17/wife-job-look-after-me-buharinigerian-girls.
} 
woman, his wife, the president's joke seems to invoke a harmful norm that applies to all women.

Superiority humour, in the sense of rape jokes, is clearly harmful, and acts as a form of external exclusion. Those who practice this kind of humour seek to preserve a harmful and unequal distribution of agency and well-being freedoms. They claim that women do not deserve access to political discussion, and that they do not deserve more freedom to lead lives they have reason to value. Therefore, such jokes are clearly harmful to women and democratic society, and they normalize oppression and violence against women.

The preceding cases were examples of how superiority humour seeks to preserve a harmful and unequal status quo for members of oppressed groups. But superiority humour can also be abused to change the status quo by deliberately antagonizing another social group to such an extent that the groups are no longer willing to communicate across their differences.

Superiority humour attacks reasonableness

Discussion is essential for the democratic process, especially discussion that occurs across group differences. Young argues that, ideally, participants in a discussion will frame their claims of need or interest as appeals to justice and they offer reasons that all reasonable participants could accept. Participants are motivated to frame appeals in terms of justice when communication is governed by norms of inclusion: everyone's needs and interests count equally, and participants are reasonable in the sense of being open-minded. 
For democratic discussion to be inclusive and treat group differences as a resource, participants in the discussion must be reasonable, in the sense of being openminded and willing to listen to others. If participants enter discussions determined to ignore or discount the claims and arguments of others, even when those claims are appeals to justice, then the discussion will not be democratic and will not produce a wise and just outcome. So, democratic society is harmed when dominant groups become less open-minded and unwilling to listen to other groups.

Janet Holmes and Meredith Mara argue that humour is effective at "constructing group cohesion, cementing in-group solidarity, and building team spirit." ${ }^{149}$ Furthermore, they argue that humour can strengthen shared beliefs and values within a group. This is not necessarily a harmful function of humour, but, like all forms of political communication, it can be abused if it causes members of dominant and powerful groups to become less reasonable towards others.

Superiority humour is, unfortunately, very successful at denigrating and ridiculing others, to the extent that some groups might become unreasonable towards other groups. Superiority humour can be used to strengthen the belief that members of one group are inferior to another group in terms of intelligence, reasonableness, sincerity, moral goodness, and so on. Over time and with repetition, superiority humour can persuade people to develop the false belief that the other group is so unreasonable that an inclusive discussion is not possible. So, superiority humour can cause internal exclusion, as one

\footnotetext{
${ }^{149}$ Holmes, Janet, \& Marra, Meredith, "Humour as a Discursive Boundary Marker in Social Interaction," in Us and Others : Social identities across languages, discourses and cultures, edited by Anna Duszak, John Benjamins Publishing Company, 2002. ProQuest Ebook Central, https://ebookcentral-proquest-com.proxy.library.carleton.ca/lib/oculcarletonebooks/detail.action?docID=623260, p. 395 .
} 
group becomes unwilling to listen to or communicate with another social group. This is particularly evident in political humour.

Many comedians are wary of engaging in political humour, because live audiences at comedy clubs and shows rarely have homogeneous political views. Thus, telling a political superiority joke can cause an awkward atmosphere in the room.

Political humour often divides audiences into two groups: those who share the comedian's political views, and those who do not. Those who share the view are more likely to laugh than those who do not share the view. So, if a comedian tells a political joke, there is a good chance only half the audience will laugh, the other half will be offended (and feel like they are being laughed at), and the mood in the room will become uncomfortable.

This problem is especially noticeable in the United States, where the country only has two significant political parties, democrats and republicans. If a comedian makes a joke at the expense of a democrat, the republicans will laugh and the democrats will probably feel offended, and vice-versa. Indeed, the late Robin Williams noted that he could not tell Bush jokes in "Red States," or states with a majority of republicans. ${ }^{150}$ Those audiences would be too offended.

This is because audiences associate themselves with the political figures and policies they support. People feel a sense of responsibility for these politicians and policies because they participated in the democratic process and voted for these politicians and policies. So, when a comedian makes a joke attacking the politician an audience member voted for, the joke is, by proxy, condemning the audience member's

\footnotetext{
150Phil Bronstein, “Good Morning, Iraq," San Francisco Daily Chronicle, February 9-10, 2005.
} Accessed at http://www.robin-williams.net/interviews/uso/o5-02.php. 
political decisions. Political decisions are often very personal, reflecting a person's values and beliefs.

The offense seems to be heightened if the comedian appears politically biased. If a comedian seems biased in their political superiority humour, then members of the audience may feel like their political views and beliefs are being unfairly represented and ridiculed. This is not how a comedy show is supposed to feel. Comedian Ron Funches argues, "That's not comedy. That's a rally." In other words, audience members might feel like they showed up at the wrong political rally, rather than a comedy show.

Furthermore, because only the comedian is allowed to speak, the audience has no chance to rebut what they perceive as unfair attacks. Instead, they must sit and endure the mockery. As Martin Short explains, “when it comes to politics, you don’t want to make half the audience feel like they're inappropriate." ${ }^{151}$ So, political superiority humour seems clearly bad at promoting dialogue across group differences, or creating the conditions for inclusive political communication.

Because live political humour is risky, political humour is mostly performed by stand-up comedians on late-night talk shows, like Jimmy Kimmel Live, The Colbert Report, and so on. These shows are "safe" places to do political humour because the audiences have the same political beliefs as the comedian. While it is true that these shows are recorded in front of live studio audiences, this is a different scenario from a comedy club.

\footnotetext{
${ }^{151}$ Ben Travers, "Steve Martin and Martin Short...," Indiewire, August 15 $5^{\text {th }}, 2018$, https://www.indiewire.com/2018/o8/steve-martin-and-martin-short-tour-netflix-trump1201994545/
} 
While the political shows are recorded, they are recorded in front of a live, studio audience, who provide a kind of laugh-track for the comedian's jokes. The live studio audience is carefully selected and screened to ensure they share the show's political leanings, thus this audience is constructed to be very receptive to the host's jokes. So, political superiority humour in the late-night talk show context tends to unite the audience in laughter, rather than divide it. However, it is not the case that humour has taken a divided audience and united it; on the contrary, the audience was constructed to be united already.

The studio audience is not a genuine audience. They are selected and constructed to have appropriate political beliefs for the show, and their laughter is often directed by "warm-up comedians" who signal when to laugh or clap. But the unified laughter of the studio audience can give television viewers at home the sense that a genuine audience of mixed beliefs and values are genuinely laughing at the jokes, expressing true, personal enjoyment of the humour. So, audiences watching at home might come to believe that laughing at the jokes is an appropriate social response.

Furthermore, audiences are good at finding a comedian whose views they share, and then only watching that comedian. Thus, the audience at home tends to be politically homogeneous as well. In the United States, late night comedy talk shows are overwhelmingly watched by democratic audiences, ${ }^{152}$ so the comedians that host these shows, like Real Time with Bill Maher and The Late Show with Seth Myers, tend to make jokes about republican figures and policies. These shows very rarely take aim at

\footnotetext{
152Jake Nevins, "Why Can't Rightwing Comics Break in to US Late-Night TV?” The Guardian, September $27^{\text {th }}$, 2017, https://www.theguardian.com/global/2017/sep/27/why-cantrightwing-comics-break-into-us-late-night-tv .
} 
democrats and spend most of their time celebrating the achievements of democrats and making republicans figures and policies the butt of superiority jokes. Thus, it would take a very thick-skinned republican to sit through an episode. The superiority humour is regularly aimed at the same political groups, so members of these groups usually do not watch late-night political talk shows. The superiority humour is exclusionary towards certain social groups, like republicans.

To be fair, the comedian-hosts of these democratic-leaning shows are careful not to make jokes that blatantly target all republican voters. Instead, these shows typically take aim at a prominent republican politician. When George W. Bush was president, comedians on democratic-leaning talk shows made him the butt of many jokes, particularly his penchant for mispronouncing or inventing incoherent words and phrases ("misunderestimated," "let our wings take dream," and so on), or suggesting that Bush was not very intelligent, or a warmonger, or a religious fanatic, or that he was being manipulated by his vice-president, Dick Cheney.

However, even though the hosts of these shows do not divide their audiences, and that they avoid jokes about "all republicans" as a category, these shows still cause harm to the possibility of inclusive democratic discussion. One of the ways narrative can be abused is by causing an audience to over-generalize through biases and stereotypes. If a political talk show is a person's only source of political information, then they will develop a very skewed picture of politics and the other parties. After all, if republican figures and policies are always presented as unreasonable or harmful, then an audience member who relies on a political talk show for information might come to believe that anyone who votes for a republican endorses unreasonable and harmful policies. 
Therefore, these shows can cause audiences to believe stereotypes about members of the other party.

Rather than demonstrating political discussion across group differences, encouraging reasonableness and dialogue, political superiority humour implies that members of the other political party are too unreasonable, ignorant, or ideologically distant to talk to. When political superiority humour of a slant (e.g., pro-republican or pro-democrat) dominates a political talk show, members of the targeted social group will feel excluded from discussion.

Trolling as superiority humour

Another prevalent form of superiority humour in stand-up comedy is called trolling. Trolling is when a comedian or other person deliberately says something offensive in order to make a certain person or group of people angry. However, trolling is also intended to amuse those who are in on the trolling. Thus, the troll's audience must consist of at least two groups: those who are angered by the troll, and those who find it funny to watch people get angry at the troll.

Trolling is a form of superiority humour because those who laugh at the troll see themselves as wiser, or more rational, than the people who are provoked by the troll's offensive humour. From the perspective of those who find the troll funny, people are provoked by the troll if they are too sensitive, overly emotional, or lack a sense of humour. Thus, because the provoked people have failed to be sufficiently thick skinned, rational, and humorous, they deserve to be subjects of derisive laughter. 
Furthermore, trolling contributes to internal exclusion. When a target group is provoked by a troll, it creates a division between the target group and those who find the trolling funny. Those who find the trolling funny believe that the provoked target group is irrational, and that they have absorbed beliefs and opinions that make them unfit for a reasonable discussion.

Thus, trolling leads to significant divisions between groups. These divisions, based on a judgment that the other group is deluded or held captive by irrational beliefs, cause an unwillingness to communicate across group differences: "Those people cannot be reasoned with, see how easily they were provoked by a harmless joke." Trolling, therefore, sees group difference as a barrier to discussion. Rather than communicate across group differences, the troll deepens the divide and tries to cause animosity between groups so that discussion becomes impossible.

For example, in 2013, comedian Sam Hyde performed a stand-up set in Williamsburg, New York. Hyde used the set to troll the audience who were physically present at the show. However, he made sure to film the set so he could post it to his YouTube channel, where his followers watched him troll the Williamsburg audience.

To prepare for his set, Hyde claims he went on the internet and compiled a list of anti-gay "facts." Hyde claims he had no intention of checking the veracity of the statements, but simply went on the internet to find the most offensive and provocative homophobic statements he could. Hyde's goal, in his own words, was to be offensive enough to "get those Brooklyn hipsters the f--- out of the room." ${ }^{153}$ Indeed, as Hyde

\footnotetext{
153Seth Abramovic, Sam Hyde Speaks: Meet the Man Behind Adult Swim's Canceled "Alt-Right" Comedy Show, The Hollywood Reporter, https://www.hollywoodreporter.com/news/samhyde-speaks-meet-man-behind-adult-swims-canceled-alt-right-comedy-show-954487
} 
simply sat on a stool and read the hate statements from a printed sheet of paper, many people walked out. On his YouTube channel, his followers laughed at what they perceived to be irrational, delusional behaviour.

This is essentially the goal of troll humour - to cause a total breakdown in discussions by deliberately offending a target group to the extent that they leave discussions and develop animosity towards the troll and the troll's fans. On the other hand, the troll's supporters are left believing that the other social group is incapable of reasonable discussion. Therefore, troll humour is especially pernicious to the democratic process. Achieving greater understanding is assumed to be impossible because the other party is incapable of engaging in a reasoned discussion.

\section{Chapter Conclusion}

In this chapter, I have presented several charges against comedy, questioning the possibility that comedy can be used as an alternative form of political communication. It seems that comedy fails to meet many of the conditions Young argued were necessary for inclusive communication. Comedy, I have argued, often bypasses reasoning and argument, and instead relies on comedic devices like surprise, intonation, facial expressions, gestures, act-outs, funny voices, and so on. Secondly, political comedy like satire fails to be a good political tool for changing existing attitudes and beliefs; on the contrary, it reinforces people's political beliefs, biases, and prejudices. Further, superiority humour causes both external and internal exclusion of vulnerable individuals and social groups, especially of women. Such humour suggests that an unequitable distribution of agency and well-being freedoms is a good and necessary state of affairs, 
and trivializes extremely harmful conditions, like rape culture. Finally, political trolling is designed to widen political divisions between individuals and social groups, leading to a breakdown in reasonableness between participants. So, comedy, at least these forms of comedy, seem to be poor candidates for an alternative form of inclusive political communication.

In the next and final chapter, I will defend some forms of comedy as an alternative form of political communication that is fully compatible with Young's conditions for inclusive discussion. Furthermore, I will argue that these forms of comedy are compatible with Sen's capabilities approach because they enhance individual agency and well being, and help individuals lead lives they have reason to value. 
Chapter 4: Comedy that Respects Norms of Inclusion

Reforming through speech

In the previous chapter, it was shown that particular types of comedy, like superiority humour and certain types of satire, fail to be inclusive, to respect equality, and to be reasonable. They, therefore, fail to facilitate communication and understanding across social differences. However, it would be wrong to conclude that all forms of comedy are unacceptable forms of political communication. After all, even argument, as a form of political communication, is often abused and manipulated. But it would be absurd to conclude that all forms of argument are unacceptable. Rather, we should conclude that misleading, incoherent, or fallacious arguments are unacceptable as forms of political communication.

Young argues that the best way to deal with oppression is through "a change in cultural images, stereotypes, and the mundane gestures...of everyday life.”154 Furthermore, she argues that misleading arguments and abuses of greeting, rhetoric, and narrative should be met with criticism, rather than abolishing these forms of communication. Thus, Young seems to suggest that speech can be an effective tool for reforming oppressive social and institutional structures, but only if speech is made inclusive, equal, reasonable, and public. Thus, speakers and audiences have a responsibility to ensure that speech meets these conditions, and to respect norms of inclusive democracy.

154Young, Justice and the Politics of Difference, p. 63. 
The same reasoning should hold for comedy. While it is not the case that all comedy ought to explicitly aim at promoting inclusive democracy, comedy ought to respect the norms of inclusive democracy. As the previous chapter shows, many forms of comedy fail to respect norms of inclusive political communication. However, there are forms of comedy that should be recognized as inclusive political communication. I argue that open-mics and comedy in general offer effective opportunities for inclusive communication, and that comedy offers a path for people to increase their freedom and well-being, and to pursue a life they have reason to value.

I argue that stand-up comedy can be an alternative form of political communication. Open mics provide an alternative venue for expressing needs, for demanding equality and respect and more equitable distributions of agency and wellbeing freedoms, and for addressing structural differences and the systematic oppression of particular social groups. The stand-up comedy performed at open mics, and in theatres and clubs, can treat social difference as a resource. Comedians like Robin Tyler, Hannah Gadsby, Dave Chappelle, and Ms. Pat all use comedy to call for equal respect and consideration for marginalized social groups.

Open Mics: Perspective of Comedians

Open mics are an essential part of comedy. Open mics are usually free of charge, and take place at comedy clubs, small bars, or even cafés. They typically occur on weeknights. Open mics differ from other forms of comedy because the comedians are not booked beforehand. Instead, prospective comedians arrive before the show and sign up. Comedians are called onstage in the order in which they signed up, and each comedian 
can perform, uninterrupted, for about five minutes. There are no restrictions on who can sign up; on the same night audiences will see first-time comedians who have never told a joke on stage and seasoned pros who are working out new material. Open mics are fundamentally more free, equal, and inclusive than other forms of comedy, and they offer everyone an equal opportunity to speak in a public setting. Open mics fulfill all of Young's normative conditions for political communication. They are inclusive, equal, reasonable, and public — at least from the point of view of comedians pursuing their trade. They can, if done well, promote inclusiveness, equality, reasonableness, and publicity for audiences as well.

First, open mics are inclusive for both comedians and audiences because they reduce internal and external exclusion. Open mics avoid external exclusion towards comedians because anyone can sign up and perform. Spots are assigned on a first-come, first-serve basis, so people are not excluded because of experience in comedy or by race, gender, religion, sexual orientation, and so on. Open mics are open to anyone who wants to try stand-up comedy - they do not externally exclude. However, if an individual has violated club rules, they might not be welcomed back. For example, many clubs put certain topics off limits, e.g., "no jokes condoning rape or violence against women." If a comedian violates the club rule, the club will probably not welcome them back.

In most clubs, the only reason a person would be blocked from signing up would be if they had done something inexcusable during a previous performance or if they violated one of the club's rules. For example, if someone signs up for an open mic, and then hurls racial slurs at audience members, they will probably not be allowed to sign up again. Many clubs now have rules that forbid comedians from doing certain kinds of 
material, e.g. jokes that amount to hate speech. An infamous example of this occurred at the Laugh Factory in Los Angeles, when Michael Richards (who portrayed "Kramer" on Seinfeld) shouted racist slurs at audience members during a live show. ${ }^{155}$ This is an example of face-to-face vilification, which Susan Brison has defined as a form of hate speech. Indeed, Richards remarked that in "the old days" the audience members would have been lynched. He then began encouraging the crowd to turn on the audience members. Richards' rant lasted three minutes, and most of the audience walked out in disgust. Richards has not performed stand-up since that incident. Fortunately, comedy clubs are good at reacting to such incidents, and if a person signs up for an open mic and proceeds to behave in a manner analogous to Richards', they will probably not be allowed to sign up again, especially not at a comedy club.

Open Mics avoid internal exclusion for comedians

Secondly, open mics also avoid internal exclusion for the people who sign up to perform. Internal exclusion is more difficult to avoid than external exclusion because internal exclusion occurs when people are simply unwilling to seriously listen to and take into consideration the needs, interests, and beliefs of others. Open mics limit internal exclusion in two ways: first, because comedy shows are designed to focus an audience's attention on the comedian, eliminating all other distractions.

The design of a comedy show directs audience attention at the stage, so everyone in the comedy club setting must listen and watch the comedian on stage. For example,

\footnotetext{
155TMZ, "Kramer's Racist Tirade Caught on Tape," https://www.tmz.com/2006/11/20/kramers-
} racist-tirade-caught-on-tape/, November $2 \mathrm{O}^{\text {th }}, 2006$. 
the host of a comedy show greets the audience in a respectful manner, signalling trust and an expectation that respect will be reciprocated. This greeting sometimes involves telling the audience that heckling will not be tolerated, and violators could be ejected.

Comedians at an open mic have about five to six minutes of uninterrupted time to say whatever they want, and the audience will listen to them. So, anyone who wants to use comedy to communicate their life experience, or share their perspective, or criticize the inequitable distribution of freedom in society, and so on, can go to an open mic, sign up, and they will be able to express themselves in an open, public setting. This is important for avoiding internal exclusion, because internal exclusion occurs when people ignore the expressed needs and interests of others. But in an open mic setting, tables and chairs are arranged to discourage the audience from talking among themselves.

Furthermore, audience members are not permitted to talk or use phones during the show. If audience members are talking to each other, or distracting people from the show, they will be asked to leave.

Unfortunately, it is impossible to guarantee that everyone who attends a comedy show will listen attentively to comedians and respectfully consider their perspective, experiences, and beliefs (e.g., a homophobic audience member listening to a gay comedian). However, comedians have a microphone and time to speak, uninterrupted. If a comedian wishes to use their comedy to communicate their unique experience and perspective, e.g. a comedian like Hannah Gadsby (whose comedy special Nanette is a powerful, autobiographical performance expressing her experiences, perspectives, and future as a lesbian woman), then the onus is on them to use that time to the best of their ability, to use argument, rhetoric, narrative, and comedy to express themselves. Maybe 
even the best comedians will fail to correct the biases and prejudices of some extremely stubborn people; however, engaging with hostile biases and prejudices is a problem for all modes of political communication, including argument.

Open mics avoid external exclusion of audience members

Open mics also avoid external exclusion of audience members. Open mics are almost always free of charge; audiences do not have to pay to get access to the show. Sometimes, open mics are "pay what you can" shows, and the host will pass a hat around to collect whatever tips the audience is willing to give. These tips are then distributed among the comedians (the amount of money is usually small, rarely more than five dollars). On the other hand, some particularly famous and successful comedians charge upwards of $\$ 100.00$ or even $\$ 200.00$ for a ticket in a large theatre. When shows are that expensive, they exclude people who cannot afford tickets. But because open mics are free of charge, income is not a significant barrier to attendance.

Raising and Addressing Some Objections

Critics might object that open mics do not provide an environment that is free from internal exclusion for audience members, because comedians might still tell jokes that express harmful biases and prejudices. In the closed setting of a comedy club, exposure to racist jokes could be a form of hostile environmental harassment, if not faceto-face vilification, as in the case of Michael Richards. For example, suppose a person of colour attends a comedy show where the audience is predominantly white. Perhaps unaware that a person of colour is in the audience, a white comedian takes the stage and 
begins telling jokes that invoke harmful stereotypes. The jokes amount to hostile environmental harassment. Indeed, had the comedian told the jokes to a room with an audience composed predominantly of people of colour, they would have been booed off the stage. But the white audience laughs, and no one takes any notice of the person of colour. This is a kind of internal exclusion. The comedian and white audience ignore the interests of the person of colour, who would not want to be subjected to what amounts to hostile environmental harassment. Rather than endure the racist jokes and feeling nervous that the jokes are getting such loud laughter, the person of colour quickly leaves the establishment.

This objection seems analogous to an objection raised against Young's call for greeting as an alternative form of communication. The objection is that greetings are often ceremonial and merely convey an appearance of inclusion. In other words, a powerful party might make a grand gesture of greeting politically weaker parties, signalling to everyone that they are being inclusive. But, after the ceremonies are finished and the real discussions begin, the weaker parties are often still internally excluded. Likewise, the norms of politeness in a comedy club are mere formalities, and once the show is over, people retain their pre-show biases and prejudices.

Young's response to that objection first calls attention to the fact that arguments are also often abused and manipulated: people cite misleading or false statistics, use misleading or false premises, and so on. However, this does not mean that argument is an unacceptable form of political communication. On the contrary, argument is essential to political discussion. So, Young argues that the best response to misleading or fallacious 
arguments is criticism. ${ }^{156}$ It is impossible to guarantee that no one will ever use misleading arguments in political discussions, so the onus is on listeners to pay attention to the arguments they hear. Young extends this responsibility to greetings, rhetoric, and narrative. People who are listening to these forms of communication should actively engage and ask questions: "Is this discourse respectful, publicly assertible, and does it stand-up to public challenge?"157 These are also important questions for audience members to ask about comedy. "Would the comedian tell this joke if there were people of colour in the audience? Or is the joke so disrespectful that it could not be repeated in public?"

Another objection is that people tend to prefer comedians who share their preferences and beliefs. In other words, a homophobic person is unlikely to go to a gay comedian's show. Instead, they will choose to see a comedian who does not threaten their beliefs and preferences, indeed, they may rather see a comedian who shares their homophobic beliefs. Therefore, as this objection goes, comedy is unlikely to facilitate communication and understanding across group differences.

For example, comedian Nick DiPaolo is politically conservative, and his comedy reflects his political beliefs. On his YouTube video podcast, he uses a black-and-white background of 1930s New York City apartment/office, so that he appears to be podcasting from an earlier time when it was easier to be a white male. ${ }^{158}$ The title of DiPaolo's March $5^{\text {th }}$ show is titled "Squaw Squashed" [sic], and the episode is about Elizabeth Warren dropping out of the democratic primary. The title is a mockery of

\footnotetext{
${ }^{156}$ Young, Inclusion and Democracy, p. 79.

157Ibid., p. 79.

${ }^{15}$ Nick DiPaolo, The Nick DiPaolo Show, https://www.youtube.com/user/nickdipaolotube/videos
} 
Warren, who had claimed Native American ancestry. DiPaolo's title uses a pejorative term that many would find offensive. Thus, DiPaolo's show title is designed to repel certain individuals (people who are offended by the pejorative term) and attract others (people who do not mind the term or are happy to see Sen. Warren being mocked). ${ }^{159}$ Like the first objection, this objection would seem to apply to many forms of political communication, not just comedy. Most people tend to seek out messages that reinforce or confirm their existing beliefs and opinions. For example, news channels tend to skew towards a particular political demographic. Fox News has a reputation for skewing more to the right of the political spectrum, whereas channels like MSNBC skew more to the left. In Chapter 3, I criticized political talk show comedy because these shows present a very one-sided perspective, and people tend to only watch shows that align with and reinforce their existing political beliefs, biases, and prejudices.

Televised political debates and town-hall meetings, on the other hand, present many different perspectives from across a wide range of social groups. Viewers and listeners are exposed to arguments, rhetoric, and narratives they might otherwise not have encountered. Thus, these meetings present an opportunity for people to communicate and understand each other across group differences. Of course, people who attend these meetings might fail to be reasonable and open-minded, and thus internal exclusion can still occur. Indeed, Young pointed out that minorities and people of colour are often internally excluded during such meetings because they are unused to speaking in such settings, they have attire, accents, or dialect that more dominant social groups do not respect, and so on.

159Nick DiPaolo, The Nick DiPaolo Show \#311: Squaw Squashed [sic], https://www.youtube.com/watch?v=ViEtImYNNoA, March $5^{\text {th }}, 2020$. 
But the first step in overcoming biases and prejudices is exposure to unfamiliar perspectives and experiences, and therefore town hall meetings and political debates are excellent domains for political discussion.

I argue that open mic comedy offers a similar opportunity for people to communicate and understand one another across group differences, and, in some ways, open mics are superior. For example, open mics demand that audiences have a certain degree of open-mindedness and reasonableness.

Open mics eliminate some forms of internal exclusion that appear in town hall meetings. For example, Young pointed out that women and minorities have experienced internal exclusion in town hall meetings, because they are unused to assertive public speaking, or because their dialect, accents, mannerisms, figures of speech, and so on trigger the biases and prejudices of others in attendance. However, in open mics such differences provide the comedian with an advantage. This is because open mics demand a certain degree of open-mindedness and reasonableness from the audience.

One of Young's normative conditions for political communication was that participants in discussions ought to be reasonable, that is, they must be open-minded towards the beliefs, opinions, needs, and interests of others. Participants must enter discussions with a willingness to re-evaluate their views in light of new evidence, perspectives, and experiences. Open mics are well-suited for exposing audiences to new evidence, perspectives, and experiences.

A major difference between open mics and booked shows is that audiences do not know who will perform on the open mic night. When people decide to go out and see comedy, they might look at the booked shows and see who is headlining, then choose to 
go to the show that has their preferred line up of comedians (potentially reinforcing their existing biases). Of course, people use different criteria to decide which booked show they will attend, but some people choose to see those comedians who align most with their own life experiences, political views, moral outlook, and so on. While it is perfectly acceptable for people to choose along those lines, they are unlikely to be exposed to unfamiliar social groups, life experiences, or perspectives. Rather, they will hear messages that reinforce their existing beliefs and preferences. These shows do not require audiences to be reasonable in the sense of keeping an open mind.

However, at open mics, the audience does not know who will perform. They do not know what kind of jokes or funny stories will be told. They might hear jokes that they will find deeply offensive, or troubling. They might hear someone express a traumatic life story in the form of a hopeful, humorous narrative, causing them to re-evaluate their own beliefs and worldview. So, simply by going to an open mic, a person must be willing to keep a relatively open mind.

Of course, there is no guarantee that, say, a homophobic person will become more accepting and understanding of gay people after attending an open mic and seeing a gay comedian.

However, such a guarantee is not possible, not for comedy, and not for any form of political communication. Some people are stubborn in their views, close-minded, and unwilling or unable to reconsider their opinions in light of new evidence, arguments, narratives, and so on. But the existence of such people is not a reflection of the efficacy or appropriateness of comedy as an alternative form of political communication. Rather, if democracies are committed to enhancing agency and well-being freedoms for their 
people, then inclusive communication is a goal that democracies should strive towards. Increasing people's ability to effectively participate in political discussion will enhance their political freedom. As Sen showed in his discussion of the linkages between freedoms, democratic political freedom can motivate political leaders to respond to the economic needs of their people.

Furthermore, open mics offer an opportunity for people to improve their public speaking skills and social confidence. Open mics occur much more frequently than town halls. If someone wants to express their needs and interests at a town hall meeting, but fears engaging in public speaking, an open mic is an easily accessible, free way to practice public speaking in a real-world scenario. Thus, open mics can provide a solution to one cause of internal exclusion: competence in public speaking to a diverse audience.

Young's condition of publicity

Open mics fulfill the requirement of publicity. It is important that political communication occur in a public way. For communication to be public, it should be easily accessible to people, and the language of communication should be such that anyone can understand what is said. For example. political communication should not be couched in esoteric or technical language that virtually no one can understand.

As I showed in Chapter 2, rhetoric is good at fulfilling the publicity requirement, because rhetoric allows speakers to express themselves in a way their audience is most likely to understand. Likewise, comedy also has a publicity requirement. Comedians want as many people as possible in the audience to understand their jokes, because the more 
people that understand the joke, the more people will laugh. So, comedians, by necessity, must use language, phrases, and expressions that their audience will understand.

Open mics are also public in the sense that they are free of charge and anyone is welcome to attend or perform. There are no exclusions based on wealth, class, gender, and so on. Furthermore, some open mics are streamed on YouTube to millions of people. For example, Kill Tony is streamed on Monday nights from the Comedy Store in Los Angeles. Kill Tony also goes on tour around the world, and these open mics are also live streamed. The host, Tony Hinchcliffe, is joined by a guest comedian, and the guests are consistently among the best and most experienced comedians in the world. One of the regular guests is comedian Michael Lehrer, who has ALS.

Before the show, hopeful comedians write their names on slips of paper, which they put in a bucket. After the show begins, Hinchcliffe draws names from the bucket. The selected comedians each get an uninterrupted sixty seconds to perform. Hinchcliffe might draw between eight and ten names from the bucket per show. After the sixty seconds is over, Tony and his guest interview the comic, asking them about their set, their life, their experiences, and so on. For a new comedian, a chance to perform at the Comedy Store for Tony and his guests is an incredible opportunity. The level of publicity is very high on YouTube, most shows reach over 80,000 views every week.

One might object that Kill Tony uses a lottery mechanism to select comedians. Lottery systems are not a reliable process for producing just outcomes; in particular, the lottery system is unbiased. For example, a prospective comedian who has worked for months writing their sixty-second set, who goes to other open mics and works on material, or who sacrifices time and opportunities in the pursuit of success in comedy, or 
who has developed a set that is inclusive and respectful of differences across political and social groups might put their name in the bucket every week for months and never get chosen. On the other hand, an audience member might decide to put their name in the bucket on a whim and get chosen that night. So, the lottery system is not a good way to choose who gets to appear on Kill Tony and reap whatever rewards may come with such high publicity.

A lottery is not perfect, but for a show like Kill Tony, it is the least-worst option for choosing comedians. First, the lottery ensures that the line up of comedians is almost unpredictable, and unpredictability is one of Kill Tony's most attractive features. Week by week, nobody knows who will appear on the show. Audience members enjoy Kill Tony because they like being surprised by the unpredictable line up of amateur comedians. So, Kill Tony requires a certain degree of open-mindedness. The lottery system ensures that even if the same person signs up week after week, they will probably only ever win a spot once. Of course, some of the people who sign up for every show have been selected multiple times, but that is relatively rare. Each show tends to have a unique line up of comedians. If spots were allocated on a first come, first serve basis, then the show would exclude anyone who could not arrive hours before the show to wait in line. Finally, because the publicity of a Kill Tony appearance is so valuable, it attracts large numbers of prospective comedians. On a given night, fifty to a hundred people could put their names in the bucket. It is not feasible to survey these people and determine who has the best claim. First of all, claims would have to be verified (many people would be willing to lie for a chance on Kill Tony), and it is difficult to imagine how this could be done without full-time teams of private investigators running background checks all over the country. 
Secondly, most prospective comedians are equally deserving of a spot on Kill Tony and almost everyone who signs up for the show is an unknown amateur. So, in a sense, most people who sign up have not earned the level of publicity the show offers. On the other hand, Tony Hinchcliffe and his guests have been doing comedy for decades, touring across the country, and gathering an audience. Tony Hinchcliffe, his guests, and the Comedy Store itself have put in the work to attract thousands of views every week. So, most people who sign up have no better claim than anyone else who signed up. Sometimes a person will sign up who has less of a claim than others but will still win a spot. However, such occurrences are relatively rare on the show. Most people who win a spot have signed up several times. Therefore, while the lottery system is far from perfect, it is the most efficient means for selecting who will be on the show.

With respect to inclusiveness and open-mindedness, the lottery system has some advantages. The lottery system eliminates prejudice and bias in the selection of comedians. While Tony probably does not harbour significant biases and prejudices, it is hard for even the most reasonable people to always act in an unbiased way. The lottery system effectively binds Hinchcliffe, ensuring that comedians are selected without bias.

Another objection that would not seem to meet Young's conditions for publicity is that comedy is sometimes too offensive to be public. Young argues that one condition for publicity is that political speech should not be uttered in an offensive manner, such that some cannot receive the speech without suffering setbacks to their "worth and dignity." 160 Comedy is not always clean. Comedians often use swear words or tell jokes that some would find offensive. So, comedy that is not clean fails to be public. Most comedy is not

160Young., p. 68. 
clean, so most comedy fails to be public. If most comedy fails to be public, then comedy is not a viable alternative form of political communication.

This objection relies on the premise that receiving "unclean" (also called "blue") comedy will incur a cost to one's worth and dignity. A problem with this premise is that the scope of "unclean comedy" will include much comedy that can be received without a loss to one's worth and dignity. In other words, the category of "unclean comedy" includes many kinds of comedy that do not overlap with the category of offensive communications that incur a setback to one's worth and dignity.

For example, Ms. Pat is an African American comedian who does not do clean comedy. It would be difficult for Ms. Pat to do clean comedy, because her comedy is autobiographical, and her life has not been easy. In order to accurately share her experiences and how they have shaped her perspectives on life, she must recount stories of trauma and abuse in vivid, explicit detail. I will consider her comedy in more detail in a later section where I show how comedy is an opportunity to increase one's agency and well-being freedoms. Ms. Pat, like almost all comedians, started her comedy career performing at open mics. Suffice it to say that there are many comedians like Ms. Pat who, despite not being "clean," nonetheless have important life experiences and perspectives that ought to be shared with the world. Listening to Ms. Pat incurs no setback to one's worth and dignity. On the contrary, Ms. Pat's comedy is dignity affirming to her, and to those who have shared her experiences. 
Equality

Finally, open mics meet the requirement of equality. Open mics provide an equal opportunity for people to express their interests and concerns through the medium of comedy. Young argues that in a democracy, "everyone should have an equal right and effective opportunity to express their interests and concerns," and that an "ideal model of deliberative democracy promotes free and equal opportunity to speak." ${ }^{161}$ Open mics meet both these requirements. Open mics respect that everyone has an equal right to speakanyone can sign up to be on the show. If you show up, you go up. Large cities with robust comedy scenes, like New York, Los Angeles, and Toronto, often have up to ten open mics every week, so there are plenty of opportunities. Secondly, open mics offer everyone an effective opportunity to express their interests and concerns through comedy.

An objection could be made against the claim that open mics offer everyone an effective opportunity to express their interests and concerns through the medium of comedy. The objection would be that open mics are not effective in the sense Young intended. Young, the objection goes, argues that an opportunity is effective if it allows the speaker to directly exert influence on the outcome of a political discussion. An example of an effective opportunity to speak would be at a town hall meeting, or before a vote, in some form of mass media, and so forth. But speaking for five minutes at an open mic to an audience of less than thirty people does not give someone an opportunity to exert influence over the outcome of a political decision. Therefore, open mics do not offer an effective opportunity in the sense Young intended.

161Young, p. 23. 
The objection, I argue, underestimates the power of open mics to provide an opportunity for people to communicate their needs and concerns, and to improve understanding across group differences. Young has argued that group differences must be treated as a resource for democracy, and that achieving greater communication and understanding across group differences is necessary for the democratic process to achieve wise and just outcomes. In particular, Young has stressed the need for communication across structural group differences (although she also stresses communication across cultural and political differences). Structural differences are differences in the opportunities and life prospects available to members of social groups due to their relationships with institutions (law-enforcement, the courts, banks, universities, legislatures, and so on) and other social groups (employers in various sectors, dominant cultural groups, minority groups, and so on). Structural differences are so important because they condition people's real opportunities to lead lives they have reason to value.

If discussion-based processes are to have wise and just outcomes that increase people's freedom and well-being, it is important for all members of democratic society to be aware of structural differences and to grant them equal respect and consideration when weighing competing claims of justice. Members of groups that are relatively wellpositioned in the structure of institutional and social relationships may have difficulty comprehending the needs and interests of groups that are not well-positioned. Young calls this difficulty, "the dominance of partial-perspective." 162 Members of more dominantly positioned groups have trouble taking up the perspective of those in different positions.

162Young, p. 83. 
People's perspectives are shaped by what they experience everyday, and many people assume that everyone has the same experiences with institutions and social groups.

For example, a white driver who lacks knowledge about structural differences might think that police rarely, if ever, stop and search innocent, law-abiding drivers. However, Stanford University's Open Policing Project has found that police require less suspicion to stop and search black and Hispanic drivers than white drivers, indicating racial discrimination. ${ }^{163}$

Biases, prejudices, and partial perspectives are like bad inputs to the democratic process. Discussion and deliberation are good, but if the participants fail to recognize the structural differences in their societies that affect the freedom and well-being opportunities of oppressed social groups, then they will not make well-informed decisions, and the outcomes will not be wise or just. For example, if the hypothetical white driver in the above example is unaware of the problem of racial discrimination in policing, his political decisions will demonstrate his ignorance. Thus, Young argues that "communication of the experience and knowledge derived from different social positions helps correct biases" that would otherwise prevent people from identifying problems and their solutions. ${ }^{164}$

Open mics and stand-up comedy in general are capable of fostering communication across group differences. According to Young, inclusion of differentiated groups has three benefits to democracy. First, it demonstrates equal respect and ensures that legitimate interests in the polity receive expression. Second, it motivates members of

\footnotetext{
163“Findings," The Stanford Open Policing Project, https://openpolicing.stanford.edu/findings/, 2020. 164Young, p. 83.
} 
different groups to frame their political claims as appeals to justice and rights. Third, it increases the understanding and knowledge of the democratic public about their society. ${ }^{165}$ Open mics, and stand-up comedy in general, can provide all three of these benefits. In the sections that follow, I will provide examples of several comedians, who treat group difference as a resource, use their comedy to achieve greater respect for marginalized social groups, frame their claims of need in terms of justice, and educate the public about their society.

Robin Tyler

Comedy has not always been inclusive and respectful of group difference. Indeed, before the civil rights era began, one of the most popular forms of comedy in the United States was blackface, e.g. popular shows like Amos and Andy. ${ }^{166}$ Women comedians were expected to make sexist jokes at their own expense; thereby reinforcing the very inequalities, harmful biases and stereotypes that limited their agency and opportunities to lead lives they had reason to value. ${ }^{167}$

However, comedy played an active role in the civil rights movement, with black comedians and women comedians taking the microphone and proclaiming their legitimate needs and interests in seeking social justice. One influential comedian who used comedy to fight for equal respect and consideration for women and members of the LGBTQ community was Manitoba-born Robin Tyler.

\footnotetext{
165Ibid., p. 115.

166 Raúl Pérez, "Race, Gender, and Comedy Awards: From Civil Rights to Colorblindness," Comedy Studies, 8:1, 68-80, 2017, DOI: 10.1080/2040610X.2017.1294413 167Val Edwards, “Robin Tyler: Comic in Contradiction,” Body Politic (1979): 22.
} 
Tyler, herself a lesbian, used her comedy in a new way. Rather than doing comedy that puts herself as the butt of the joke, Tyler inverted the trope of the self-deprecating female comedian and instead critiqued the society that oppressed her. ${ }^{168}$ Crowds were not uniformly receptive to her comedy. Indeed, earlier I mentioned the hypothetical case of a homophobic audience member encountering a gay comedian. Such occurrences were not hypothetical for Tyler, who experienced them often. However, as a brilliant comedian, she used comedy to expose homophobia.

For example, in 1979, Tyler became the first comedian to perform openly lesbian material on national television (in the United States for Showtime's $1^{\text {st }}$ Annual Funny Women's Show) ${ }^{169}$ Her goal was to entertain and educate the audience. During the set she tells the story of an interaction with a homophobic heckler who was offended by Tyler's new style of comedy. In this case, the heckler cannot tolerate a successful lesbian comedian. But rather than simply sit in silence, or leave the show, they decide to interrupt.

Heckling is a kind of exclusion in that the heckler wants to silence the speaker by interrupting them and forcing them to speak on the heckler's terms. Most clubs will eject hecklers, but some comics enjoy silencing the heckler with a witty retort. However, rather than simply insult the heckler, Tyler's style of comedy is what Krefting calls "charged comedy." Instead of relying on stereotypes or accepting the trope that women should be the butt of the joke, Tyler exposes the heckler's homophobia and arrogance.

\footnotetext{
168Ibid., p. 22.

169 Rebecca Krefting, All Joking Aside : American Humor and Its Discontents, (Baltimore: Johns Hopkins University Press, 2014), Accessed March 25, 2020. ProQuest Ebook Central, p. 141.
} 
After a few heckles failed to break Tyler's stride, "he said the one thing that was really supposed to upset me. He said [in a deep and gravelly voice], 'Hey are you a lesbian?' And I said, 'Hey, are you the alternative?' [laughter that moves into sustained hooting, cheers, and clapping]." ${ }^{170}$ Tyler says that she often encountered a doublestandard when it came to making jokes at the expense of men: "We took all of the jokes that had ever been done on women and we did them on men. And when a man jokes about a woman it's called funny but when a woman does jokes on men it's called antimale." ${ }^{171}$ But Tyler's self-professed mission was to confront these biases, prejudices, and double standards with comedy. She welcomed these opportunities. Over the course of multiple comedy albums, Tyler's comedy revealed and critiqued "sexism in advertising and education, wage inequalities, gendered double standards, and homophobia." ${ }^{172}$

Krefting notes that Tyler, unlike male contemporaries George Carlin and Richard Pryor, unabashedly used comedy to express the needs and interests of women, mothers, and the LGBTQ community. ${ }^{173}$ In other words, she did not practice comedy for the sake of comedy, she practiced comedy because she believed it was an effective means to express her feminist beliefs. Tyler believed her comedy was instrumental in "generating discussion, edifying audiences, enlisting support for LGBTQ causes, and humanizing the movement in order to encourage extending civil liberties to the LGBTQ community." 174 Indeed, her beliefs were so radical, and her comedy was so direct, that she found it difficult to break into the mainstream in a time when mainstream audiences expected

170Ibid., p. 141-142.

${ }^{171}$ Pat Harrison and Robin Tyler, Wonder Women, LP (US: 20th Century, 1973).

${ }^{172}$ Krefting, p. 145.

173Ibid., p. 146.

174Ibid., p. 148. 
women to self-deprecate. Tyler was ahead of her time. However, while she was never accepted by mainstream audiences, her brash comedy won her a degree of fame and notoriety (and probably infamy to some such as the bigoted heckler). She used her fame and notoriety to accomplish a lot for gay and women's rights. Indeed, Tyler, et al. v. the County of Los Angeles eventually ended, after a lengthy appeals process, with the court ruling in Tyler's favour, legalizing same-sex marriage in California.

While Tyler never broke into the mainstream, she laid the groundwork for future comedians to use comedy to raise important concerns of social justice. A similar, modern comedian is Hannah Gadsby, whose autobiographical comedy is a searing, and sometimes intentionally serious, indictment of sexism and stigmas surrounding homosexuality and autism.

\section{Hannah Gadsby}

Gadsby's comedy is intentionally confrontational and angry, and leaves audiences stunned. But this is what Gadsby wants. She wants to use her revolutionary style of comedy to demand justice and respect for people who have suffered sexual violence in silence.

Gadsby takes common comedic tropes and inverts them. Recall the example of Jay Leno's political comedy, which took advantage of the tensions surrounding increased immigration, and then released that tension with jokes about immigrants. Gadsby inverts this formula with respect to the tension men experience surrounding discussions of sexual violence against women. Instead of releasing that tension and allowing the audience to feel like they have been released from responsibility to listen to experiences of sexual 
violence, Gadbsy heightens the tension. For example, early in her Netflix special Nanette, Gadsby tells a story about growing up in rural Tasmania ("known for our potatoes and frighteningly small gene pool") ${ }^{175}$, where homosexuality was illegal until 1997. In the story, she is waiting at a bus stop after the pub closes and starts flirting with a girl who is also waiting. Suddenly, a man approaches and shoves Gadsby away, saying, "Fuck off faggot, get away from my girlfriend.” The girl tells him to stop, and the man stops and says, “Oh sorry, I don't hit women [laughter]. I thought you were a faggot cracking on to my girlfriend [laughter]." Gadsby then turns to the audience and says, "Now I do understand that I have a responsibility to lead people out of ignorance, but I left him there people [laughter]."176

In a typical stand-up set, this would be the end of the joke. However, later in the special, Gadsby returns to the story. She admits that the story actually ended quite differently. The man did not stop, in fact, he "beat the shit out of her." ${ }^{177}$ No onlookers stopped him, Gadsby did not go to the hospital or the police, because her self-worth was so injured that she did not think she deserved medical treatment or justice. The audience's reaction is silence, and the tension in the room is palpable. "This tension is yours," Gadsby yells. "I am not helping you with it anymore. You need to learn what this feels like." ${ }^{178}$

Unlike Tyler, Gadsby has "broken in" to the mainstream, as evidenced by her Netflix comedy special Nanette and world-tour of the same name. She has a memoir

175Hannah Gadsby, Nanette, Netflix, 2018

${ }^{176}$ Ibid.

177Ibid.

178Ibid. 
coming out that will probably be a best seller. ${ }^{179}$ In an ironic twist, Gadsby did not break into the mainstream until she began using her comedy to explicitly attack social injustices and inequalities and their effect on gay people, people with autism, and gay people with autism (like Gadbsy herself). But now, she is one of the most talked about comedians in the world.

Gadsby is also an example of how comedy can offer a career path in art for people who might otherwise struggle. Indeed, Gadsby, born in Tasmania, was semi-nomadic and homeless for a time. However, she believes that comedy saved her life, because comedy is inclusive towards anyone who wants to try. Comedy allowed Gadsby to express herself, including her experiences of homophobia (although it was not until later in her career that Gadsby up-ended the tension-release formula with respect to sexual violence): “Comedy is great in that it's accessible to someone like me, from a low socioeconomic background, struggling in life. The gatekeepers are a lot stronger in other art forms.” ${ }^{180}$

\section{Dave Chappelle}

Dave Chappelle is an African American comedian whose comedy has often focused on structures of oppression in the United States. His comedy is notable for its capacity to educate audiences about structural inequalities in society. Like Tyler and Gadsby, Chappelle does not shy away from confronting the ignorance of white people

\footnotetext{
179Jenny Valentish, "I Broke the Contract," The Guardian: The G2 Interview, July 16, 2018, https://www.theguardian.com/stage/2018/jul/16/hannah-gadsby-trauma-comedy-nanettestandup-netflix 180Ibid.
} 
about the experiences of African Americans. However, Chappelle does this with an accessible, conversational style.

In 2000 he released a special called Killin'Them Softly, which highlighted the changing landscape of race in the United States. Performed in a large theatre in Washington D.C., Chappelle's opening joke is about how the police treat black people and white people differently. Chappelle, however, introduces a new, and subtle, dynamic into this familiar comedic trope. Chappelle notes that while the police often discriminate and profile black people, white people in general seem less frightened of black people than they were in the past.

Chappelle begins the bit by remarking on how much Washington D.C. has changed since the eighties. "There's a lot more white people walking around," Chappelle says to laughter. He explains that in the eighties, the epidemic of crack cocaine led to white people fleeing to the suburbs. But now, he notes that white people and black people are not so scared of each other, and mixed-race friendships are becoming more acceptable. Chappelle declares that black people should have white friends, “...for safety. Because when shit goes down, someone's gonna need to talk to the police [laughter]. Black people are very afraid of the police. That is a very big part of our culture. It doesn't matter how rich you are, how old you are, we've got every reason to be afraid of them."”181

He then points to a woman in the front row. "You're a white lady. Have you ever been pulled over? [she nods]. What do they say, 'Let me see your driver's license and registration,' right? [she nods]. See? I'm just guessing [laughter]. That's not what they say to us [laughter]. You wouldn't believe what they say to us." Most of the people

181Dave Chappelle, Killin' Them Softly, 2000. 
laughing are black, because they can relate to Chappelle's experiences of discrimination. If the white audience member did not know this was a common experience among black people, then this would have been a very informative moment.

However, Chappelle notes that for many years he did not realize that his experiences of discrimination and humiliation at the hands of the police was "a black thing." He explains that it was only after hanging out with his white friends that he realized how differently the police treated him because of his race.

At this point in the bit, Chappelle clarifies his point: 'I'm not saying I don't like the police. I'm sayin' I'm scared of 'em. Because sometimes, we want to call them too." Chappelle is calling attention to an experience common among black people in the United States: fearing to call police to report crimes.

Chappelle goes on: "Somebody broke into my house once. Now would be a good time to call right?" Chappelle shakes his head. "My house was too nice. They'd never believe I lived in it." Chappelle pretends to be a white police officer entering the house and seeing Chappelle: "Oh my God, he's still here!” the officer says, before bopping Chappelle on the head with a nightstick. "Open and shut case, Johnson. I saw something similar once when I was a rookie. Apparently this $\mathrm{n}^{* * * * *}$ broke in and hung pictures of his family everywhere. Well, let's sprinkle some crack on him and get out of here.” ${ }^{182}$ The joke is that the officers are so racially biased that they believe Chappelle is the burglar, rather than the homeowner.

While the whole scenario seems exaggerated, such incidents have happened and continue to happen to African Americans. Chappelle's joke was from his comedy special

182Ibid. 
Killin'Them Softly, which premiered in 2000. But such incidents continue to this day. For example, in August 2019 in Raleigh, North Carolina, in the middle of the night, police entered Kazeem Oyeneyin's home and arrested him. That night, Oyeneyin's friend had accidentally triggered the burglar alarm. Kazeem went downstairs and turned it off, before going back to bed. However, minutes later, police arrived, handcuffed Kazeem and marched him out of the house.

Oyeneyin is a concert promoter and nightclub owner who lives in an affluent, predominantly white neighborhood. In an interview after the incident, he said it was just another case of a black man being profiled as a criminal because he lived in a wealthy, white neighborhood. "It's a stereotype I just don't want to live with." ${ }^{83}$ Chappelle's comedy is unfortunately all too accurate.

At this point, an objection could be made that Chappelle's comedy is clearly not effective at producing real social change. After all, Chapelle's joke was from the year 2000 , and in 2020 , the premise of the joke actually occurred in real life when police arrested a wealthy black man in his own home because they assumed he must be the burglar. Clearly, stand-up comedy is not the most effective way of correcting racial profiling in the police force.

Chappelle seems to address this potential objection in his next joke. He explains that the "whole police brutality thing is common knowledge now. But there was a time when only minorities knew about that. I'm not gonna say white people didn't believe $u s$,

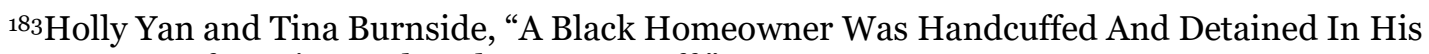
Boxers After His Burglar Alarm Went Off," CNN, https://www.cnn.com/2019/o8/27/us/raleigh-burglar-alarm-homeownerdetained/index.html?utm_medium =social\&utm_content=2019-0827T15\%3A54\%3A51\&utm_term=link\&utm_source=twCNN, August 27, 2019.
} 
but you were a little skeptical. I don't blame you, but as soon as it was printed in Newsweek you believed it." Chappelle pretends to be an upper middle-class white man learning about police brutality in Newsweek: "Oh my God! Honey did you see this? Apparently the police have been beating up negroes like hotcakes! I'm serious! It's in the May issue."

Chappelle's point is that black people and minorities have been complaining about police brutality and racial profiling for decades, but people who have never experienced profiling or discrimination have not listened to them. Instead, they only started believing these stories when they were printed in mainstream newspapers and reports; in other words, when the stories were repeated by white voices. While Chappelle's comedy will not end racial discrimination, it succeeds in edifying audiences about the significant structural differences that exist within society, and reminds audiences that they have a responsibility to listen to the claims of equality and respect expressed by the most marginalized members of democratic societies.

Ms. Pat

The final comedian I will consider is Ms. Pat (Patricia Williams). In addition to educating audiences about structural differences that exist for impoverished black women in the United States, Ms. Pat uses her comedy to overcome biases against black people and to encourage people to be agents in control of their lives. She, like Gadbsy, credits stand-up and open-mics as instrumental in allowing her to overcome her trauma by escaping poverty and the prison system. Another reason Ms. Pat does comedy is to work through the trauma of her early life, and to help audiences learn how to deal with their 
own traumatic experiences and offer cautionary tales for young girls without mentors. Ms. Pat is an excellent position to accomplish these goals, given her own life experiences.

Williams's childhood was traumatic and abusive. She was raised in Atlanta, Georgia, in extreme poverty by a violent single mother who frequently fired a gun to enforce discipline. “My momma didn't do a lot of whoopin' because she was a small lady, and she had five kids who were bigger than her. So she would walk around with a .22 pistol threatenin' the hell out of us. And I used to think, 'We poor as hell, where's she keep gettin' all these bullets?"

Ms. Pat's stories are almost like cautionary tales for young women. "A lot of times young girls look for love in the wrong place, and I was one of those young girls. I never had anybody to tell me they loved me." ${ }^{184}$ When Williams was twelve, she fell in love with a man. Her mother had told her, "If a man don't hit you, he don't love you." So when the abuse started, "I thought, the more he hits me, the more he loves me." Once, he hit her on the back of the head with a gun, and the gun went off, fracturing the back of Williams's head. Her abuser ran away, but as Williams lay bleeding, she recalls, "I was still in love. I was still in love. I thought oh my God, he shot me. He must really love me."

By sixteen she had two kids, and the father had abandoned the family. Like many people in seriously deprived urban environments, she could not just get a job. Young has called attention to how black people in impoverished urban environments are oppressed by discriminatory institutional relations. Racist housing policies force black people into

184Larry Charles, Larry Charles's Dangerous World of Comedy, Netflix, 2018. 
neighbourhoods with poorly maintained housing. Politicians prefer to respond to more affluent neighbourhoods, and so the impoverished neighbourhoods receive poor social opportunities such as education and healthcare. Lack of education leads to lack of legitimate employment opportunities, Thus, discriminatory actions and policies create unequal distribution of the range of agency and well-being freedoms that Sen discusses (political freedom, economic facilities, social opportunities like education and healthcare, and so on) for people of colour in these urban neighbourhoods. And, unfortunately, for single mothers struggling to feed their children, they are forced into crime.

Williams began selling crack cocaine to support herself and feed her kids. After getting shot a second time in a drug deal gone wrong, Williams was sent to jail. In jail, she resolved to change herself, and her life. When she got out, her parole officer was so amused by her stories that she recommended Williams try stand-up. Williams began performing at open mics and fell in love with the honesty of comedy. Ms. Pat was born.

"You know what's crazy? I take all the negative I was handed in my life, and I make a good living off it. If you take nothing from my show, learn how to laugh at the bullshit in your life. Cause when you laugh at the bullshit in your life, you control it." 185 For example, Ms. Pat tells the story of how she was shot twice: "Growin' up in the hood I've been through a lot in my life, I have. I've been shot two times and hit by a dump truck [laughter]. Nobody gives a fuck who shot me, they want to know, 'Who hit you with a dump truck?' [laughter]. The same dude who shot me [laughter]. We was in love. [laughter]. I wish this shit wasn't true [laughter].”186

185Ibid.

${ }^{186}$ Ms Pat, Ms. Pat Live At Gotham!, 2014, https://www.youtube.com/watch?v=MIVXFb79Dko 
It could be objected that laughing at "the bullshit in your life" is not a good way to control it. After all, Ms. Pat did not change her life by laughing at it, she changed her life by resolving to change herself and stop living with abusive men. Nor does Ms. Pat seem to think that one can laugh their way out of poverty. She got out of poverty by making other people laugh. Furthermore, when Ms. Pat laughs at her own stories, she is laughing from a position of relative safety: she is a highly successful and affluent comedian.

However, despite Ms. Pat's material success, trauma still lingers. That is the nature of trauma; it never just goes away. Hannah Gadsby, for example, is still dealing with her trauma through her show Nanette. For these women, comedy helps them deal with the trauma of their lives. And for both, comedy has provided a path out of deprivation. Through comedy, they have significantly increased their agency and wellbeing, and now lead lives they have reason to value.

Much of the value for these comedians comes from using their comedy to reach out to people like them, who are similarly suffering in deprived conditions of inequality and lack of agency and real opportunity. Both Ms. Pat and Gadsby point out that they never had anyone to tell them these stories when they were younger, but they wished they had. ${ }^{187}$

187Valentish, “I Broke The Contract...” 2018. 


\section{Conclusion}

In this thesis I have demonstrated the importance of freedom of speech for democratic societies. John Stuart Mill showed that freedom of speech is essential for individual mental well-being, but he was willing to exclude certain oppressed groups from discussion. Amartya Sen's approach demonstrated that freedom of speech has even greater capacity to improve well-being and agency, because freedom of speech is inextricably linked to political freedoms, which are in turn linked to economic facilities and social opportunities. However, Sen too falls short, and does not recognize that oppressed social groups in democratic societies lack effective access to speech, and thus cannot use speech to increase their agency and well-being freedoms. Iris Marion Young's work on oppression, social group differences, and inclusive communication corrects for the deficiencies in Mill's and Sen's accounts.

Exposure to different narratives, experiences and perspectives can have a powerful effect on audiences. When we learn how other people see us, it can cause us to come to a better understanding of ourselves. Young calls this contextualizing our perspective: "Listening to those differently situated from myself and my close associates teaches me how my situation looks to them, in what relation they think I stand to them. Such a contextualizing of perspective is especially important for groups that have power, authority, or privilege." 188 The more diverse voices and perspectives we encounter, the more we learn about the people we are accountable to in our shared democratic society.

188Young, Inclusion and Democracy, p. 116. 
Furthermore, we can contextualize our perspective more sharply, putting into focus structural differences and systems of oppression that often occur right before our eyes.

Stand-up comedy and open mics offer an incredibly diverse array of perspectives and experiences in an accessible, inclusive, and equal environment. Therefore, listening to stand-up, and going to open mics, is an excellent way to learn not just about other social groups, but also to learn about ourselves. If one can keep a relatively open mind, performing or watching comedy and attending open mics is an excellent way to treat social group differences as a resource.

Open mics provide a venue that is inclusive, equal, reasonable, and public. Open mics do not tolerate exclusive practices, either by comedians in the form of hate speech, or by audience members in the form of heckling. Shows like Kill Tony provide unprecedented publicity for amateurs to express themselves. Open mics are well attended by diverse audiences, creating an intersection for social groups differentiated by socioeconomic status, race, gender, sexuality, religion, and so on. Comedians like Hannah Gadsby and Robin Tyler frame their appeals in terms of justice for women and the LGBTQ community. Dave Chappelle and Ms. Pat educate the democratic public about experiences and perspectives they would otherwise never encounter, overcoming racial biases and prejudices. In each case, these comedians have changed their lives and the lives of others by taking responsibility for promoting greater understanding across differences. This is one of the aims in Young's account of inclusive democracy. It can be one of the aims for stand-up comedians. 


\section{Bibliography}

Abramovic, Seth. Sam Hyde Speaks: Meet the Man Behind Adult Swim's Canceled "AltRight" Comedy Show. The Hollywood Reporter,

https://www.hollywoodreporter.com/news/sam-hyde-speaks-meet-man-behind-adultswims-canceled-alt-right-comedy-show-954487

Alonge, Sede. “'My Wife Belongs In The Kitchen'? President Buhari isn't helping Nigeria." The Guardian, October 17 $7^{\text {th }}, 2016$.

https://www.theguardian.com/commentisfree/2016/oct/17/wife-job-look-after-me-buharinigerian-girls.

Aristotle and George Henry-Lewes, "Book I," In The Ethics of Aristotle: With Introductory Essay by George Henry-Lewes. Walter Scott Publishing Co, London, 1890, p. 1-35, Chapter xxvi.

doi:http://dx.doi.org.proxy.library.carleton.ca/10.1037/12981-001. https://proxy.library.carleton.ca/login?url=https://search-proquestcom.proxy.library.carleton.ca/docview/867640887? accountid=9894.

Bakassi, Okey. “Okey Bakassi Thrills Crowd at GLO Laffta Fest.” October $18^{\text {th }}, 2015$, https://www.youtube.com/watch?v=DhQGudsL4w\&list=PLlhgitmxGouaj44yByKZywVqCbc0VPBhg.

Berlin, Isaiah. Two Concepts of Liberty: An Inaugural Lecture Delivered before the University of Oxford, on 31 October, 1958 Oxford: Clarendon Press, 1958.

Brison, Susan. "The Autonomy Defense of Free Speech." Ethics 108, no. 2 (1998): 31239. Accessed April 2, 2020. doi:10.1086/233807. p. 314.

Bronstein, Phil. "Good Morning, Iraq." San Francisco Daily Chronicle, February 9-10, 2005. Accessed at http://www.robin-williams.net/interviews/uso/05-02.php.

Chappelle, David. Killin’ Them Softly. 2000.

Charles, Larry. Larry Charles's Dangerous World of Comedy. Netflix, 2018.

Cohen-Almagor, Raphael. "Harm Principle, Offence Principle, and the Skokie Affair." Political Studies 41, no. 3 (09/01/1993) p. 453-470

Colbert, Stephen. White House Press Correspondent's Dinner. April 29 ${ }^{\text {th }}, 2006$, https://www.youtube.com/watch?v=2X93u3anTco

Crocker, David. Ethics of Global Development. Cambridge: Cambridge University Press, 2008. 
DiPaolo, Nick. The Nick DiPaolo Show, https://www.youtube.com/user/nickdipaolotube/videos

DiPaolo, Nick. The Nick DiPaolo Show \#311: Squaw Squashed [sic], https://www.youtube.com/watch?v=ViEtImYNN0A, March $5^{\text {th }}$

Edwards, Val. "Robin Tyler: Comic in Contradiction.” Body Politic. 1979.

Enfield, Harry. “Loadsamoney- I've got piles!” BBC's Friday Night Live, https://www.youtube.com/watch? $v=g X u R v$ thgn $4 U$.

"Findings," The Stanford Open Policing Project, https://openpolicing.stanford.edu/findings/

Foot, Tom. "Harry Infield: How Loadsamoney Has Changed Hampstead." Camden New Journal, January $17^{\text {th }}, 2019$, http://camdennewjournal.com/article/harry-enfield-howloadsamoney-has-changed-hampstead

Gadsby, Hannah. Nanette, Netflix, 2018

Harrison, Pat and Tyler, Robin. Wonder Women, LP. US: 20th Century, 1973

Hamada, Rachel. "Nigerians Turn On Comic For Rape 'Joke'.” The Guardian. January $8^{\text {th }} 2014$, https://www.theguardian.com/world/2014/jan/08/nigeria-basketmouth-rape-joke

Hattenstone, Simon. "Harry Enfield: I Don't Like Doing Me.” The Guardian. September 25, 2010, https://www.theguardian.com/theguardian/2010/sep/25/harry-enfieldinterview

Hobbes, Thomas. Of Man, Being the First Part of Leviathan, 1651 (Hoboken, N.J.:

Generic NL Freebook Publisher, Accessed March 2, 2020)

http://search.ebscohost.com.proxy.library.carleton.ca/login.aspx?

direct=true $\& d b=$ nlebk\&AN=2008503\&site=ehost-live, p. 20.

Holmes, Janet, \& Marra, Meredith. "Humour As A Discursive Boundary Marker In Social Interaction," in Us and Others : Social identities across languages, discourses and cultures. Edited by Anna Duszak, John Benjamins Publishing Company, 2002. ProQuest Ebook Central, https://ebookcentral-proquestcom.proxy.library.carleton.ca/lib/oculcarleton-ebooks/detail.action?docID=623260.

Koggel, Christine. "A Critical Analysis Of Recent Work On Empowerment.” Journal of Global Ethics 9, no. 3, 263-275, DOI: 10.1080/17449626.2013.818383, September $1^{\text {st }}$ 2014. 
Krefting, Rebecca. All Joking Aside: American Humor and Its Discontents. Baltimore: Johns Hopkins University Press, 2014, Accessed March 25, 2020. ProQuest Ebook Central.

LaMarre, Heather et al, "The Irony of Satire." International Journal of Press/Politics 14, no. 2, April 2009

Madison, James. The Writings of James Madison. Edited by Gaillard Hunt (New York: G.P. Putnam's Sons, 1901), volume 9.

Matsuda, Mari. Words That Wound. Matsuda et al. Boulder: Westview Press, 1993.

Mill, John Stuart. On Liberty. Electric Book Company, 2000. ProQuest Ebook Central, https://ebookcentral-proquest-com.proxy.library.carleton.ca/lib/oculcarletonebooks/detail.action?docID=3008614.

Mill, John Stuart. Public and Parliamentary Speeches: Volumes XXVIII-XXIX. Toronto: University of Toronto Press, 1988. Accessed March 29, 2020. ProQuest Ebook Central

Mill, John Stuart. Subjection of Women. Project Gutenburg 2008, http://www.gutenberg.org/files/27083/27083-h/27083-h.htm

Ms Pat, Ms. Pat Live At Gotham! 2014, https://www.youtube.com/watch?v=MIVXFb79Dkt

Ms. Pat, This Is Not Happening. Comedy Central, February 25, 2015, https://www.youtube.com/watch?v=pFVNt1jbnqE

Nussbaum, Martha. Creating Capabilities: The Human Development Approach. Cambridge: Harvard University Press, 2011.

Pérez, Raúl. "Race, gender, and comedy awards: from civil rights to colorblindness." Comedy Studies, 8:1, 68-80, 2017, DOI: 10.1080/2040610X.2017.1294413

Rogan, Joe. The Joe Rogan Experience \#1437: Stephen Dubner, March 5 ${ }^{\text {th }}, 2020$, https://www.youtube.com/watch?v=DETj3ncN19g .

Santa Ana, Otto. "Did You Call In Mexican? The Racial Politics of Jay Leno's Immigrant Jokes." Language in Society, Vol. 38, No. 1 (Feb., 2009),

Sen, Amartya. "Democracy as a Universal Value," Journal of Democracy 10, no. 3, July 1999 ,

Sen, Amartya. Development as Freedom. New York: Random House, 2000. 
Sen, Amartya. Inequality Reexamined. Oxford Scholarship Online, November 2003 DOI: 10.1093/0198289286.001.0001.

Travers, Ben. "Steve Martin and Martin Short," Indiewire. August 15 $5^{\text {th }}, 2018$, https://www.indiewire.com/2018/08/steve-martin-and-martin-short-tour-netflix-trump$1201994545 /$

“Kruschev's Secret Speech,” Edited by Amy Tikkanen. The Encyclopedia Brittanica, https://www.britannica.com/event/Khrushchevs-secret-speech, February 18, 2019.

Young, Iris Marion. Inclusion and Democracy. Oxford: Oxford University Press, 2000.

Young, Iris Marion. Justice and the Politics of Difference. Princeton: Princeton University Press, 2011.

Young, Iris Marion. "Polity and Group Difference," in Theorizing Citizenship, ed. by Ronald Beiner. Albany: State University of New York Press, 1995.

Valentish, Jenny. "I Broke the Contract." The Guardian: The G2 Interview. July 16, 2018, https://www.theguardian.com/stage/2018/jul/16/hannah-gadsby-trauma-comedy-nanettestandup-netflix

Yan, Holly, and Burnside, Tina. "A Black Homeowner Was Handcuffed And Detained In His Boxers After His Burglar Alarm Went Off." CNN. https://www.cnn.com/2019/08/27/us/raleigh-burglar-alarm-homeownerdetained/index.html?utm_medium=social\&utm_content=2019-0827T15\%3A54\%3A51\&utm_term=link\&utm_source=twCNN, August 27, 2019 